\title{
Character education as perceived and implemented by selected middle school teachers of one rural county in West Virginia
}

Lisa D. Lucas

West Virginia University

Follow this and additional works at: https://researchrepository.wvu.edu/etd

\section{Recommended Citation}

Lucas, Lisa D., "Character education as perceived and implemented by selected middle school teachers of one rural county in West Virginia" (2009). Graduate Theses, Dissertations, and Problem Reports. 4493.

https://researchrepository.wvu.edu/etd/4493

This Dissertation is protected by copyright and/or related rights. It has been brought to you by the The Research Repository @ WVU with permission from the rights-holder(s). You are free to use this Dissertation in any way that is permitted by the copyright and related rights legislation that applies to your use. For other uses you must obtain permission from the rights-holder(s) directly, unless additional rights are indicated by a Creative Commons license in the record and/ or on the work itself. This Dissertation has been accepted for inclusion in WVU Graduate Theses, Dissertations, and Problem Reports collection by an authorized administrator of The Research Repository @ WVU.

For more information, please contact researchrepository@mail.wvu.edu. 


\title{
CHARACTER EDUCATION AS PERCEIVED AND IMPLEMENTED BY SELECTED MIDDLE SCHOOL TEACHERS OF ONE RURAL COUNTY IN WEST VIRGINIA
}

\author{
Lisa D. Lucas \\ Dissertation Submitted to the \\ College of Human Resources and Education \\ at West Virginia University \\ in partial fulfillment of the requirements for the degree of \\ Doctor of Education \\ in \\ Curriculum \& Instruction
}

Mary E. Haas, Ed. D., Chairperson

Helen M. Hazi, Ph.D.

Lynn Cartwright, Professor Emeritus

Patricia A. Obenauf, Ed. D.

Cynthia K. Stackpole, D. Min.

Department of Educational Theory

Morgantown, West Virginia

2009

Keywords: character education, middle schools, public schools,
teacher perceptions

Copyright 2009 Lisa D. Lucas 


\begin{abstract}
Character Education as Perceived and Implemented by Selected Middle School

Teachers of One Rural County in West Virginia
\end{abstract}

Lisa D. Lucas

This qualitative phenomenological study examined selected middle school teachers' perceptions of character education in one rural county in northwestern West Virginia. It investigated how they think about and implement character education, what they consider to be obstacles that interfere with the teaching of character education, as well as factors that may foster delivery. Research questions include: 1) What are selected middle school public school teachers' perceptions of character education in terms of how do teachers define character education? How important is character education? 2) How do selected middle school teachers implement character education? 3) What fosters and inhibits the implementation of character education?

Study design consisted of 12 semi-structured teacher interviews. Six of the teachers were randomly chosen from the school's Character Development Team with the remaining six randomly chosen from the balance of the instructional staff. Classroom lesson observations and document analysis of lesson plans and instructional materials were also employed. Observations and document analysis sought to identify Kagan's (2002) five approaches (curricular, extracurricular, spotlight, contextual, and structural) to integrating character education.

Emerging results of data analysis revealed that teachers appeared to highly value character education, yet they struggled to articulate a verbal definition of it despite the school's emphasis on the Character Counts! Program with its defined six traits of respect, responsibility, trustworthiness, caring, fairness, and citizenship. They feel personally responsible for delivering it. They overwhelming cited teacher modeling as the means by which they implement it. Teachers maintain that they have good students and have always taught character education. The school was rich in Kagan's contextual as well as extracurricular approaches. Kagan's curriculum, structural, and spotlight approaches were nearly non-existent, but teachers claimed to use the spotlight approach, which utilizes teachable moments that naturally occur within the classroom. Teachers cited their own backgrounds consisting of parents, religion, and the teachable moment, respectively, as elements that foster delivery of character education. Poor student value systems consisting of poor parenting, lack of parenting, and societal influences, respectively, such as television, music, and electronic games emerged as the primary inhibiting factor to delivering character education. 


\section{DEDICATION}

This endeavor must be dedicated to my Lord and Savior, Jesus Christ.

Throughout this process, He has taught me many things about His ways and myself. I have learned what it is like to live in His will and to be utterly dependent upon Him.

This dissertation is proof that through Christ all things are possible and miracles

really do happen! 


\section{ACKNOWLEDGEMENTS}

My dear husband of nearly twenty-two years, David Lucas, has stuck with me like glue with unwavering faith that I could complete this thing I started numerous years ago. He has held me when I cried and been patient during my confusion. He has rejoiced with me in my successes. Few husbands would have exhibited such patience and selflessness. He told me he wants me to achieve my dream as he is already living his. I couldn't have finished this dissertation without his steadfast love and support.

My dear son, Adam, has also been instrumental in this grueling situation. This entire process has been the toughest challenge of my life. I had to finish it so I could show my son that people don’t quit when something becomes difficult. He keeps telling me to get tough with it. I am proud to say I am this young man’s mother.

Dr. Helen Hazi, my former advisor, has gone above and beyond in assisting me to prepare and present a quality dissertation. She is well versed in all the pitfalls and stumbling blocks of this process. She gave me space when things became overwhelming and welcomed me with open arms to help me pick up the pieces when I was ready to begin anew. She is more than my advisor-she is a friend. Without her, there would be no dissertation. We even had a little fun along the way!

Dr. Mary Haas, my current advisor, must be gratefully acknowledged here as she selflessly agreed to shepherd my progress from data collection to the final defense. She has worked hard to help me be successful. I appreciate all her learned assistance and admire her professional and caring ways. 
Dr. Marion Kostka, through his humor, reassuring smiles, and pragmatic wisdom, kept me from quitting by not taking myself too seriously and toning down my perfectionist tendencies. He kept me aligned.

Herb \& Joyce Haslebacher, my Christian mentors and role models were a quiet, constant source of support, as I knew they were always praying for me.

Jenny Waters, a fellow doctoral student, served as my cyberspace editor and proofreader, must not be overlooked when expressing gratitude. She helped to clean me up and made me appear my very best. Her computer expertise picked up and went far beyond where mine stopped.

Diane Colebank, a talented writer whose upcoming work will appear on the bestseller list, has been a valuable editor, reader, and encourager. I appreciate her keen objective eye and humorous approach to life.

I do not know where this endeavor will lead me, but I will relish the trip as this effort has been well worth it. The road less traveled has made all the difference... 


\section{TABLE OF CONTENTS}

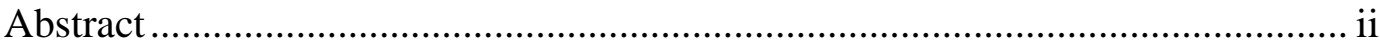

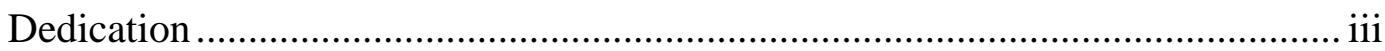

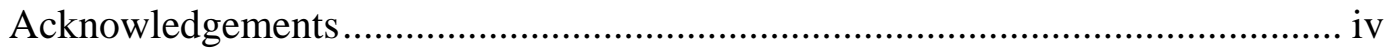

Table of Contents ................................................................................... vi

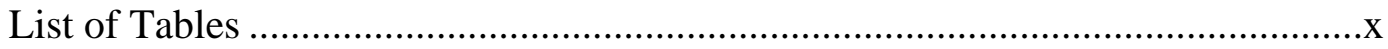

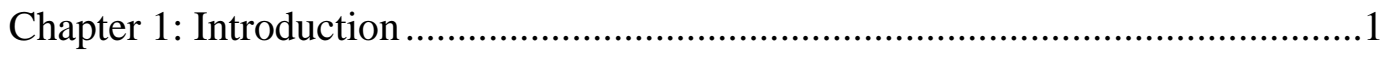

Introduction................................................................................. 1

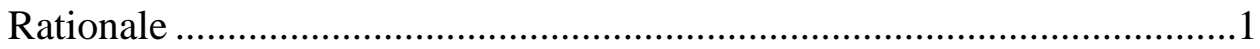

Targeted County and School Description ..............................................2

Purpose

Research Questions ..................................................................4

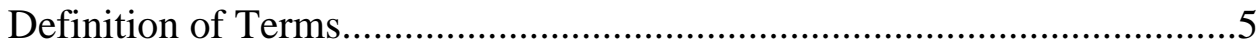

Research Design.............................................................................

Organization of the Document.........................................................6

Chapter 2: Review of Related Literature ....................................................

Roots of Character Education ...........................................................8

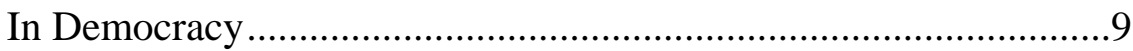

Decline in Moral Emphasis.....................................................10

Beliefs Concerning Human Nature ...........................................15

Need for Character Education....................................................15

Character Education, Morality, Religion ...................................18

Resurgence in the 1990 s ........................................................20 
Teacher Endorsement................................................................26

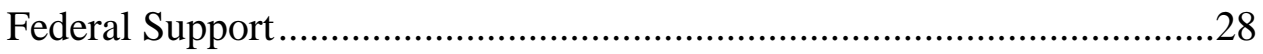

West Virginia Character Education ...................................................29

Connection to Safe and Drug-Free Schools...........................................33

Safe and Drug-Free Schools Initiative .................................................34

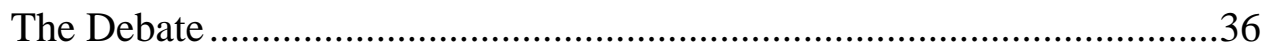

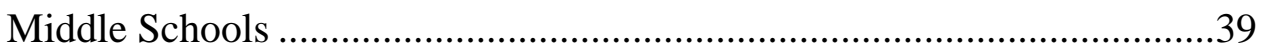

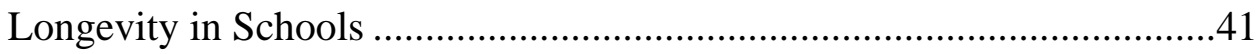

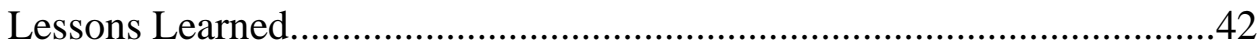

What Character Education Must Do ....................................................43

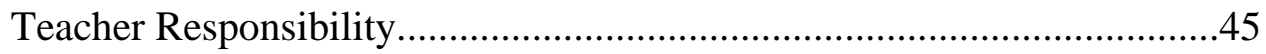

Research Findings .....................................................................45

Research Review................................................................45

Marshall University/West Virginia University Study...................47

Teacher Perceptions Research ................................................49

Dissertations Research ........................................................55

Kagan’s Five Approaches to Delivering Character Education ..................62

Chapter 3: Methodology ..........................................................................68

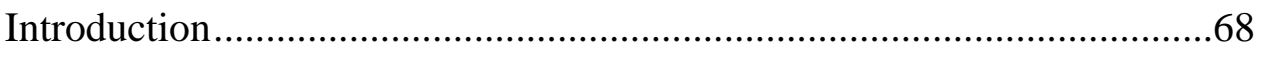

Role of the Researcher .................................................................69

Research Design....................................................................... 71

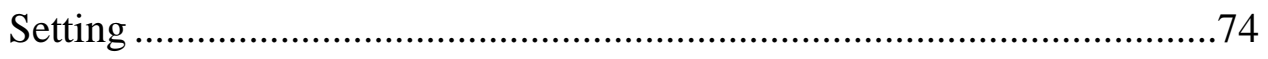

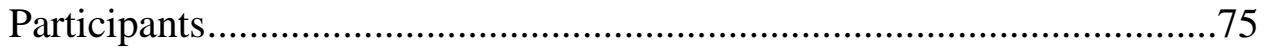




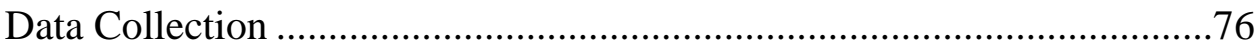

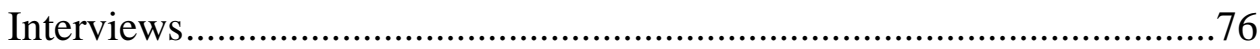

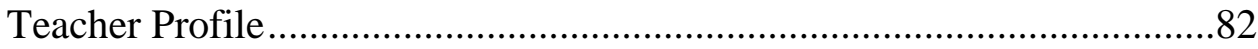

Expert Correspondence .....................................................................83

Document Analysis ........................................................................8

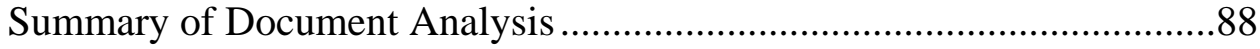

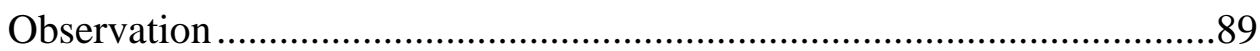

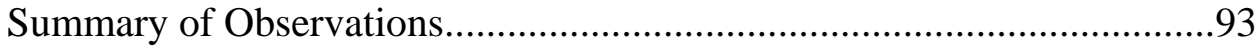

Teacher Correspondence....................................................................94

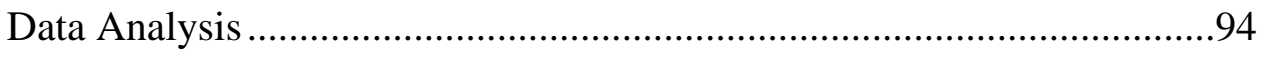

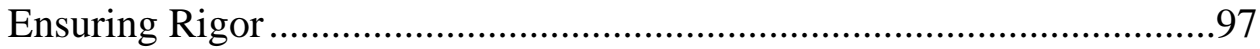

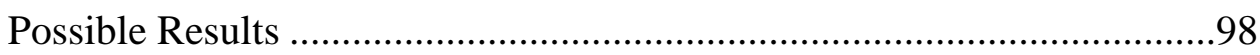

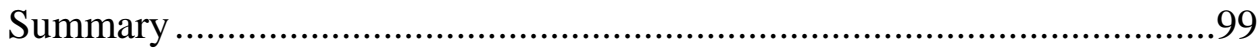

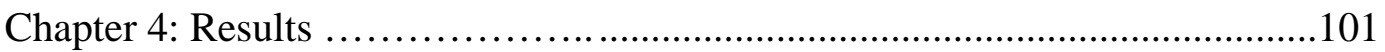

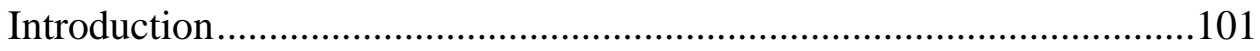

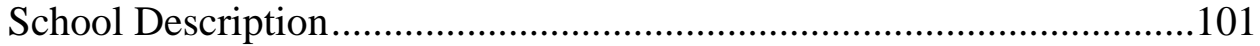

Major Findings........................................................................102

Research Question \#1a..............................................................102

Research Question \#1b ...........................................................106

Research Question \#2 ........................................................111

Research Question \#3 ............................................................116

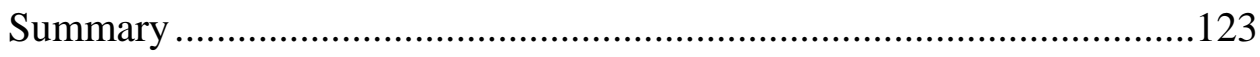

Chapter 5: Discussions, Conclusions, Recommendations .................................125 


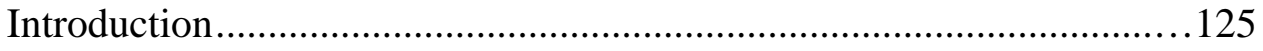

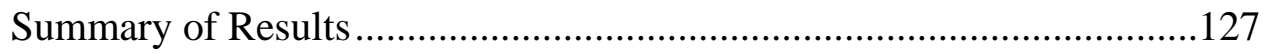

Limitations to the Study ...............................................................130

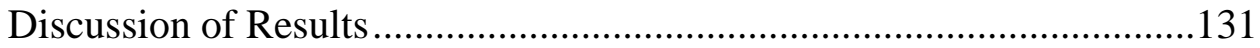

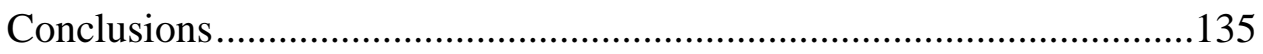

General Recommendations ........................................................137

Recommendations for Future Study ..............................................138

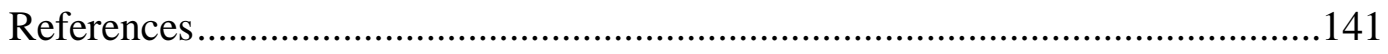

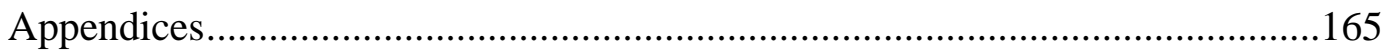

A. Interview Questions and Relevant Literature of

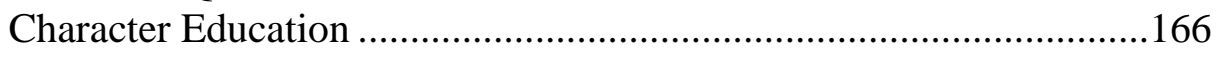

B. Demographic Data of Interviewed Teachers...................................169

C. Interview Protocol ..........................................................................170

D. Expert Biographies..................................................................173

E. Letters of Correspondence to Experts ...........................................176

F. Interview Questions Expert Response Sheet ..................................177

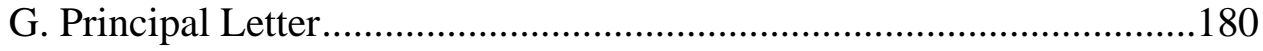

H. Character Development Team Letter of Participation .......................182

I. Non-Character Development Team Letter of Participation .................184

J. Transcribed Teacher Interview Sample Page ....................................186

K. Correlation of Three Research Questions to Interview Questions......187 


\section{LIST OF TABLES}

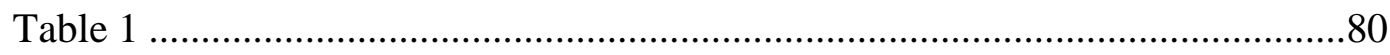

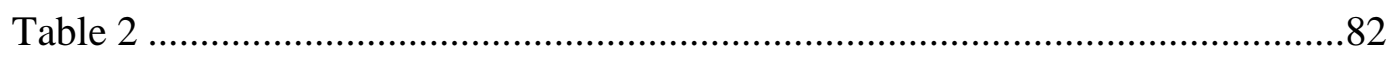

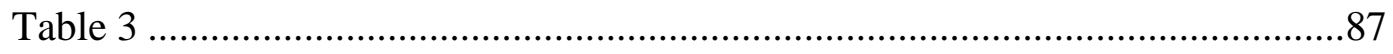

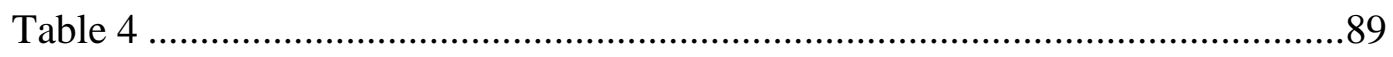

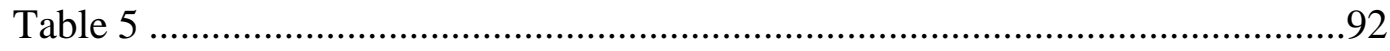

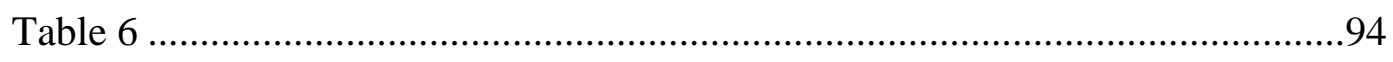

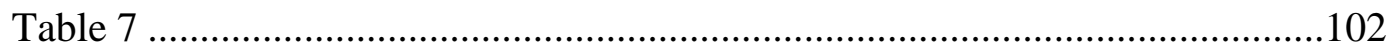




\section{CHAPTER 1}

Nothing is of more importance for the public weal, than to form and train up youth in wisdom and virtue.

Benjamin Franklin (n.d.)

\section{Introduction}

This chapter illuminates the substantial role of moral or character education throughout history. It also includes sections on the rationale, definition of character education, purpose of the research, the three research questions, definition of terms, research design as well as organization of the document.

\section{Rationale}

The educational focus upon character education has fluctuated with time, but it has always been present in some form. Today, character education has become increasingly important as it is considered to be one possible remedy to fill a perceived void in society. It has long been of interest to this researcher as to what constitutes the formation of good character.

It is important to note that the term character education is known by different names such as moral reasoning, moral/values education, ethical instruction, or the teaching of virtues. It is an umbrella term that often denotes a wide array of teaching and learning for personal development. Character education is said to be "broad in scope and difficult to define precisely” (Otten, 2000, para. 3). For purposes of this study, character education is defined as "teaching students to know, care about, and act upon core ethical values such as honesty, respect, and responsibility, honesty, fairness, and compassion” (Character Education Partnership, 2007, para.7). 


\section{Targeted County and School Description}

The purpose of this research was to understand middle school teachers’ perceptions of character education, how they implement it, as well as obstacles that inhibit delivery and factors that expedite it. This study was conducted in a small rural middle school located in northwestern West Virginia. In 2008 the county being researched had a population of 8,841. Manufacturing was the largest business supporting the county’s economy employing $30.4 \%$ of the workforce. The average income of all employed persons in this county was $\$ 33,812$. Its unemployment rate in 2007 was $6.2 \%$ (STATS Indiana, 2009).

The middle school that was studied contained grades six through eighth and had an enrollment of 365 students. It was the only middle school in the county and has 29 fulltime teachers. According to the 2006-2007 No Child Left Behind Report Card for this school, the sixth grade students tested on the Westtest scored $85.8 \%$ on reading and $85.0 \%$ in mathematics. The seventh grade scored $82.8 \%$ in reading and $81.9 \%$ in mathematics. The eighth grade scored $82.6 \%$ in reading and $76.9 \%$ in mathematics. The school achieved annual yearly progress (West Virginia Department of Education, 2006-2007).

At the research school there was an ongoing four-county, five-year ongoing study conducted by the West Virginia Department of Education, Marshall University, and West Virginia University by Chapman and Corrigan (2007). The 2005 grant proposal cited that the four counties of their study were chosen from the results of youth at risk indicators from Kids Count 2002 data. The four county school systems volunteered to take part in the study. Indicators included poor and disabled children comprising the 
percentage of births to unmarried teenagers ages 10-19, percentage of births to mothers with less than a $12^{\text {th }}$ grade education, percentage of high school dropouts, and percentage of children approved for free and reduced-price school meals in grades K-12. Chapman and Corrigan (2007) noted that the four counties chosen in West Virginia were samples of convenience.

Eight schools were randomly chosen from the four counties with two elementary schools as treatment groups and two elementary schools as control groups, one middle school as a treatment group and one middle school as a control group, and one high school as a treatment group and one as a control group. Within each of the two middle school groups, three focus groups of students and their teachers were selected. The middle school control group provided data for the ninth grade parent focus group. No data was collected from the experimental middle school focus group. Each group was comprised of six to eight people who were interviewed to obtain their thoughts concerning character.

The proposed study has no connection to the Chapman and Corrigan (2007) study. It did, however, involve research in one of the eight schools in their study. This study examined character education in the one treatment school of the two middle schools. Both were investigating character education.

While this dissertation dealt solely with teachers, the Chapman and Corrigan (2007) research dealt with students, teachers and parents. This research examined one school while the Chapman and Corrigan (2007) study involved eight schools. Their study explored all three educational levels while this researcher was focusing solely on the 
middle school level. This study was qualitative in nature and the Chapman and Corrigan (2007) was one of experimental design.

This proposed research used one school that was participating in the Chapman and Corrigan (2007) study for two main reasons. First, it was chosen because it consisted of teachers who served and did not serve on the school's voluntary Character Development Team, which was charged with formulating a school wide plan for implementing character education. These two perspectives yielded rich data from different vantage points. Second, the site was geographically convenient and was accessible via Dr. Chapman.

Purpose

The purpose of this study was to examine perceptions of selected middle school teachers from one rural county in West Virginia according to how they thought about and implemented character education, what they considered to be obstacles that interfere with the teaching of character education, as well as factors that might foster delivery. Research Questions

The research addressed the following questions:

1). What are selected middle public school teachers' perceptions of character education?

a. How did teachers define character education?

b. What importance did teachers attach to character education?

2). How did selected middle school teachers implement character education?

3). What fostered and inhibited the implementation of character education? 


\section{Definition of Terms}

Character-Exhibiting a life of virtue and strength (Rutland, 2003).

Character Education-“ Teaching students to know, care about, and act upon core ethical values such as respect, responsibility, honesty, fairness, and compassion” (Character Education Partnership, 2007, para.6).

Curriculum-That array of activities, materials and tests offered by an educational institution (Goodlad, 1984).

Embedded Curriculum-This term was used by Kagan (2002) to describe how instruction is delivered. It is sometimes referred to as the hidden curriculum.

Hidden, Implicit or Invisible Curriculum-Values imparted through the delivery of explicit curriculum (Goodlad, 1984).

Morality-The terms morality, values, and ethics are all terms that have been used to refer to character education. They cannot be defined separately.

Program-A system for implementing educational mandates such as character education (Berkowitz \& Bier, 2004).

Religion-“A discrete system characterized by certain types of beliefs and practices, myths and rituals” (Nash, 1999, p. 12).

\section{Research Design}

This qualitative phenomenological study entailed data collection primarily consisting of semi-structured interviews, while being supported by direct observation and document analysis when possible and available. Interviews were held according to participant schedules. Each consisted of 19 proposed questions. Patton’s (1990) matrix was utilized 
to construct interview questions. Questions were submitted to a panel of experts for review and revision and then a pilot study was completed.

Document analysis took place as permitted by the participants who were interviewed. Individual teacher's lesson plans, curriculum materials, were analyzed with a form designed by the researcher.

Teachers were directly observed teaching in their classrooms as an unobtrusive observer. The physical environment, including participants’ classroom and general school areas, were noted for evidence of character education emphasis. An observation form was utilized and devised by the researcher following suggestions based upon Creswell (2003).

Data analysis will be done using Creswell’s Data Analysis Spiral (1998). Rigor was insured through internal validity, reliability, and external validity measures. An unbiased reader was utilized to secure consensus on emergent themes.

\section{Organization of the Document}

After Chapter 1, the final document includes four chapters. Chapter 2 consists of the review of literature and includes the following: the roots of character education; the need for character education; reemergence of character education in the 1990s to address moral concerns; teacher endorsement as well as responsibilities; federal and state trends; curriculum issues; the unique middle school level considerations; longevity in schools; lessons learned; general character development; theoretical basis; and research findings. Chapter 3 describes the methodology and includes an introduction; followed by research design; participants; data collection method; procedures for analysis of data; and summary of steps for data collection and analysis. Chapter 4 is devoted to the description 
and analysis of data, and Chapter 5 includes conclusions, discussion, and recommendations. 


\section{CHAPTER 2}

The function of education is to teach one to think intensively and to think critically... Intelligence plus character - that is the true goal of education.

Martin Luther King Jr. (Speech at Morehouse College, 1948)

\section{Introduction}

This chapter begins with sections that trace the roots of character education that include character in democracy; decline in moral emphasis; beliefs concerning character education; need for character education; character education, morality, and religion; as well as character resurgence in the 1990s and efforts up to the present. Also discussed are federal support for character education, West Virginia and character education, connection to Safe and Drug-Free Schools, the debate concerning whose values should be taught, and middle school issues. Additional sections pertain to teacher endorsement, federal support, and character education in West Virginia. The connection of character education to Safe and Drug Free Schools is presented, along with the initiative on the national level, and the debate concerning whose values should be taught. There are portions that deal with guidelines for implementation, and longevity in schools, lessons learned, what character education must do, and teacher responsibility. The final sections of the chapter discuss research findings from a research review of 39 character education programs, an ongoing five-year study of character, teacher perceptions and those revealed from Dissertation Abstracts International.

Roots of Character Education

The basic concept of character education is thought to be as old as civilization itself. Transmission of cultural values was the means of perpetuating and sustaining generations 
throughout time (Titus, 1994). Moline, writing about Aristotle’s teachings, concluded that people do not naturally develop to be virtuous or morally mature (as cited in Laud, 1997). It is only through the individual's personal efforts and those of the community that moral excellence can be realized. Humans need the interaction and instruction of others to significantly develop character.

Throughout history all over the world, it has been asserted that education has held the two primary goals of helping people become smart and helping them become good (Center for the $4^{\text {th }}$ and $5^{\text {th }}$ Rs, 2004; Lickona, 1991; Socrates, as cited in Plato's The Apology, trans.1963 ). Distinguishing between smart and good aspects, Dr. Thomas Lickona, perhaps known as the backbone of the current character education movement, notes, "Wise societies since the time of Plato have made moral education a deliberate aim of schooling. They have educated for character as well as intellect, decency as well as literacy, virtue as well as knowledge” (1991; p. 6). He further noted the efforts of societies to produce citizens who will use their intellect to build better lives for themselves, those around them, thus formulating a better world. Martin (as cited in McKay, Archibald, Carr \& Stirling, 1996) also views moral cultivation in education as equal in importance to academics. He claims moral formation is the underlying foundation upon which character education rests.

\section{In Democracy}

Our nation's founding fathers were well aware of the importance of fostering moral development as central to the success of democracy. Education was felt to be necessary not only to instruct the moral tenants of individual needs, but also to perpetuate a democracy (Ryan, 2003). The development and transmission of moral values was 
viewed as the main emphasis of education since colonial times. The church took a huge role in educating students both in content and morality and its influence remained centuries after the church's physical role in education diminished. Religion and morality was largely taught through indoctrination utilizing didactic methods (Raths, Harmin, and Simon, 1996). Indoctrination is teaching content focused upon the acceptance of certain beliefs or doctrine (Green, 1971). Didactic methods involve practical, concrete and authoritative means of instruction (Morrison, 2001). After the American Revolution, the national government ratified The Northwest Ordinance of 1787 that declared, "Religion, morality and knowledge, being necessary to good government and the happiness of mankind, schools and the means of education shall forever be encouraged” (Article 3). Despite reinforcing the country's bond to transmit religion and morality, the act was the first to enumerate knowledge acquisition as an educational mandate. This legislation marked the beginning of the trend when academic, technical and social goals began to compete for attention in education. The mid- nineteenth century common schools were the first educational institutions in which knowledge began to take priority over moral instruction within the school curriculum (Laud, 1997; McClellan, 1999). Academic and vocational goals became more important as moral education diminished to simple civility and a perpetuation of a democratic society (Laud, 1997).

\section{Decline in Moral Emphasis}

Although the aforementioned authors cite the decline of character education as the main mission of American education until the late nineteenth century, both McClellan and Yulish (as cited in Titus, 1994) noted the focus diminishing during the early decades 
of the $20^{\text {th }}$ century. By the 1950s, they, along with Leming (1993), deemed formal character education programs in the United States nonexistent.

Social forces during the $20^{\text {th }}$ century helped to define the waning importance upon character education as reflected in the school curricula. These four powerful societal views were logical positivism that resulted in moral relativism, personalism, increasing pluralism and the steady national trend of secularism. These pervasive forces prompted people to view everything—including morality—as in a state of change (Lickona, 1993).

The force of logical positivism, which arose in Europe and traveled to the American universities, originated from Darwin. His conclusions about evolution translated into questions concerning the changing nature of things (Lickona, 1993). The philosophy of logical positivism separates subjective values from facts, which were thought to be proven in a scientific, objective manner. The positivists characterize values or morality as related to feelings rather than truth. Knowledge was seen as changing, based upon the situational context, and always relative. Thus, there was no moral truth but rather objective right and wrong based on scientific facts. From this belief arose moral relativism, which claimed morality or values to be personal or dependent upon each individual's concept of correct. Positivists then asserted morality as unscientific and therefore identifyed it as unsuitable for the school curricula.

The second major force simultaneously shaping American society during the 1960s was personalism, a worldwide trend that edified the individual. Each person believed he or she should be entitled to choose one's own values and that no one has the authority to impose such held values upon another. This movement in thinking weakened social institutions such as marriage and parenting and strengthened the sexual revolution 
because it did not recognize moral authority or norms. Self-fulfillment was paramount and social commitments were de-emphasized (Lickona, 1993).

Pluralism, the third transformational force shaping America during the $20^{\text {th }}$ century, further emphasized and elevated the rights of the individual. Pluralism asserts the acceptance of all views, as opposed to one view, as being correct. This individualistic thinking led to the debate concerning whose values should be taught in schools (Lickona, 1993; Titus, 1994). What was thought to be fair for each person became a source of contention when society had to make decisions concerning groups of people.

Pluralism is still a major force within the current culture. As an example of how this view has permeated society, Marsden (as cited in Nash, 1997), concludes that Christian colleges, whether they are public or parochial, find it "impossible" to reach consensus “...Mainly because the mandate of pluralism in Western culture is too strong” (p. 70). One view of truth is not strongly held by the population. This force is prevalent in all levels of education, as well as other institutions or groups throughout American culture.

Although Nash (1997) advocates a respect for plurality in today's society, he wrote concerning the history of such, "Pluralism frequently gives rise to unruly public disagreements and intractable divisions....people more than ever need the skills and dispositions to deliberate effectively together in order to reach political compromise and achieve consensus” (p. 11). His concept of character education includes the accommodation for plurality. He hopes that teachers will encourage a "democratic character" within citizens through which they may participate in collective decision making; respect liberty, autonomy, and political equality; and be able to achieve consensus through thoughtful and deliberate debate. 
Finally, secularism arose along with pluralism. This fourth major force attempted to separate religious and government interests. Pluralism and secularism, along with the United States Supreme Court's emphasis on the “establishment clause” of the First Amendment to the Bill of Rights of the United States Constitution, discouraged and deterred any teaching of religion or related values in the public school (Titus, 1994). This clause prevented any public entity from establishing or favoring any religion. During the 1960s it became impossible to agree on whose values were to be taught and morality was viewed to be related to religion, so it was altogether avoided in education (Lickona, 1993; Titus, 1994).

As the twentieth century continued, the nation reflected a stronger and stronger tendency toward freedoms and rights of individuals in society, thus casting aside the more direct ethical or moral indoctrination of former centuries. Following the 1962 United States Supreme Court decision Engel $v$ Vitale that made school prayer illegal, education struggled with the issue of including any values in school curricula (Ries, 1999). For example, in New York, the State Board of Regents formulated and designated what they believed to be a nondenominational prayer for daily use in the public schools. The Supreme Court invalidated the State’s prayer requirement as being in violation of the First Amendment's prohibition of the establishment of religion. From this concern came the "values clarification” movement. This movement resulted, in part, from moral relativism and was viewed as the way to address ethical instruction. Also known as “moral values education,” this approach garnered much attention and support from the educational world (Brooks \& Goble, 1997). 
The 1960s and 1970s saw a pronounced emphasis upon values education. This movement focused on the process of thinking skills. Integral to this thinking approach was values clarification and moral reasoning, which entails moral dilemma discussions, and decision making processes. Central to this approach was the belief that students inherently live in value turmoil and its subsequent apathy and capriousness (Kirschenbaum, 1977). This curriculum refocused character education's original intent of distinguishing right from wrong and conducting oneself correctly (Center for the 4th \& 5th R's, 2004).

The main goal of values clarification was to assist the student in the examination and formulation of his own values thus alleviating value confusion (Kirschenbaum, Harmin, Howe, and Simon, 1977). In the values clarification approach, values per se were not taught at all and all personal values were acceptable. The approach was based upon the premise that values issues have no right or wrong. Teachers were to remain neutral and were strongly discouraged from imposing any personal or societal values upon the student. In short, teachers were to facilitate value or moral discussions, yet they could not evaluate right or wrong, nor in any way shape the value developing process (Brooks \& Goble 1997; Lickona, 1991; Mehlig, 2002; Ries, 1999; Titus, 1994).

The values clarification curriculum consisted of situations or dilemmas that were designed to help students become aware of their own values or priorities. The approach was thought to foster "growth, freedom, and ethical maturity" (Brooks \& Goble, 1994, p. 29). Kohlberg (as cited in Crain, 1985; as cited in Lickona, 1993) insisted that moral discussions which highlight moral reasoning helped students to judge which values were better than others. This was thought to be achieved by the students working through the 
process of resolving moral conflicts through moral reasoning guided by the teacher in conditions appropriate to students' moral reasoning stage growth. Lickona (1993), however, in his evaluation of Kohlberg's moral reasoning approach, concluded that the theorist greatly undervalued the school's role in developing student morals, and that moral reasoning itself does not constitute good character. Lickona (1991) also noted that value clarification discussions failed to distinguish to students the difference between what they might want to do and what they should do. Titus (1994) also analyzed Kohlberg’s cognitive methodology and held the criticism that he failed to address and incorporate the behavioral and emotional aspects of character.

\section{Beliefs Concerning Human Nature}

The perception of human nature has driven values education from colonial times. Children were thought to be inherently bad or sinful, so teachers required rigid adherence to rules and authority, as well as other moral behaviors (Cohen as cited in Laud, 1997). Values or moral education solely stressed proper behavior as opposed to the development of moral reasoning skills. Educators from the seventeenth through the nineteenth century utilized the elements of discipline, curricula content, and teacher examples to implant moral values into the perceived sinful youth (Laud, 1997).

\section{Need for Character Education.}

Through the last three decades of the twentieth century, there have been increasing signs of moral decline in the nation's youth. Educators reported the general erosion of good behavior over the previous 20 years with students showing decreased respect for teachers and classmates (Vincent, 2003). Ries (1999) documented nationwide rising drug use and crime rates along with failing academic achievement grades by the mid 1980s. In 
1991, Titus noted increased substance abuse, teen pregnancy, and Auto Immune Deficiency Syndrome. Lickona (1991) noted the trend of moral decline coincided with society's emphasis upon the individual and the school's neutrality on values. There was also an increase in violence and vandalism, stealing, cheating, peer cruelty, disrespect for authority, bigotry, cursing, sexual preoccupation, and abuse, self-centeredness, and selfdestructive behavior in school aged children as well as a decline in civic responsibility (Lickona, 1991). He further noted that the moral erosion seen in America's school children was first observed in society.

In reaction to these monumental problems, there has been a groundswell of concern about values and the need, once again, to address them within the school curricula (Center for $4^{\text {th }}$ and $5^{\text {th }}$ R's, 2004; Ries, 1999; Wynne \& Ryan, 1997). Titus (1994) noted, "Historically, character education has been emphasized when educators and the public view social stability as threatened, and moral standards weakened” (para. 13). Elam, Lowell, and Gallup (as cited in Starr, 2005) reported the $23^{\text {rd }}$ Annual Gallup Poll of the Public's Attitudes Toward the Public Schools indicated more than $90 \%$ of the respondents agreed schools should be involved in teaching the values of courage, caring, acceptance, and honesty. In 1994, results from the poll indicated a "strong and growing support for character education” (Titus, 1994, para. 14). Again, more than $90 \%$ of the respondents advocated instruction of core values and a majority of those surveyed supported including classes on values and ethical behavior in school curricula. In addition, two-thirds of the respondents approved of non-devotional instruction about world religions that would involve teaching factual tenets of religions without indoctrination (Elam, Lowell \& Gallup, 1994). McClellan (1999) further noted, "Public 
support for some form of moral education seems stronger at century’s end than at any time since the 1950s” (p. 104).

Morality and ethics continue to concern the nation. A 2000 Gallup Poll listed the top five major societal concerns of the nation were economic concerns, education, health care, and crime, as well as morality and ethics. The 2007Annual Gallup Poll of Values and Beliefs continues to show Americans to be very pessimistic about the nation's moral values. It notes that few Americans rate the nation's moral values positively and nearly $50 \%$ of those polled view them as poor. Furthermore, 8 in 10 Americans believe morality is getting worse, which is slightly higher than reported three years previously. It is apparent that issues of morality are of significant importance to Americans.

Researchers have examined the cause of immoral behavior. Benson and Engeman (1975) as well as Brooks and Goble (1997), concluded that the major underlying cause of illegal, irresponsible, and at-risk behaviors in youth is the lack of instruction. They believed responsible behavior must be a matter of instruction. Vincent (2003) concurred with these assertions:

Our lack of consistency and proper instruction and modeling has created a climate where standards have not been taught and reinforced. Children are born with certain dispositions that can be developed into moral behavior. However, if they are left without a guide-without a moral compass — they may choose a more harmful and potentially destructive path. Children, for the most part, act based upon what is expected of them. They learn by observation and by instruction. (p. $x-x i)$ 
Thomas Lickona best summed up the feelings of the last few decades of the twentieth century by saying "Schools cannot be ethical bystanders at a time when our society is in deep moral trouble. Rather, schools must do what they can to contribute to the character of the young and moral health of the nation” (1991, p. 5). In 1999, National Education Association President Bob Chase expressed the same sentiment:

I believe that a values vacuum exists in American society, and that teachers must not be casual or apologetic about confronting it. We must integrate character education into the fabric of the curriculum and into extracurricular activities. We must train teachers in character education—-both pre-service and in-service. And we must consciously set about creating a moral climate within our schools. (as cited by Benninga, Berkowitz, Kuehn, \& Smith, 2006, para. 4; Starr, 2005, para. 7)

Responsible educational curriculum of today must address character issues if it is to address these problems in society. Current educators must not only agree with this premise, but they must also agree upon what constitutes plausible character education as well as methods for effectively implementing it within today’s curriculum. In 2007 Corrigan, Chapman, Grove, Walls, \& Vincent noted, “As a result of this ongoing pursuit to increase moral excellence in our youth, character education continues to persevere and search for evidence supportive of a more definitive role within the modern American education system” (p. 104).

Character Education, Morality, and Religion

It must be acknowledged that there exists a nebulous distinction and much 
confusion between the concepts of character education, morality, and religion. Character education in any curriculum configuration is inextricably linked to morality (Wynne \& Ryan, 1997). In fact, education itself is a moral endeavor (Nord \& Haynes, 1998; Schwartz, 2005, 2007). Schools teach morals directly or indirectly through the curriculum in ways such as community service and volunteerism. Textbooks, lessons, and materials, which focus upon initiatives such as multicultural education, sex education, and drug education, also impart morals. The school policies of dress codes and discipline policies address morals. The student government and extracurricular activities stress certain morals (Nord \& Haynes, 1998). School customs and traditions certainly embody things held dear by that particular institution. In short, schools communicate to students expectations about what is normal, and what is determined right and wrong. Through this process, students are guided into patterns of moral behavior (Nord \& Haynes, 1998).

To some, morality is embedded in formal religion (Arthur, 2008; Glanzer \& Talbert, 2005; Tirri, 2003; Wynne \& Ryan, 1997). Lickona notes (1991) that some educational professionals believe that by any instruction of moral or value-laden ideals, they are promoting religion. Consequently then, "the fact that our society includes people of different religious beliefs, as well as people of no religious beliefs, is for some an obstacle to moral education” (Lickona, 19991, p. 39).

Character education, then, which can be viewed as moral or value education, is fearfully perceived by some teachers as religious education. This paper does not explore religious instruction through character education, but it acknowledges the close and perceived connection between the two. It is clearly understood that although instruction 
pertaining to religion is perfectly appropriate, the First Amendment to the United States Constitution emphatically prohibits the establishment or promotion of a specific religion in public schools.

Although of great value in the proper contexts of home, church or private schools, moral education should not be mistaken for religious education. Such a mistake could impede the moral development of public school children by binding them to certain creeds (Nucci \& Junker, 1982).

Resurgence in the 1990s

Societal concerns of sexual behaviors and substance abuse in youth prompted or contributed to a re-emergence of character education. Although not labeled as such, sex and drug education during the last three decades of the twentieth century gradually began to emphasize character-related programs. The purpose of these programs was to instill in students desirable character traits in students in the hope they would refrain from unhealthy behaviors. Leming (1993), in his assessment of these programs, observed a shift from simple information dissemination regarding the perils of risky sexual and drugrelated behaviors to attempts to promote particular attitudes. He concluded, “The 'affective' or 'humanistic’ strategies of the early-to-mid 1970s focused on teaching students personal skills such as problem solving and decision making and sought to develop positive health-related attitudes" (p. 65). He also discovered that the "socialinfluences” strategies of the 1980s, which involved positive peer pressure and group activities to promote group norms, were the most effective in decreasing substance abuse in teens. 
According to Skinner (2003), the concept of character education, as it is currently perceived, initially started in the early 1990s. Lickona, in his 1991 book Educating for Character, re-emphasized the belief that there was still a universally held group of beliefs and values which all people can acknowledge should be taught. In 1999 Lickona noted that people, regardless of their religious convictions, could come to the consensus that “moral and intellectual virtues are the rational foundation of a civil society and the basis for good character” (para. 23). He attributed its success in emerging as the main focus in education to its highlighting human commonality and unifying rather than separating humanity. Lickona (1993) wrote that along with the onset of this new movement, good character was returned to its rightful "historical place as the central desirable outcome of the school's moral enterprise” (para. 14). Both Lickona and Skinner noted that although the movement was certainly of noteworthy importance, the depth and breadth of it were unknown as a result of the lack of scientific research done on the topic of character education in schools during this time.

The Character Counts! Coalition and the Character Education Partnership have both been influential in furthering the character education movement since the 1980s. The Character Counts! Coalition and the Aspen Declaration originated from the efforts of the Josephson Institute while the Center for the $4^{\text {th }}$ and $5^{\text {th }}$ Rs was formed from the Character Education Partnership. Both the Josephson Institute and the Character Education Partnership are national organizations that strive to provide information and to train people in fostering good character.

The Josephson Institute of Ethics (2004), a nonpartisan and nonprofit organization started in 1987, was formed with the intent of improving the moral quality of society 
through training and encouraging individuals and organizations to formulate sound decision-making skills and behavior. To date, the Institute has trained more than 100,000 leaders from government, armed forces, business, journalism, law and law enforcement, education and nonprofit entities. (Josephson Institute of Ethics, 2004).

As a result of the 1992 release of results of a survey of 9,000 people where the respondents reported cheating, lying, stealing, and drunken driving were the norm, the Josephson Institute of Ethics assembled over 30 experts representing education, religion, ethics, and scholars at Aspen, Colorado, to address these issues. Educators, ethicists, and nonprofit leaders met to share knowledge concerning character development and explore ways in which they might work cooperatively. Their main goal, however, was to reach "consensus concerning ethical values that could be taught at home, in the classroom, or at the workplace without offending political, racial, religious, gender, or economic sensibilities” (Character Counts!, 2004, para. 8). This assembly resulted in the Aspen Declaration (Character Counts!, 1992). The Declaration identified six attributes, which they believed comprised character education, and included the core virtues of trustworthiness, respect, responsibility, caring, justice, and citizenship. The charter group believed these six pillars surpassed any societal, faith-based, or socioeconomic divisions between members of society. These six attributes came to be known as the Six Pillars of Character (Character Counts!, 2004). The Aspen Declaration represented a reaction to the nation's and educational world's outcry for action. McClellan (1999) contended that the traditional moral instructional approach outcome of the charter reflected a compromise and blurring of the sharp theoretical differences that prompted vigorous debate between acknowledged experts during the 1970s and 1980s. 
The Aspen Declaration was the founding document for the Character Counts! Coalition that was formed in 1993 and continues to the present (Lickona, 1993; Lickona, 1999; Skinner 2003). The intent of forming the Coalition was to implement the goals of the Aspen Declaration. It consisted of a national, diverse partnership of schools, communities, education, and human-service organizations that utilize the Six Pillars of Character in their individual and cooperative programs. The Coalition's hope was that by consistently focusing upon the same virtues, better character would be understood and reinforced. They also hoped to build awareness and teach parents to better support their children in character formation (Character Counts!, 2004).

The Character Education Partnership was formed in March of 1993 with representatives of government, labor, youth, parents, faith, business, communities, and media. Its goal was to make character education the top national education priority and to identify and foster effective practices (Lickona, 1993). The Partnership served as an umbrella organization for character education by providing resources and integrating character education into schools and communities (Character Education Partnership, 2004). The membership consisted of national education organizations including the American Association of School Administrators, the Association for Supervision and Curriculum Development, the National Council for Social Studies, the National School Boards Association, and the National Parent Teacher Association (Center for the $4^{\text {th }}$ and $5^{\text {th }}$ Rs, 2004). Its board of directors included corporate leaders as well as character education experts such as Richard Riley, Former U.S. Secretary of Education; John F. Smith, General Motors Corporation; Barbara Bush, Former First Lady; Diane Berreth, Deputy Executive Director, Association for Supervision and Curriculum Development; 
Marvin Berkowitz; Sanford N. McDonnell Endowed Professor of Character Education at University of Missouri-St. Louis; and Thomas Lickona, Director for the Center for the $4^{\text {th }}$ and $5^{\text {th }}$ Rs (Character Education Partnership, 2004). The Partnership identified eleven principles by which schools may plan curricula:

1. Promotes core ethical values as the basis of good character.

2. Defines "character" comprehensively to include thinking, feeling, and behavior.

3. Uses a comprehensive, intentional, proactive, and effective approach to character development.

4. Creates a caring school community.

5. Provides students with opportunities for moral action.

6. Includes a meaningful and challenging curriculum that respects all learners, which develops their character, and helps them to succeed.

7. Strives to foster students' self-motivation.

8. Engages the school staff as a learning and moral community that shares responsibility for character education and attempts to adhere to the same core values that guide the education of students.

9. Fosters shared moral leadership and long-range support of character education initiative.

10. Engages families and community members as partners in the character-building effort.

11. Evaluates the character of the school, the school staff's functioning as character educators, and the extent to which students manifest good character (The Character Education Partnership, 2004). 
The Center for the $4^{\text {th }}$ and $5^{\text {th }}$ Rs was founded in 1994, and resides in the School of Education of the State University of New York at Cortland. It furthered the Partnership’s Eleven Principles by training more than 4,000 kindergartens through twelfth grade educators from over 30 states and 10 countries. Training takes the form of summer institutes and on-site staff development. The Center also disseminates information, provides evaluation services, and conducts research on character education.

Within the last 15 to 20 years the dilemma has not been whether to provide character education, but instead what values, or curricula to provide. Brooks and Goble (1997) noted that those who pondered this issue have most likely been influenced by the ethical or moral relativism of society, which says there are no commonly held ethical values. In contrast, Skinner (2003) believed that non-controversial common and civil moral virtues such as respect, honesty, and courage, along with civic values seen in the United States Constitution and the United States charter, comprise most of today’s character education curricula.

The debate concerning whose values should be taught in character education would imply that there is a choice between specific values and no values at all. Doyle (1997) argued that sanitary, value-free schools are impossible because a school will hold values like knowledge, be they right or wrong, good or bad. He contends that schools, by virtue of the institution, definitely shape character and do so toward a positive or negative end. The Character Education Partnership at its inception (1993) also voiced this opinion and noted that when schools do not directly address values, they tacitly communicate that values are unimportant. 
In 1997, Brooks \& Goble noted the abrupt schism between the awareness of the need for character education and its effectual realization within the school curriculum. They argued that educators needed to either re-examine or re-dedicate themselves to direct character education contending that graduates will profit from it as better parents, workers, and citizens in what they term a "morally rudderless society” (p. 63).

\section{Teacher Endorsement.}

Educators throughout the twentieth century have remained staunch advocates of character education as demonstrated through statements issued by nationally recognized education organizations. For example, in 1918 the Commission on Secondary Education, an entity of the National Education Association, issued a profound historic statement concerning the goals of education entitled "Seven Cardinal Principles of Education." These principles consisted of health, command of fundamental processes, worthy home membership, vocation, citizenship, worthy use of leisure, and ethical character (National Education Association Memo, 1963). The National Education Association’s 1954 resolution, 1963 statement, as well as their 1965 teacher survey, reflected a strong, consistently recognized need by educators to make provisions for ethical instruction (Brooks \& Goble, 1997). A 1997 teacher survey conducted by the National Center on Addiction and Substance Abuse reported that over half of the respondent educators perceived a decline in student morality since they began teaching. In addition, those who had taught five years or less also perceived an ethical decline as well as an increase in drug usage in their students (as cited in Starr, 2005). Teachers, because of their vantage point with students, are the prime indicators of the need to address the growing issue of character-related issues in students. 
United States Department of Education Senior Advisor on Character Education to the Assistant Deputy Secretary of the Office of Safe and Drug-Free Schools, Linda McKay, led a 2006 meeting of the Center Resource Group that summarized the status of character education in the nation. The following findings constituted what was known about character education nationwide.

1. If school climate is good, students learn better

2. We need a shared vocabulary.

3. Teachers don't feel they have the skills and preparation, and feel character education is in competition with standards in core classes.

4. There is limited evidence of success at the district level.

5. It is important to start early, have scope and sequence, provide opportunities, and hold implementers accountable.

6. We must look at what we're accountable for.

7. There is a lack of quality practices.

8. Character education needs to be long term and done well.

9. We need to start at the elementary level and involve parents daily, and use an incorporated common language.

10. Successful elementary school practice does not translate into high school.

11. Some students feel patronized or think that character education is useless, but it can sometimes be empowering, for example, in civic engagement.

12. Attention must be given to marketing.

13. Implementers need support, perhaps a requirement to do character education (p. 4). Gaps in current practices and research in character education were identified as 
1. In order to focus on outcomes, the field will need to follow standard protocols to identify a moderate number of core measures or research constructs.

2. There is a communication and engagement disconnect between the public and schools.

3. There are disincentives to disclose, maintain, and share data.

4. Current teenage culture is not supporting character as "in" or "cool."

5. Music and entertainment provides poor modeling that must be overcome.

6. Character education must be rooted in community.

7. Schools of Education do not teach leadership education uniformly.

8. America does not have a consensus or understanding of what character is.

9. We talk about character in adult ways rather than understanding how youth think about it. (p. 4)

\section{Federal Support}

In addition to the efforts of private organizations, the federal government has gotten involved in character education. Skinner (2003) reported that since the early 1990s, the federal government has advocated for and promoted character education in public schools and offered grants to those institutions initiating programs. Numerous curricula have been formulated by profit as well as nonprofit organizations. In 2000, Otten documented that state grants from the United States Department of Education involved over 30 states, with 16 states having some form of legislated character education. As of January 2004, the program by the U.S. Department of Education entitled Partnerships in Character Education had awarded grants to 45 states including West 
Virginia as well as the District of Columbia to initiate and support character education (Editorial Projects in Education, 2004).

Throughout the last decade, the United States Department of Justice and the United States government have increasingly expanded their support for character education implementation in the nation's schools. Since 1995, the United States Department of Education through the Partnerships in Character Education program has awarded 97 grants to state and local educational institutions to design, implement, and sustain character education (United State Department of Education, 2005). This amounts to 27 million dollars, which provided funding in 48 states (Gilbert, 2003). As of 2006, over \$104 million in 10 years has been allocated to fund more than 100 grants across the United States (United States Department of Education, 2006).

West Virginia Character Education

State character education programs across the nation share two common traits. They are, "the involvement of the whole community in designing and implementing character education for its schools; and the commitment to making character education an integral part of the education process” (United States Department of Education, 2005, para.12). These tenets need to be considered and incorporated when systems design and implement character education program. In 1995 the state of West Virginia passed a safe schools measure, House Bill 2073 (passed March 11, 1995), which mandated the State Department of Education to formulate “a preventative discipline program” comprised, in part, by a weekly character education discussion. Former West Virginia governor Bob Wise emphasized character education as part of his 2001 gubernatorial platform (personal communication, October 29, 2003). Four months after taking office, the governor signed 
into law Senate Bill 125; House Bill 2208 (2001) which charged the State Board of Education to "establish comprehensive character education into all aspects of school culture, school functions, and existing curriculum by September, 2001” (West Virginia, November 4, 2003). This bill translated into West Virginia State Code § 18-2-13 which requires character education to contain the following components (pg 16):

1. Honesty;

2. Caring;

3. Citizenship;

4. Justice;

5. Fairness;

6. Respect;

7. Responsibility;

8. Voting;

9. Academic achievement;

10. Completing homework assignments;

11. Improving daily attendance;

12. Avoiding and resolving conflicts;

13. Alternative to violence;

14. Contributing to an orderly positive school environment;

15. Participating in class;

16. Resisting social peer pressures to smoke, drink and use drugs;

17. Developing greater self-esteem and confidence;

18. Effectively coping with social anxiety; 
19. Increasing knowledge of the immediate consequences of substance abuse;

20. Increasing knowledge of the consequences of one's actions;

21. The corrupting influence and chance nature of gambling; and

22. The value of decent, honest work.

It is interesting to note that the following point \#23 from the Senate Bill 125 was omitted from the code. "The eleven principles set forth by the character education Partnership in their 'Eleven Principles of Effective Character Education'” (2001, para. 3). When the West Virginia Department of Education was asked about this omission, they weren't sure, but ventured the guess that the statement would show preference for one program over another (L. Burton, personal communication, August 27, 2007).

Preceding the passage of H.B. 2208 in 2001, the West Virginia Department of Education applied for and was granted one million dollars as a national pilot site for the Character Education Pilot Project (L.G. Burton, personal communication, October 29, 2003). This federal grant, in turn, funded 25 Lighthouse Pilot Sites and planning grants throughout the state. Lighthouse Sites received training as well as professional contact and program support. The grant primarily financed professional teacher development and program evaluation. In keeping with the mandate to implement character education across the curriculum and throughout the school environment, pilot sites were required to individually formulate a plan for implementation as well as follow through with the plan. The primary goals of the grant within each site were to increase attendance, reduce discipline referrals, and increase achievement (L.G. Burton, personal communication, October 29, 2003; Character Education Pilot Project). The grants ran from May 20012005 with the hope, that sites would be able to sustain their respective programs after the 
grants expired. The grant covered the first seven traits included in the state code: honesty, caring, citizenship, justice, fairness, respect, and responsibility. She added that the seven traits selected for inclusion are those identified in West Virginia's United States Department of Education grant application (L.G. Burton, personal communication, October 29, 2003). All 55 counties, regardless of whether or not they were selected as pilot sites by the state grant, were responsible for implementing H.B. 2208 as it is delineated by the state educational code. Burton (2007) reported that approximately 50\% of those pilot sites sustained some form of their character education programs after the grant ended (personal communication, June 11, 2007).

According to a 2003 West Virginia Department of Education press release, after an evaluation of character education in 193 schools encompassing all 55 counties, 16 counties had fully integrated character education into their curriculum while 39 counties had partially integrated character education into their curriculum (December 11, 2003). Full integration is defined as a whole-school comprehensive character education program. Partial integration is defined as character education programs sustained or conducted in part of the school such as in separate classrooms, but not encompassing the entire school (L.G. Burton, personal communication, June 11, 2007). In response to this report, the State Superintendent of Schools said "Students who develop strong character at an early age demonstrate responsibility for their academic performance, respect for others and respect for themselves” (as cited in 2003, West Virginia Department of Education, para. 3).

West Virginia received a 1.8 million dollar federal grant entitled Partnerships in Character Education Grant Program, which runs from 2005-2009. One goal of this 
project is to develop a training manual and website universal accessibility about character education implementation. (P. Chapman, West Virginia University Educational Leadership Professor, personal communication, November 11, 2006; L. G. Burton, West Virginia Department of Education Coordinator of Character Education, personal communication, June 11, 2007). The grant works with four southern counties in West Virginia and is conducted along with West Virginia University (West Virginia Department of Education Office of Student Services and Health Promotion, 2005; L.G. Burton, personal communication, June 11, 2007). The focus of the project is to create a replicable model for character education to work in rural areas based upon research of what works for these communities. As a part of the research, baseline date was collected the first and second year of implementation (P. Chapman, West Virginia Educational Leadership Professor, personal communication, October 14, 2006; L.G. Burton, personal communication, June 11, 2007). Burton (2007) reports preliminary data from this research suggests a correlation emerging between student character and academic performance (personal communication, June 11, 2007).

\section{Connection to Safe and Drug-Free Schools}

Character education programs do not function alone. It is necessary to note the connection between character education and safe and drug free school programs. In West Virginia, they are often linked together through activities, conferences and funding. All state counties utilize federal Safe and Drug-Free Schools money to some degree for character education (K.Green, personal communication, November 6, 2003). The state Coordinator for the Office of Student Services, Lisa Burton, noted that students who acquire and implement West Virginia’s six adopted character traits of respect, 
responsibility, caring, fairness, trustworthiness, and citizenship as endorsed by Character Counts! are less likely to violate the West Virginia student Code of Conduct or safe school law (L.G. Burton, per comm., October 27, 2003 As a result of the Safe School Law passed on March 9, 2002 (Senate Bill No. 4), and HB 2073 passed on March 11, 1995 character education in each of the 55 counties is partially or totally financed and counties eligible for Lighthouse Pilot grants received additional funding (L.G. Burton, per comm., October 27, 2003).

Safe and Drug-Free Schools Initiative

Prompted by the 1999 student shootings at Columbine High School in Jefferson County, Colorado, the National Threat Assessment Center of the United States Secret Service began a joint effort along with the Safe and Drug-Free Schools Program of the United States Department of Education to research and prevent school attacks. This collaboration is known as the Safe Schools Initiative (United States Department of Education, 2002; Maxwell, 2006a). The Safe School Initiative built upon and expanded the United States Secret Services’ Exceptional Case Study Project, which was a five-year study that identified and compiled those aberrant thinking and behaviors of people who attempted or succeeded in carrying out fatal attacks on famous persons since 1949 (United States Department of Education, 2002).

The joint study between the United States Secret Service and United States Department of Education examined 37 shootings defined as targeted where the school was the chosen site of violence. These incidents spanned the years of 1974-2000 and the results yielded the conclusion that most attackers displayed some sort of identifying behavior before the violent episode that could be an indication of pending attack (United 
State Department of Education, 2002; Maxwell, 2006). Ten significant findings and accompanying implications were released in the May 2002 report entitled The Final Report and Findings of the Safe School Initiative: Implications for the Prevention of School Attack in the United States. Shootings were found to be the leading cause of school-related violent deaths among homicides, suicides, and weapons-related deaths that happened at or near schools since the 1992-1993 school year (Maxwell, 2006). Dr. James Phares (2006), Superintendent of Marion County Schools, Fairmont, West Virginia, surmised that of the 323 school shootings in American public schools since 1992-1993, "It is extremely rare that an outside intruder was responsible for the shootings.... The vast majority of shootings were carried out by students” (p.3B). It is interesting to note that Phares (2006) said after violent incidents such as these in public schools of recent years, there is always a "flurry of activity—nationwide, statewide and locally" and.... "a rush in these situations to do something that gives the illusion that things will be safer” (para.3). Furthermore, he added that if schools continue to remain vigilant, they are doing what they need to do to maintain the safest environment humanly possible. As Maxwell in 2006 stressed, any new safety policies or security measures should be carefully and thoroughly examined, free from emotionality so that schools will not be turned into "fortresses," as he terms them (para. 11). Certainly school violence is a dynamic issue that with each incident introduces new variables that need to be considered (Phares, 2006). Glassner (1999) said in his book. The Culture of Fear, there is a misbelief that every child is in "imminent risk of becoming a victim [of a violent crime] which has as its corollary still is a darker delusion: Any kid might become a victimizer" (p. 68) which is perpetuated in society in large part by the overexposed 
media coverage. Children are led to believe that they live in constant danger although such events in schools are exceedingly rare. This low incidence of school violence needs to be remembered by all educational entities.

\section{The Debate}

Closely following the debate in character education concerning whose values should be taught comes one that questions whether or not character education should be delivered within the school curriculum or as a separate subject. Some scholars believe character education should be infused, or integrated into the existing curriculum; while others advocate it being taught as a separate, stand-alone class.

Many scholars represent the school of thought that advocates infusing character education into the curriculum. According to Ryan and Bohlin (1999), character education should be infused everywhere within the curriculum because learning and teaching are moral acts and the classroom is an ethical society unto itself. They identify intellectual and moral development as two essential components of character education, and insist that they should be included in all school endeavors. Ryan and Bohlin assert moral and value issues occur naturally in the curricula and need to be explored. The integrated or infused lesson plan actually complements the major academic discipline because the nature of the content area lends itself to the presentation of the selected character traits. This type of approach most easily blends into today's overcrowded curricula where even basic reading, writing and math instruction must compete for adequate time.

Titus (1994) also believes values may be effectively taught without specific character education programs because the typical academic curriculum inherently 
possesses components of good character development. He endorses and lists such things as observance of holidays, national patriotism, study of famous people in literature and history areas, as well as responsible work behaviors. He notes that numerous subject disciplines may be designed to teach character education directly or indirectly. Direct instruction is most likely to occur with scheduled, specific lesson plans, while indirect instruction may happen through the use of such things as slogans and school bulletin boards.

In addition, Wynne (1989) writes that activities outside the academic realm of schooling lend themselves well to character development. The values of altruism, loyalty, diligence, and courage, for instance, may be presented and fostered by participation in various clubs, sports, governance groups, or community service organizations. These activities provide a place in which students may formulate and practice value choices.

In contrast, other scholars believe character education must be taught as a separate subject. Brooks \& Goble (1997) offer two noteworthy cautions against integrating character education into the current curriculum. First, they argue that to include values as an integral part of the curriculum, textbooks would have to be revised. They note that over the last three decades, factual content has taken great precedence over value content. This revision would have to be widespread and of great expense to already threadbare school budgets. In addition, they challenge educators to give character education the same consideration and teach it "specifically, systematically, and separately" if they believe character education to be as important as core subjects (p.98). 
In addition, Brooks \& Goble (1997) question how educators may assume character education can be appropriately addressed without specific and detailed lesson plans. They again assert that important core subjects are not randomly nor incidentally taught, and so must be presented in a deliberate manner, stressing, "Character education that is perceived to be everywhere is doomed to be less effective than character education that is specific, has objectives, an evaluation component and reinforces the good character of students and staff” (p. 102). Lickona (1992) notes, "The whole truth is that values are caught (through good example) and taught (through direct explanation)” (p. 76). The stand-alone lesson possesses the components of any other core subject.

An additional concern for many scholars is the increase in knowledge available to students. Due to the exponential increase in recent years in the amount of knowledge available that has merit to be included in the curriculum, some scholars are concerned that students may not be able to thoroughly reflect, process, and discern the most important aspects of information. They may, instead, develop a mechanical ability to take in large amounts of superficial rote knowledge and factual information without developing the ability to recognize and assimilate the deeper moral and intellectual components of life and learning (Ryan \& Bohlin, 1999).

Careful not to be misunderstood, Brooks \& Goble (1997) endorse a two-fold approach of specifically designated character education classes as well as integration within the existing curriculum. They assert that character education instruction should not be erased from other areas of the curriculum just because they advocate it as an area that should stand alone and be taught in an organized, detailed manner. They write that this structured approach to teaching principles, processes, and practices of good character 
is a solid springboard from which character education may be integrated or infused into all facets of the school's curriculum. Along with infusion, they note modeling and example as other means of indirectly presenting values. Modeling consists of appropriate role figures exemplifying desirable character traits through their everyday behaviors.

\section{Middle Schools}

The National Middle School Association (2003) listed eight essential cultural components needed for successful middle schools. The culture includes educators who value working with this age group and are prepared to do so; courageous, collaborative leadership; a shared vision that guides decisions; an inviting, supportive, and safe environment; high expectations for every member of the learning community; students and teachers engaged in active learning; an adult advocate for every student; and schoolinitiated family and community partnerships. They note that these elements result in effective programs that contain the six characteristics of curriculum that is relevant, challenging, integrative, and exploratory; multiple learning and teaching approaches that respond to middle school students' diversity; assessment and evaluation programs that promote quality learning; organizational structures that support meaningful relationships and learning; school wide efforts and policies that foster health, wellness, and safety; and multifaceted guidance and support services (p. 7).

Young adolescents present unique developmental characteristics. Scales (2003) wrote about their moral development and distinguished 12 traits specific to middle school students. 
They

1. are in transition from reasoning which focuses on "what's in it for me" to that which considers feelings and rights of others;

2. are increasingly capable of assessing moral matter in shades of gray as opposed to viewing them in black and white absolutes, although this moral reasoning may not be evident in practice;

3. generally idealistic, desiring to make the world a better place and make a meaningful contribution to a cause larger than themselves;

4. often show compassion for those who are downtrodden or suffering and have special concern for animals and the environmental problems that our world faces;

5. are capable of and value direct experience in participatory democracy;

6. are often impatient with the pace of change, and underestimate the difficulties in making desired social changes due to their lack of experience;

7. are likely to believe and espouse values such as honesty, responsibility, and cultural acceptance, while at the same time learning that they and the people they admire can be morally inconsistent, and can lie or cheat, avoid responsibility, and be intolerant;

8. are at times are quick to see flaws in others but are slow to acknowledge their own faults;

9. are often interested in exploring spiritual matters, even as they may become distant from formal religious organizations. However, many youth, especially African Americans, may continue to embrace religion as a vital apart of this stage. 
10. are moving from acceptance of adult moral judgments to developing their own personal values; nevertheless, they tend to embrace major values consistent with those of their parents and other valued adults;

11. rely on parents and significant adults for advice, especially when facing major decisions.

12. greatly need and are influenced by trustworthy adult role models who will listen to them and affirm their moral consciousness and actions;

13. are increasingly aware of, concerned, and vocal about inconsistencies between values exhibited by adults and the conditions they see in society. (p. 44-46) Longevity in Schools

Lickona (1993) discussed four factors that serve as determinants to the character education movement's prolonged success. First, he emphasized support for schools in terms of entities that help shape and strengthen moral values. Churches, media, as well as policy makers need to undergird the family with children's needs being paramount. These institutions play a crucial role in shaping and sustaining moral values of the young. Second, the role of religion in terms of examining and tracing values development in our country must become a determining factor in grounding character education. This scrutiny of faith origins, cultures, and patterns is necessary when social issues are considered which entail drawing from a faith background and other value-laden resources to make such decisions concerning issues of premarital sex or responsibility to the homeless. Third, a cohesive, moral leadership within the school setting provides and perpetuates a standard of respect and responsibility. 
This united effort in establishing, expecting, and enforcing high moral ideals helps to instill and sustain moral ideals within youth. The entire school staff must exemplify the school's delineated values to create this climate or those who do will only meet with limited success and feel demoralized in their attempts. Fourth, it is imperative that teachers must receive direct instruction in the form of pre-service or in-service training on how to teach character education. Lickona (1993) claims it is far more complicated than teaching basic subject matter because it requires personal growth in addition to skills competency.

For these multifaceted reasons, it appears easy to question whether character education will be a lasting and vital entity of the future public school curriculum. School personnel as well as those groups who shape and configure them must agree to wholeheartedly support and sustain this vital initiative.

\section{Lessons Learned}

Leming, in his 1993 review of the, "small, disparate, and inconsistent," (p. 69) research base dating back to the 1920s, pinpointed three techniques that failed to result in change or improvement in moral conduct. First, didactic methods alone-those intended for teaching but which are very moralistic—such as pledges, codes, or teacher exhortation, were found to be ineffective in fostering good character. Second, the development of students' reasoning and thinking capabilities concerning moral conduct does not transfer into virtuous behavior. Third, school efforts that exclude the students' social surroundings and focus solely upon the learner will not succeed. He noted that character develops within a social context and the student's relationships and types of 
interactions within that context mold his or her moral conduct. Leming also cautioned that schools should not expect easy, dramatic outcomes in fostering good character. What Character Education Must Do

In 1993 Lickona wrote in order for character education to be effective, schools must operate from a sufficient theory of what constitutes good character. This definition is thought to be important as it enables schools to set clear goals. Leming, in the same year, called for a "grand theory" of character education and noted that research based upon such a theory was the next needed progression in the development of future character education. A grand theory would guide practice. He wrote, “At present, atheoretical thinking and research on character education hampers the effort to develop effective programs” (Leming, 1993, p.70). Leming also reported that current research in the field consisted of unrelated findings from sociology, philosophy, child development research, sociopolitical analyses as well as a myriad of varying program evaluations. In short, Leming asserted a solid body of cohesive research must be compiled so that it may effectively inform educational practice. Research does so by focusing the entire character education movement and providing guidance to curriculum planning and research in a manner that supplies cumulative knowledge concerning the schools’ part in developing character.

By extracting from the writings of Aristotle, Emile Durkheim, John Rawls, and Lawrence Kohlberg, Leming (1993) formulated a theoretical perspective that identifies three levels of character formation. At the first and lowest level, rules exist eternal to the learner and behavioral conformity is reached only through discipline and self-interest. At the next level, rules exist within social groups and the learner's desire for acceptance by such groups motivates him or her to comply with the rules. At the highest level, the 
learner interprets rules in terms of self-chosen principles. Within the third level, moral principles are perceived differently based upon the learner's age and education (Kohlberg, 1984; Rest, 1986). Positive change in character happens in relation to how learners view their obligations to those around them (Narvaez (2002). Narvaez translates constructivist theory as students' responses, moral framework and views of understanding, changing and becoming more developed as they experience life.

Approaches to providing moral experiences include classroom character curriculum and community service learning. Character curriculum consists of materials that tell or instruct children how to live exemplary lives. Many take the form of ethical literature. This direct, simple method tells or reports ethical behavior. Halverson (2004), in reviewing the work of Narvaez (2002) and other colleagues, concluded this approach does not work because it labels intricate groups of behaviors into one word terms such as "loyalty" or "respect" that children may not have the experience to understand and assimilate (Narvaez, Bentley, Gleason \& Samuels, 1998; Narvaez, Gleason, Mitchell, \& Bentley, 1999). The second approach, Community Service Learning, is an attempt to provide moral instruction and exposure to moral situations when students volunteer their time in carrying out projects in school or the community. Research conducted by Sprinthall, Hall and Gerler (1992) and Leming (2001), found that these experiences proved to be beneficial if combined with deliberate support, discussion, and exploration into decision making with a focus on moral aspects of community service. Through this research, students were found to reason about ethical issues in a more organized manner than those in control groups. 


\section{Teacher Responsibility}

Today's teachers must be courageous enough to discern the impact of societal and cultural influences upon the school, and how they individually reflect its values and norms. Teachers need to examine whether these values are ones they wish to instill within their students. Educators are thought to comprise the educational system as both its cause and effect. Educational institutions themselves may not be able to fully address and solve these global problems, and educators should not be charged with the sole or major responsibility in solving them. It is helpful, though, to bring to note the fact that school personnel significantly contribute to educational facets of the moral crisis today (Purpel, 1989).

In a 2002 White House Conference on Character and Community, Narvaez presented three suggestions for educators to develop and foster good character. First, educators must assume responsibility for a comprehensive intentional character education program with skill instruction instead of a randomized approach. Next, teachers must offer learning experiences commensurate with students' demonstrated levels of ethical knowledge in an apprenticeship fashion. Third, educators must organize and situate learning situations in a variety of collaborative community configurations. This means that the student will be exposed to many different groups and moral situations.

\section{Research Findings}

\section{Research Review}

Berkowitz, Battistich, and Bier (2008) reviewed 87 research studies of 45 different programs that explored character education from "What Works in character Education” by Berkowitz and Bier (2004) along with “The What Works Clearinghouse: 
Character Education by The United State Department of Education Institute for Educational Sciences (2002). This review was conducted to consolidate and summarize effective practices of both and to identify knowledge still needed in the area of character education. Of the 33 "What Works in character Education" program and the 13 in the “The What Works Clearinghouse: Character Education” program, there was a duplication of six programs, so 39 were reviewed instead of 45 .

Results from the review showed four major effective conclusions. First, character education was found to effectively promote character development. All 39 programs were deemed effective. Second, character education was found to impact academic achievement. All but one of the 39 programs reflected positive academic gains. Third, Character education was shown to impact many aspects of character development. When comparing the Character Education Partnership three-part definition (cognitive, affective, behavioral), there appeared to be much variation across the 39 programs. The "What Works in Character Education” program showed the most commonly impacted factors were sexual behavior, character knowledge, and socio-moral knowledge. Fourth, Character education tends to be a set of implementation strategies. The most common strategies were professional development, interactive teaching methods, direct teaching of character concepts, family or community participation, and modeling or mentoring. Research into grass roots character education programs that are developed according to local context showed that quality character education, in terms of academic achievement, included adult modeling and promotion of character, opportunities for service and volunteerism, the fostering of a caring community and positive relationships, and a clean, safe environment. 
Berkowitz, Battistich, and Bier (2008) said there is still much to be known concerning the impacts of character education. They listed six areas of improvement.

1. More resources are needed for research in character education and related fields. More funding is needed to build an adequate body of scientific research to effectively guide educational practice.

2. The vast majority of character education studies are program outcomes of individual studies. Reviews need to span multiple studies such as the one discussed here.

3. Very little is known about character education strategies. More research on individual practices is needed.

4. More research concerning implementation in general is needed. Very little is known about stages of implementation, the complex interactions of different contextual and implementation variables, and other aspects of what works and what does not.

5. Longitudinal follow-up studies of existing and proposed studies are also rare. It is not known which effects are temporary and which are enduring.

6. Better research instrumentation and better knowledge about existing instrumentation are also needed. (p. 429-430)

Marshall University/West Virginia University Ongoing Study

The following section is a summary of the first year research from a four-year longitudinal study conducted by Marshall University and West Virginia University, both in West Virginia. The two institutions are working in conjunction with character education specialists from the West Virginia Department of Education as a result of a 
grant provided to the West Virginia Department of Education by the United States Department of Education. The study began in 2005 with the collection of baseline data and will continue through 2009 (Chapman, 2006a; Corrigan \& Chapman, 2005).

The study, entitled “Integrating Effective Character Education Programs into Rural Schools: Measuring a Replicable Model,” is a sizeable research endeavor now in its third year (Chapman, 2006a). The purpose of the study is to replicate efforts of four West Virginia counties that have infused character education into their curricula and to make the curricula freely accessible to all 55 counties in the state. The curricula will take the form of a manual or workbook and will be able to be available on the worldwide web. In short, a replicable model is anticipated to emerge from the study participants that will provide a comprehensive program model and all information needed to initiate and integrate a character education program. (Chapman, 2006a, 2006b).

The study is both quantitative and qualitative in nature. It utilizes a longitudinal survey pretest/posttest, 23 focus groups comprised of students, parents, and educators, observations and interviews. The design is quasi-experimental upon a randomly selected sample-four counties of eight public schools. The schools in the study consist of two control elementary schools and two experimental elementary schools, one control middle school and one experimental middle school, and one control high school and one experimental high school (Chapman, 2006a, 2006b; Corrigan \& Chapman, 2005).

The first year, 2005, served as the baseline data collection year. Teachers, students, and their families were followed for two more years. Treatment consisted of educational efforts directed at all stakeholders to integrate character education in all facets of the school culture and community to enhance overall student learning 
(Chapman, 2006a). Most pertinent to this dissertation's purposes from the first year baseline data collection was the emergent theme expressed by public school teachers concerning their perceptions of character education. Teachers in the study viewed character education as another underfunded “add-on” program. In casual conversations and information gleaned from preliminary teacher focus groups, Chapman (2006a) noted the teachers expressed a disdain for such temporary, under-funded mandates as No Child Left Behind and considered character education to fall into the same category. (P. Chapman, personal communication, December 6, 2006). The teachers also reported they felt pressured and restricted in how they teach due to increasing accountability. Teachers emphasized that school has lost its fun and is now all business (Chapman, 2006a, 2006b). Kagan (2002) referred to the transient nature of these educational innovations as the “replacement cycle” (p. 3).

\section{Teacher Perceptions Research}

Researchers have examined teacher perceptions of character education. The following represents findings from five studies exploring teacher perceptions regarding their interaction with knowledge and teaching of character education. These studies reflect positive findings for teachers in self-character growth as well as their attitudes and commitment to incorporating character education in their classroom curriculum.

The first study by Hauer (2003), which examined the relationship between character education and teachers’ moral vitality, concluded that training teachers in specific methods of teaching character education, as well as increasing their understanding and appreciation of it, may boost their teacher confidence and provide impetus for them to sustain their efforts. Hauer defined moral vitality to include a range 
of teacher attitudes that indicate enthusiasm for and an understanding of a moral inclination toward teaching. The specific objective of the study was to investigate whether moral vitality of teachers was connected to how they incorporated character education into their teaching. Indicators such as class meetings, incidence of parent meetings, and incidence and degree of character education topics and methods were used in lessons. Seventy percent of the teachers from five elementary, one k-12 school and one k-8 school participated. All of the schools in the study promoted a comprehensive character education curriculum, and the 124 teachers who completed the Moral Vitality of Character Education survey were encouraged to integrate character education within their classrooms for at least two years before the study. It was postulated that teachers who exhibited a great degree of moral vitality would be most likely to practice or integrate character education methods in their instruction. This hypothesis was supported by the results of the study.

In another study, Leming (2000) found in his research studying the Heartwood curriculum that character education influenced teachers as well as students. In the study, teachers reported better communication in addition to increased empathy, competence, and closeness to students. It was concluded that by teaching character education, teachers were more able to foster character within themselves as well as their students. Additional results from a study by Leming \& Silva (2001) yielded an increased understanding, responsibility, and commitment to character-related tasks as educators dealt with children concerning character-related issues.

Another study of importance regarding teacher perceptions of character education was one by Mathison (1998) This study assessed both in-service and pre-service teachers’ 
attitudes concerning general attitudes toward character education, perceived ability or degree of preparedness to teach it, professional responsibilities toward the delivery of character education instruction, and perceptions of obstacles to character education in public schools. The population of teachers in this study numbered 287 with 137 being pre-service or student teachers from San Diego State University's School of Teacher Credential Program. Those 150 employed and termed “experienced” teachers came from four culturally diverse metropolitan areas of Minneapolis, Minnesota; Louisville, Kentucky; Dallas, Texas; and San Diego, California. All grade levels were represented in this study and all teachers in the study completed a survey that was completed using a Likert scale. Each of the two groups had separate instruments. Both instruments were identical with the exception the student teacher survey had 27 items on it rather than the 20 items on the experienced teacher survey. The seven extra items were added to assess pre-service teachers' knowledge of law concerning character education and religion in public education (Mathison, 1998). There was no evidence of proven validity or reliability of the measurement surveys used.

Results from both groups of teachers revealed that they value character education but disagree on what character education is and how it should be taught (Mathison, 1995). Teachers saw a very fine distinction between education and indoctrination. Mathison reported that many teachers are fairly ambivalent toward the practice of character education in the classroom. Student teachers showed a hesitancy to discuss moral issues for fear of controversy or lawsuits stemming from First Amendment law. Mathison (1998) notes “A disturbing lack of understanding about U.S. Constitutional law as it applies to character education in the public school” (p. 16). 
In conclusion, Mathison (1998) posed implications for further research. Two noteworthy implications pertaining to teachers were 1) What skills/information did teachers feel they needed to pursue character education in their classroom with confidence and effectiveness and 2) How were teacher preparation programs addressing the issue of character education with future teachers? (p. 16). It appeared that teachers feel uncomfortable in their right and ability to effectively deliver character education in their classrooms.

A 2002 study by Milson and Mehlig involved only elementary school teachers, but merits discussion here because it involves teachers' sense or perception of efficacy for delivering character education. Efficacy refers to the teachers’ perceived confidence in themselves to effectively deliver character education. According to the authors, teachers who feel competent to provide this type of education are more likely to believe in their own ability to build students' character and overcome negative influences hindering students outside of school. They along with Gibson and Dembo (1984) contended that teacher persistence and motivation are connected, and those who exhibit high levels of efficacy tend to be more tenacious when faced with obstacles and exert more effort in teaching situations. In order to train and groom teachers to provide character education, it is important to understand those elements of character education that hinder the efficacy of teachers (Milson \& Mehlig, 2002).

In this study, a sample population of 254 elementary education teachers from a large suburban school district was given the Character Education Efficacy Belief Instrument, a survey developed and validated by Milson and Mehlig (2002) with documented reliability. Results of the study suggested that elementary school teachers 
feel efficacious concerning most aspects of character education, and those teachers who earn undergraduate degrees from private, religiously affiliated institutions have a greater sense of efficacy for teaching character education. The authors suggested that further research into these religious schools might illuminate how pre-service teachers may be more effectively trained to teach character education in schools. Milson and Mehlig noted that they did not explore whether middle and secondary school teachers share the same beliefs and that this question urged future investigation.

Milson and Mehlig (2002) cite Jones, Ryan, and Bohlin (1998) in order to explain the greater level of efficacy for character education as coming from those who earned undergraduate degrees from private, religiously affiliated universities. Results from the research can be summarized as, "religious institutions are almost twice as likely as public institutions and significantly more likely than secular private institutions to report having a community service program which explicitly incorporates character education themes” ( Milson \& Mehlig, 2002, p. 21). Furthermore, they noted that religious programs more clearly defined the philosophical basis for addressing character education than did the secular institutions:

Given their more clearly articulated mission-level commitment to character, religiously affiliated programs not surprisingly rated their efforts to integrate character education into the curriculum much higher than secular and public programs.... Deans from religious institutions tend to describe character education as extending from a teacher's own moral character rather than as a technique to be issued or covered. (p. 25) 
As noted from study respondents, they went on to claim that religiously affiliated institutions tend to include character education as their main goal, "educating teachers spiritually as well as emotionally, intellectually, physically, and socially so they may in turn teach their future students with the same outcome” (Milson \& Mehlig, 2002, p. 25).

Milson \& Mehlig (2002) questioned whether the generalized sense of efficacy teachers reflected for character education delivery would be evident regardless of the type of students they teach. A relatively high level of uncertainty suggested that teachers doubt their own ability to change the character of some students. Teachers were shown to have confidence in their own ability to effectively teach most students, but felt uncertain in their capability to change character with those students who have “...certain shortcomings of character. In other words, teachers felt less efficacious when they were teaching precisely the students who need character guidance the most” (p. 6).

As a follow up to the previous study, Milson (2003) conducted a study involving elementary, middle, as well as secondary school teachers' perceived efficacy to shape student character. The same Character Education Efficiency Belief Instrument used by Milson and Mehlig (2002), was administered to 930 teachers that represented all fifty states in the United States as well as Guam, and Puerto Rico. The sample was selected from members of the Association of Supervision and Curriculum Development. The organization was chosen because its nationwide membership consists of active teachers whose members span the entire spectrum of subject areas and grade levels. Additionally, it was thought these teachers represent a wide array of experience and knowledge of character education. Milson (2003) noted, 
The motivation, resilience, and persistence required of teachers for character education is arguably greater than most other teaching tasks. For teacher training in character education to become effective, there is a need to understand how teachers perceive their ability to accomplish the task of character education. (p. 90)

The results of the research generally support the findings of Milson and Mehlig's (2002) study in that elementary school teachers felt efficacious about character education instruction, and, disturbingly, both studies indicated those teachers doubted their ability to change students who exhibited poor character behaviors such as dishonesty, disrespectfulness, or irresponsibility (Milson, 2003). High school teachers, especially those teaching science or social studies, had more doubts about effectively delivering character education than middle or elementary teachers. Additionally it was found that staff development and character education conference sessions positively impacted teachers' sense of efficacy for delivering character education, but university-based coursework did not provide any measurable impact upon teacher efficacy (Milson, 2003).

Dissertations Research

A search was done in Dissertation Abstracts International to obtain all research done on character education between the years of 1990-2009. Sixty-two studies have been conducted on character education in the public school setting during this time period. The greatest number of studies appeared to come from institutions on the eastern and southeastern, and southern sections of the United States including such institutions as the University of Pittsburgh, the University of Pennsylvania, the University of Virginia, the University of North Carolina, the University of Georgia, the University of Central Florida, the University of Phoenix, and Texas A\&M University 
Over one-sixth of the dissertations addressed character education and the public schools. Representative topics include efficacy of pre-service teachers (Koller, 2006), a statewide evaluation of student discipline referrals (Morrison, 2006), graduate students' attitudes regarding morals (Richert, 2005), staff development for character education (Forlow, 2002), an analysis of state character education policies (Costa, 2004), character education in a Jewish day school (Roso, 2004), Catholic parish (Pilcher, 2003), a Christian character education model (Smith, 1998), as well as design standards for all school levels counseling facilities conducive to character education (Colvin Booher, 2001). Headen (2006) studied a character education program in one urban elementary school. Jones (2006) explored the relationship between teacher calling, teacher passion, and character education.

Elementary schools were represented in less than one-sixth of this search which include topics include the study of traits such as social skill acquisition (Gooding, 2004), harmony among diverse groups (Preisman, 2004), citizenship (Stuen, 996), and specific programs such as Lifeskills and Lifelong Guidelines Program (Anderson, 2005), and Lessons in Character (Devargas, 1998). Olvera (2006) conducted a case study on the role of an elementary teacher in affecting character development. Beets (2007) investigated 20 elementary schools as they implemented the Positive Action program.

One-sixth of the dissertations involved elementary or kindergarten through twelfth grade. Representative topics include traits dealing with dishonesty (Huseman, 2006), national discipline problems (Bonner, 1997), discipline problems in Texas (Morrrison, 2006); programs such as citizenship education (Carriveau, 2003); and programs geared to at risk students in relation to character education (Jackson, 1993). LeBlanc (2007) 
studied staff development in character education. One dealt with character development related to academic performance based upon research done by the dissertation advisor, Bill Reynolds and Jo Anne Martin-Reynolds (Bauer, 1991). Burton (2008) studied teacher, administrator, and grant coordinators' perceptions of a character education grant in West Virginia from 2001-2005. Brewer (2008) studied the Great Expectations character approach in relation to student achievement.

Over one-sixth of the dissertations researched character education in secondary schools. There appeared to be an even distribution of research studies done among eastern states and western states, as well as the midwestern states. Two of these focused on character education in the subject areas of social studies (Guidry, 2006) and English (Curfman, 1992). Two dissertations studied principals’ perceptions of character education, one concerned leadership within a high school in China (Kao, 2005), and one involved implementation, importance and effects of character education in a high school (Baker, 2004). Gelpi (2008) studied Jesuit high schools as communities of character. One dissertation studied the trait of dishonesty in relation to character education (Houseman, 2006). One study summarized the national historical prospective of values and attitudes in the public schools (Spawn, 1995). One study examined character education through student leadership development, citizenship education, and service learning curricula (Finney, 2002). Rosebrock (1996) studied Teen Leadership. One dissertation evaluated the teaching of values in agricultural education (Lockaby, 1997). This study was a quantitative nationwide poll that assessed what values should be taught to students enrolled in high school agriculture classes that most lend themselves to this area. The Amoroso (1995) dissertation quantitatively compared attitudes of academic to 
technical/vocational teachers in the delivery of character education. The Stoppleworth (2001) study consisted of ethnographic research of all participants’ perceptions of a character education initiative at one high school. Beck (2008) studied teacher learning within ethical and spiritual education in one middle school.

Less than one-sixth of the dissertations studied middle schools with topics including such traits such as morality, citizenship, leadership skills and programs involving school safety and antiviolence (Crawford, 1999; Kaufman, 2004; Neil, 1998; Purvis, 2002). Udayar (2008) studied the effect of Character Plus on 55 middle schools in Texas. Tapper (2008) studied the principal's role in character education efforts in one middle school located in Texas. Robinson-Lee (2008) studied a framework for understanding character education in one school. Lewis (2007) studied the effects of integration into curriculum of one suburban middle school. Suma-Belanger (2006) conducted a heuristic case study of teaching as a moral educator.

Two dissertations have significance in regards to this study and merit a closer look. In a qualitative design, Stoppleworth (2001) researched perceptions of all stakeholders participating in character education at a high school in North Louisiana. The examiner purposefully sampled 42 of the students, teachers, club sponsors, administrators, parents, as well as community support people with structured and unstructured interview, document analysis, and participant observations to describe the extent, quality, and impact of character education at the school. Participants were asked to define character education, discuss its value, and discuss its connection to values, the scope of character education at the school, the impact upon climate and culture as well as the general education of the students and how character education effects student attitude and 
behavior. Results of the research concluded that character education was perceived as an initiative to improve students' morality or values, but was not viewed as an effort to control morality in any way. There was little, if any, perceived difference between character education and values per se. Overall, character education was viewed as positively affecting the climate, culture and educational environment of students due to both classroom and extracurricular activities.

This dissertation (Stoppleworth, 2001), deals with a qualitative analysis of teacher's perceptions even though it researches only one high school. This study was conducted in the southeastern part of the United States. Although the research included perceptions of numerous other stakeholders at the school, it appears to be the only one that deals with teacher perceptions in a qualitative interpretive manner, and attempts to address the connection between character education and religious perspectives and how this impacts the curriculum.

In the second dissertation summarizes Burton’s (2008) qualitative study involving six schools that investigated teachers perceptions of character education programs implemented as a result of a grant provided to West Virginia teachers through the Department of Education through 2001-2005. The study sought to examine the successes and struggles of the schools in the grant's fourth year. The sample consisted of two elementary schools, two middle schools, and two high schools of the 30 pilot schools funded to create character education programs in the state of West Virginia. One teacher from each school was interviewed along with a school administrator and county grant coordinator. Three different protocols (teacher, administrator, coordinator) were used in a converging interview approach utilizing open-ended interviews. The study investigated 
the grass roots model in which districts, schools, teachers, as well as all stakeholders formulate their own character education program by using a framework, such as Character Counts! The three research questions that guided the study included 1) How do county administrators, principals, and teachers perceive the implementation and integration of the United State Department of Education character education grant? 2) How do schools differ in the types of character education models implemented and the successes and weaknesses of those models? 3) What factors are essentials in implementing and integrating effective character education?

The two middle school teachers were asked 11 to 15 questions that pertained to their perception of implementation and integration of the grant, which yielded 8 major themes. Major themes that emerged were commitment and support by all is a must, especially the administrator; integrated within the discipline policy and practiced with clear expectations; involvement from parents, community, and students is essential; a school wide integration throughout the school environment and existing curriculum; rewarding student for good behavior; character education used as a catalyst to improve behaviors, academics and the school culture in how people treat each other; a common language among all involved, and consistency.

The two middle school teachers were asked 10 to 12 questions that pertained to how schools differ in the types of character education models implemented and the successes and weaknesses of those models. The results yielded eight themes which consisted of the best aspect of the grant was it provided funding to purchase needed materials; made the school a more caring place and it allowed students to be rewarded for good behavior; the biggest challenge was finding the time and pulling the grant together; more involvement 
from either staff or students was needed; the models were seen as effective and would be chosen again and were selected due to flexibility in making it their own (Character Counts! And Virtues Project); students developed and emotional attachment to the school; the grant provided positive interactions with adults and adults were seen as role models; the character education model taught the students direct skills; and parents and community were involved throughout the grant.

The two middle school teachers were asked eight questions that pertained to factors that were considered to be essential in implementing and integrative effective character education. The results yielded six themes that consisted of the grant was comprehensive in that it covered all the character traits; the principal was committed and supportive; character education influenced achievement; character education served as primary prevention; staff development was essential; and specific factors are needed for character education to be effective. The last themes yielded a myriad of answers with no consensus.

Middle school results have only been reported thus far in this summary. Five themes that emerged consistently from all participants (elementary, middle, and high school teachers, school administrator, grant coordinator) were a commitment and support from all is a must, especially from the administrator; character education must be integrated within the discipline policy and practiced with clear expectations; school wide integration throughout the environment and existing curriculum must occur; character education is used as a catalyst to improve behaviors, academic and the school culture; a common language among all those involved must be utilized.

This study yielded much data and some of the interview questions touched upon aspects of character education programs pertinent to this study. It provided middle 
school data and reported on aspects such as student rewards, teacher modeling, school contextual factors, as well as barriers and elements found to be effective in program formation and implementation. This dissertation appears to most closely match this study because it addressed middle school character education and teachers’ perception of it. Kagan's Five Approaches to Character Education

Numerous strategies exist for the delivery of character education in schools. One scholar, Dr. Spencer Kagan’s (2002) work is given special explanation here because his five approaches to delivering character education were heavily utilized to answer the three major research questions of this study. He has taken two schools of thought in character education and devised the following approaches in more detail. The first two approaches illustrate the separate or stand-alone perspective while the latter three elaborate on the integrated or infused approach. Kagan (2002) has very concisely summarized the major pedagogies into five major instructional methods of a) The Curriculum Approach, b) The Extracurricular Approach, c) The Spotlight Approach, d) The Contextual Approach, and e) The Structural Approach. Kagan firmly advocates the Structural Approach and has, through his research dating from 1968 developed and perfected well over 200 structures. Each of the five strategies will be explained as well as Kagan's reasons for preferring the latter strategy in the delivery of character education.

The first of Kagan’s strategies, the Curriculum Approach, is also referred to as the “separate” or "stand-alone” configuration. This strategy emphasizes separate character lessons. Lessons or units may consist of core virtues such as honesty, respect, pride, or caring. Materials may highlight real-life people who exemplify desirable character 
virtues. Kagan (2002) noted that special material designed specifically to advance character development is the definitive feature of the Curriculum Approach.

The second strategy, the Extracurricular Approach to character education, involves furthering character through the school's activities that occur in addition to the regular academic schedule. Kagan (2002), in this approach, lists specific activities such as promoting pride through school beautification projects; charity through school clothing or food drives; citizenship through class meetings or student council; or good sportsmanship through participation in many forms of athletics. The possibilities are numerous. Kagan defines this approach as those which build character in a setting apart from and in addition to the typical academic curriculum.

The Spotlight Approach, the third strategy, is at times referred to as "integration" or "infusion" of character education into the curriculum. The strategy is named such by Kagan (2002) because while teaching typical course content, the instructor may "highlight" or "spotlight” character aspects that naturally occur and complement the lesson. He lists as an example of this approach the teacher, while presenting a history lesson, might discuss the importance of minority rights. This illustrates respect. Another example illustrating this strategy might be the music teacher while presenting the life and works of a great composer like Beethoven highlighting the trait of perseverance in the face of adversity. The characteristic of this approach that distinguishes it from others is the focus upon aspects of the regular curriculum that foster character development (Kagan, 2002).

The Contextual Approach is the fourth strategy according to Kagan (2002), which creates an atmosphere or context for character development by the environment 
deliberately created for pupils by the teacher. Activities in this approach mentioned by Kagan include portfolios that develop pride in individual accomplishments; class rules that develop good citizenship; a quiet library zone that encourages respect for others; and a class appreciation box that fosters gratitude. The definitive characteristic that makes this approach different from the others is the creation of school and classroom environments that nourish and encourage positive character.

The Structural Approach, as noted by Kagan (2002) for the fifth strategy, is the most effective approach because it stresses how character education is taught. In this pedagogy, he notes, “How we teach forms character more than what we teach” (p.2). He illustrates the strategy in two examples. First, a teacher lecturing about democracy cannot assure that students will grow to be more democratic as a result. He instead advocates students working on a cooperative project that includes group decisionmaking, respect for minority opinions, as well as peaceful resolution of conflicts. By doing so, Kagan affirms the greater likelihood of students becoming more democratic in attitude and behavior. Secondly, he gives the example of students participating in peer tutoring to teach helpfulness as being far more effective than directly teaching a virtue. Kagan (2002) notes, “There is a curriculum embedded in instruction, and it is the embedded curriculum that determines character formation more than the explicit curriculum” (p. 2). He refers to these embedded curricula as "structures.” The Structural Approach is unique when compared to others discussed here in that it teaches academic offerings through the regular use of character structures that give chances for students to learn and reinforce the virtues. In short, these structures effectively teach academic 
material while promoting good character. Many of these carefully designed instructional strategies have character virtues embedded within them.

One example of the Structural Approach is called "Paraphrase Passport." This structure is to be used when discussing a controversial issue. The turn or passport that enables the student to speak on the topic is to accurately paraphrase what the person before him said. As a result of this method, students learn to listen to, empathize, and perhaps gain more respect for differing opinions other than those personally held. Kagan (2002) feels this structure enables students to practice respect and empathy as well as realize their importance, rather than simply listening to a lesson espousing the necessity of acquiring the virtues of empathy and respect.

Kagan presents several convincing arguments for his preference of incorporating the Structural Approach in delivering character education. He notes six reasons to support his recommendation. First, it bridges the transference gap. Psychologists use this term to when the situation of acquisition is different from the situation of performance. In brief, the gap occurs when students simply cannot relate to the concept being presented based upon their experiential background. The Structural Approach alleviates this condition because virtues are obtained or reinforced through actual interaction or practice. Second, by using the structures on a regular, continuous basis, virtues may be reinforced over the course of a school year instead of presented and then forgotten due to time constraints. Third, this approach reduces teacher preparation time because it allows the instructor to present virtues and regular academic content together as integral parts of each lesson instead of preparing separate lessons for each area. Fourth, character education is not sacrificed as a result of time constraints at the end of the school year because it is not taught as a stand-alone entity. As a 
result, teachers are not forced to make disquieting decisions of whether to focus upon core grade level subject matter or upon material on virtues. Fifth, teachers today make many instructional choices based on material covered by yearly-standardized tests. Since values are not covered on these tests, they may be sacrificed. Under the Structural Approach by perpetually utilizing varied structures, students may still progress in their acquisition of positive character traits. Sixth, this approach breaks the "replacement" or "bandwagon" cycle. It appears to have the qualities needed to outlive other educational trends currently or previously in vogue. The specialized Curriculum Approach forms the replacement cycle. Educational innovation and trends will come and go, but the Structural Approach offers the advantage of delivering character development in every lesson and in all subjects (Kagan, 2002) and as a result, outlasts fads in curriculum content.

The Structural Approach has received support from scholars and practitioners. One well-known scholar, Lickona, endorsed Kagan’s Structural Approach to teaching character education in his book Character Matters (2004, p. 128-129). In addition, he wrote about the use of it by Maureen Muldig, Principal of Walberta Park Primary School in Syracuse, New York, a K-2 school. Muldig was trained at the Center for the $4^{\text {th }}$ and $5^{\text {th }}$ Rs 2004 Summer Institute in Character Education and has trained school faculty in their use.

When asked about the effectiveness of this approach, Muldig indicated she believed it was highly effective. She elaborated that the Structural Approaches teach kids social skills in an authentic way whereby they are actually practicing compliment giving, turn taking, understanding perspectives, listening, etc, while learning academic content. She continued that the structures are ways of teaching the content and not an add-on to 
the curriculum. Therefore Muldig considered it very time saving because the children do the structures to learn content and practice, as well as to learn social skills. Additionally, Muldig found that children were highly engaged, therefore increasing learning. They were more simultaneously engaged rather than teachers calling on one student at a time. Muldig further reported there existed a wide variety of structures available for use (M. Muldig, personal communication, November 12, 2004). 


\section{CHAPTER 3}

People grow through experience if they meet life honestly and courageously. This is how character is built.

\section{Eleanor Roosevelt (n.d.)}

\section{Introduction}

The purpose of this chapter is to propose a research design, the rationale, methods, and procedures that address the research questions: (1) What are selected middle public school teachers’ perceptions of character education? (2) How do selected middle school teachers implement character education? (3) What fosters and inhibits the implementation of character education?

This study presents the perceptions of character education of middle school teachers' that are and are not associated with any specific character education program. The researchers interviewed middle school teachers from a rural county in western West Virginia who are and are not part of each school's Character Development Team involved in the West Virginia Department of Education, Marshall University, and West Virginia University character education program development five-year research project. As previously explained in greater detail, the Character Development Team at each school is responsible for designing the school's character education program and training their colleagues (P. Chapman, personal communication, November 9, 2006).

This chapter format includes the introduction, followed by the research design, a description of the setting and participants, and a plan for data collection and analysis, ensuring rigor as well as summary of the methodology and possible results. 


\section{Role of the Researcher}

The role of the researcher is to serve as an instrument of data collection and analysis in qualitative research. Inherent in each researcher are beliefs and assumptions towards the subject being studied which must be illuminated. It is important to note these so that I can remain cognizant of them and thus monitor my subjectivity. By doing so, I may increase my awareness of any way by which these views may skew the research, and perhaps use them in a positive way. They may be utilized to help me learn more about my own values, attitudes, beliefs, interests, and needs (Glesne, 2006).

I have the belief that schools of every level should not incur the primary responsibility for teaching character to students. It is indeed unfortunate that in our society schools once again are charged with a task that should be a fundamental duty of parents. Parents have the first obligation for instilling the proper morals in their children followed by support from the church and community. Parents have neglected this duty. Casey Jordon, Criminal Law Professor Law Professor at Western CT State University, appeared on The O'Reilly Factor and stated, “There is no character education by parents. They expect schools to instill character in their children” (Tabacoff, 2008a). Schools often are the first contact many children have in instruction of right and wrong. Bill O’Reilly said on a broadcast two months later in another conversation concerning parents and character, "Schools cannot count on parenting. They must provide values-based courses” (Tabacoff, 2008b). Ideally, schools should serve in supporting good character by providing stable and sound role models as well as reinforcing traits learned at home.

Character education should naturally reinforce in the student a way of life, or "just the way we do things” mind set. It could be presented as a stand-alone lesson on a 
limited basis with the younger student, but more so for the older student integrated into the standing curriculum as a structural approach such as the one advocated by Kagan (2002). It then becomes the way to do things and exemplifies traits such as consideration of others, respect of self and others, discipline, to name a few. These universally held traits do not conflict with religion or morality, but simply contribute to the formation of what constitutes a good person.

I strongly believe that educators should strive to educate the whole child. By this I mean that teachers need to consider developing the entire person rather than just focusing upon imparting content. My twenty years of educational experience in special education has led me to hold such a belief. I was trained to focus upon content as well as methodology. I subscribe to the idea of educating the whole child. As a special educator, I was trained to take into account many other things in addition to academia.

Methodology should be a focus that goes hand-in-hand with content. Character education can then easily be integrated into curricula that have little room for anything but the very basics of content. In my experience of talking to and having friendships with elementary, middle, and secondary teachers, as well as observing in-service and staff development calendars, the middle and high school teachers were focused on content and much less on methodology. This may not be the case in other places, but it definitely was a factor in my locale.

I have seen many educational initiatives come and go such as assertive discipline and the open concept of education. The Chapman and Corrigan study baseline data documented that teachers viewed character education as just another add-on, under funded mandate like No Child Left Behind (Chapman, 2006a). At this point, I struggle to 
keep an open mind, give each initiative my best effort, and believe that they will survive time. Sometimes good programs came along but lacked adequate support and funding, so they faded away. Other times, a new program came under the veil of a new initiative, but was really cloaked in a new package. At any rate, the attitude of many teachers was that they would survive past the new guidelines and teaching constraints to teach another day just as they had before. I must wonder how much emphasis the educational policy makers will give the character education initiative ten years from now. Although worthwhile, I too wonder if character education will become a distant memory in American education.

Research Design

Wiersma (2000) emphasized, "research design is a plan or strategy for conducting the research" (p. 82). All research, whether it is quantitative or qualitative in nature, must have a well-planned design. Research design consists of the planning for research. It is known as the entire attack plan or strategy to answer the central problem. It is comprised of the procedures to be followed, the data collected, and the analysis of such data (Leedy \& Ormrod, 2001). According to McMillan and Schumacher (2001), a carefully planned research design must first define the subjects to be researched, the instruments that will be used to conduct the research, the procedures for data collection and the procedures for analyzing the data. It is important that research be deliberately constructed so as to minimize error or sources of bias, which would diminish the credibility of the study. As stated by Patton (1990), “purpose is the controlling force in research” and, "no single study can serve all [sic] different purposes and audiences equally well” (p. 150). 
Research designs in qualitative research, although not as rigid in structure as those in quantitative research, vary due to the context, purpose and nature of the research (Wiersma, 2000). Patton (1990) asserts, “qualitative methods permit the evaluator to study selected issues in depth and detail. Approaching fieldwork without being constrained by predetermined categories of analysis contributes to the depth, openness, and detail of qualitative inquiry” (p. 13). Leedy and Ormrod (2001) note that qualitative research continuously unfolds throughout the study due to its flexible and open-ended nature.

Qualitative researchers must guard against using produced data, particularly those derived from interviews, to verify that something occurred or to prove that a phenomenon exists (Garman, 1994). Garman astutely notes, "the essential mode of inquiry of qualitative research is for portraying deeper understanding not for verification of the phenomenon under study” (p.13). The author says that researchers tend to verify as opposed to explain, to interpret, and to illuminate. Qualitative researchers must guard against this pitfall and focus upon deeper understanding so that they may exhaust the very purpose of this type of research.

In this study, the researcher conducted interviews, made observations, and completed document analysis. The researcher's primary means of data collection were through interviews. The researcher employed observations as participating teachers permitted. In addition, the researcher analyzed documents under the same constraints.

This qualitative research is a phenomenological study. Leedy and Ormrod (2001) distinguish this design from other qualitative ones in that it seeks to understand the experience from the participants' point of view and focuses on a particular phenomenon 
as it is lived and perceived by human beings. In phenomenological studies, research is conducted through in-depth, semi-structured interviews with a purposeful sampling of 525 individuals (Leedy \& Ormrod, 2001). This type of sampling is also known as “purposive” or judgmental sampling. Purposeful sampling is defined as the deliberate choosing of a sample based upon, “ knowledge of population, its elements, and nature of the research goal” (Babbie, 1990, p. 97). This type of sampling is defined as, “... those from which one can learn a great deal about issues of central importance to the purpose of the research...” (Patton, 1990, p.169). Patton (1990) notes that these deliberate qualitative methods of inquiry yield information-rich data to provide in-depth study of the research questions.

The criteria for sampling are specified as the researcher deliberately chooses the best sample that will most help illuminate the problem or research questions (Creswell, 2003). Flick (1999) asserts that the sampling issue must be considered at several junctures of the research process. In an interview study such as this, Flick states that the sampling question must be answered when selecting the population and again when a sample is taken from that population. During the interpretation, Flick notes that the sampling decision again arises because it must be determined what data should be interpreted in general and what data should be interpreted in greater detail. Lastly, the issue arises again when considering which data to use to best illustrate the findings.

To this end, one of the schools involved in the West Virginia grant was selected. Since the literature points to limited information about character education on the middle school level, one of the middle schools receiving the treatment within the four county area was chosen for the study. 


\section{Setting}

Religious preference of the county’s residents is primarily Protestant with $29 \%$ of the 2000 census population being listed as either Evangelical Protestant or Mainline Protestant. Over two-thirds of this population was designated as “unclaimed,” meaning they were not included in any of the 188 groups listed in the Church and Church Membership Data. The unclaimed designation does not assume that this group is atheist or is nonreligious (ARDA, the Association of Religion Data Archives, 2006). This data may become important because this study explored the perceived connection between character education and religion.

This study was conducted in a small rural middle school located in northwestern West Virginia. In 2008 the study county had a population of 8,841. Manufacturing was the largest business supporting the county's economy employing $30.4 \%$ of the workforce. The average income of all employed persons in this county was $\$ 33,812$. Its unemployment rate in 2007 was 6.2\% (STATS Indiana, 2009).

The middle school that was studied contained grades six through eighth and had an enrollment of 365 students. It was the only middle school in the county and has 29 fulltime teachers. According to the 2006-2007 No Child Left Behind Report Card for this school, the sixth grade students tested on the WestTest scored $85.8 \%$ on reading and $85.0 \%$ in mathematics. The seventh grade scored $82.8 \%$ in reading and $81.9 \%$ in mathematics. The eighth grade scored $82.6 \%$ in reading and $76.9 \%$ in mathematics. The school achieved annual yearly progress (West Virginia Department of Education, 2006-2007). 


\section{Participants}

The researcher selected a purposeful sample of teachers in the county’s high school. A sample is defined as "a subset of a population” (Pagano, 2001, p. 6). Further, a sample is the group that is studied since it is impossible to examine an entire population. As explained earlier in this document, the researcher used purposeful sampling to select the participants of this study. Purposeful sampling applies to participants, sites, documents, or audio/visual material to be examined (Creswell, 2003). The four components of sampling as identified by Miles and Huberman (1994) include "the setting (where the research will take place), the actors (who will be observed or interviewed), the events (what the actors will be observed or interviewed doing), and the process (the evolving nature of events undertaken by the actors within the setting)” (p. 185).

Lichtman (2006) writes, "because your goal in qualitative research is to describe and interpret rather than to generalize, there are no hard rules about how many you should study” (p. 119) in agreement with Patton (1990). Lichtman continues that while most qualitative research endeavors use a very small number of participants and cover material in depth, it is typical for many qualitative studies to involve fewer than 10. In turn, it is sometimes difficult in qualitative research to project the exact number of interviewees beforehand. Patton (1990) insists sample size depends upon what the researcher needs to know, the purpose of the inquiry, what is at stake, what will be useful, what will have credibility, as well as what can be done given the available time and resources. As a result, the researcher did not predetermine a sample size for this study.

McMillan and Schumacher (2001) write, “ending data collection is closely connected to the research problem and the depth and richness of the data collected” (p. 
406). It comes to a close when the researcher determines that further collection will not yield more insights to the research problem. Lincoln and Guba (1985) call this "the point of redundancy." Others term this juncture of data collection when it yields more data but no new insight as “data saturation” (Wiersma, 2000). Following the guideline of Leedy and Ormrod (2001)), the sample for the study ranged between 5-25 teachers. This study began with the investigation of 12 teachers and did achieve data saturation with this number.

In the initial phase of the study, six teachers belonging to the school's Character Development Team were randomly chosen and asked to participate. The degree of Character Development Team participation was said to vary because the number of team members kept expanding (P. Chapman, West Virginia University Project Investigator, personal communication, August 23, 2007). An additional six teachers who were not on the team were then randomly drawn from a numbered faculty list. These names were randomly selected until at least twelve volunteers were obtained at the onset of the study. The researcher remained on-site for data collection for large parts of 10 days in working with participating teachers’ time constraints.

\section{Data Collection}

\section{Interviews}

The following is a discussion of interviews, document analysis, and direct observation. The researcher utilized interviews as the primary source of data. Borg, Gall, and Gall (1993) noted of interviews, “elicited data can be obtained in a much greater depth than is possible with other measurement techniques” (p. 113). Responses to interview questions may prompt subsequent elaborative or probative questions so that a 
topic may be more fully explored. According to Lichtman, (2006), the elaborative questioning strategy, "provides an opportunity for the participant to say more, to clarify and elucidate his or her responses, and allows for additional input. It may provide other ideas that the informant has thought about” (p. 124). The probative strategy allows the researcher to get to the underlying meaning of what the participant has said. Lichtman notes that although the researcher might believe the meaning is known, it is important to follow up with clarification because words have different meanings and perceptions. Both of these questioning techniques allow an issue to be explored to its fullest.

Due to the abstract nature of teaching character education, this qualitative research was done by semi-structured interviews. The semi-structured interview involves a series of general questions to be asked to all participants, but may be modified or expanded as the interviewing situation dictates (Lichtman, 2006). The interview is the most advantageous procedure for this research scenario. As stated by Borg, Gall and Gall (1993), this method is the form of "direct interaction between the researcher and subject that can be adapted at any time in order to obtain the fullest responses from the individuals being studied” (p. 113). While “generalizability” is limited in this process, understanding of the cases studied is greatly increased (Patton, 1990).

The skilled interviewer needs to be aware of several obstacles that may distort either data reported, or the interviewer's perception of the interviewee (Wiersma, 2000). In terms of inaccurate data reported, two things may happen. The interviewee may give incorrect information. Borg, Gall and Gall (1993) and Wiersma (2000) call this “response effect.” They note if this effect is present, there is a difference between the actual response and the true response. This may occur because the interviewee judges a different 
response other than true one will be perceived as more favorable. The interviewer must be able to recognize this phenomenon and probe to elicit accurate information. Another cause of data collection error may stem from inconsistent or unfavorable interview conditions (Wiersma, 2000). The interview time may be too long, inconvenient, threatening or uncomfortable for the interviewee.

The interviewer must guard against natural biases toward the interviewee. Initial impressions may color an objective assessment. Interviewers need to take time to establish rapport, appear relaxed and unhurried, while being cognizant of time constraints and always respectful (Wiersma, 2000). Wiersma recommends a time length of between 45-60 minutes per interview. The interviewer shared personal teaching experience of nearly 20 years on the secondary school level to help develop rapport with the participant. Due to the time constraints of public schools, 40-45 minutes during teacher planning periods, lunch, before and after school were times during the school day used for interviews.

The researcher developed and used an interview protocol for the study. Creswell (1998) defines a protocol as, “a predetermined sheet one which one logs information learned during the observation or interview” (p. 126). This is a written plan for the researcher to follow. Developing a plan for the interview helps the researcher stay organized and focused. This study followed Creswell's protocol format. Creswell's format is comprised of a heading, a scripted opening statement, key research questions, possible probes to follow up key questions, transition statements, space for recording notes, as well as space for records and reflections (Creswell, 2003). The opening script 
addresses elements required by the Internal Review Board for research of human subjects.

Formulation of the structure of the main body for this interview design began with examination of the three proposed major research questions. A total of 19 questions were asked of the interviewees (See Table 1). Creswell's format was followed with the addition of seven biographical questions. The seven additional questions included three demographic queries pertaining to teaching experience, one question concerning religious preference, and one question recording gender. Religious preference is sought because this study examines religion in relation to character education (Halstead, 2000; Lickona, 1991, 1999; Nord \& Haynes, 1998; Nucci \& Junker, 1982; Wynne \& Ryan, 1997). Gender information could also be addressed because male teachers may tend to be custodial and detached in nature while female teachers may be more humanistic (Friedman, 1995). This information may impact curriculum delivery. 
Table1: Interview Questions

\begin{tabular}{|c|c|}
\hline Question Number & Question \\
\hline Demographic & Record Gender \\
\hline Demographic & Position of Interviewee. \\
\hline Demographic & Number of Years Teaching Experience. \\
\hline Demographic & Number of Years Experience on Middle School Level. \\
\hline Demographic & Number of Years at this School. \\
\hline Demographic & Subject(s) Taught. \\
\hline Demographic & Religious Preference. \\
\hline \#1 & How would you define character? \\
\hline \#2 & What importance do you attach to character education? \\
\hline \#3 & $\begin{array}{l}\text { By what actions does the school indicate character education is } \\
\text { important? The county? }\end{array}$ \\
\hline \#4 & $\begin{array}{l}\text { How responsible do you feel for integrating character education } \\
\text { in your classroom? }\end{array}$ \\
\hline \#5 & $\begin{array}{l}\text { How, if at all, have you changed the way you deal with } \\
\text { character education since it has been legislated by WV State } \\
\text { Code 18-2-13? }\end{array}$ \\
\hline \#6 & $\begin{array}{l}\text { What in your personal background or past experience has } \\
\text { influenced the way you teach character education? }\end{array}$ \\
\hline \#7 & $\begin{array}{c}\text { How do you values and beliefs impact your approach to } \\
\text { teaching character education? }\end{array}$ \\
\hline \#8 & $\begin{array}{l}\text { What kinds of things do you do to teach character education? } \\
\text { From where do you get your ideas? }\end{array}$ \\
\hline \#9 & What gets in the way of integrating character education? \\
\hline$\# 10$ & What helps you teach character education? \\
\hline \#11 & $\begin{array}{l}\text { How do you think the school's emphasis on teaching character } \\
\text { education has affected what teachers do? }\end{array}$ \\
\hline$\# 12$ & $\begin{array}{l}\text { Is there anything else you would like to add that we haven’t } \\
\text { discussed? }\end{array}$ \\
\hline
\end{tabular}


From these three research questions and the review of literature, 12 questions apart from the 7 biographical questions, were determined and revised several times to answer the three major research questions. Each question was tied to a concept and a scholar in literature. The researcher identified emergent concepts of character education in public schools and the relevant scholar who researched the concept. Each of the interview questions, the research question number, exhibited concept, and citation(s) were compiled into a matrix that can be found in Appendix A.

Patton's (1990) breakdown of question analysis matrix was employed to categorize interview questions, observations, and document analysis to ensure that complete content was gathered. Four of the six categories of the matrix of experience/background questions, opinion/value questions, knowledge questions, and demographic/background questions, feeling questions, and sensory questions were utilized. Four questions dealt with experience/behavior, which answered what the interviewee has done professionally. Six questions focused upon the interviewee's opinions and values. These questions pertained to analysis and interpretation, with perceptions of issues. Two questions concerned factual knowledge. Finally, seven questions addressed demographic and background information that provided characteristics unique to each interviewee. The interviews researched the four categories shown on Table 2. Observations researched behavior/experience and knowledge. Documents analysis revealed data concerning teachers’ opinion/values and knowledge related to character education. 
Table 2: Data Sources for Interview Questions, Observations, and Document Analysis Categorized for Inclusion of Patton's Analysis

\begin{tabular}{|c|c|c|c|c|c|}
\hline Question Type & Past & Present & Interviews & Observations & $\begin{array}{c}\text { Document } \\
\text { Analysis }\end{array}$ \\
\hline Behavior/Experience & \#11 & $\# 7, \# 8, \# 9$ & $X$ & $X$ & \\
\hline Opinion/Value & $\# 12$ & $\begin{array}{c}\# 2, \text { \#3, \#5 } \\
\# 6, \# 10,\end{array}$ & $\mathrm{X}$ & & $\mathrm{X}$ \\
\hline Knowledge & \#4 & $\# 1$ & $\mathrm{X}$ & $\mathrm{X}$ & $\mathrm{X}$ \\
\hline Demographic/Background & $\begin{array}{c}\text {-Middle } \\
\text { School } \\
\text { Teaching } \\
\text { Experience } \\
\text {-Total } \\
\text { Teaching } \\
\text { Experience } \\
\text {-Number } \\
\text { of Years at } \\
\text { School } \\
\text {-Subjects } \\
\text { Taught }\end{array}$ & $\begin{array}{l}\text {-Gender } \\
\text {-Religious } \\
\text { Preference } \\
\text {-Position } \\
\text { at the } \\
\text { School }\end{array}$ & $\mathrm{X}$ & & \\
\hline
\end{tabular}

\section{Teacher Profile}

The school researched yielded these demographics for the sample. A table of demographic data of the teacher sample may be found in Appendix B. A total of 12 teachers were interviewed. Ten are female and two are male. Teacher gender was noted because of research recording possible differences in treatment of students (Friedman, 1995). Subject areas represented include English, social studies, science, health, music, art, physical education, and special education. Content areas were recorded because some areas tend to lend themselves more easily to character education than others. Years of teaching experience range from 7 to 34 years for an average of 22 years. Teaching 
experience on the middle school level ranged from 1 to 34 years for an average of 17 years. Since it opened in 1993, 7 of the 12 teachers have been working at the school. The five other teachers have taught at the current facility ranging from one to five years with an average of three and one-half years. All of these teachers may be considered to be veteran as the youngest three have seven years of experience. The remainder of the staff does, however, have three times their experience. Teaching experience was documented due to research that years of experience may impact teacher perception of character education (Mathison, 1995). Religious preference as identified by the 12 teachers include three Methodists, one Nazarene, one Church of Christ, one Pentecostal, one "Christian," two "Christian-non denominational," one Protestant, one Roman Catholic, and one Catholic. Preferences were documented because there is research noting a possible connection between religiously affiliated undergraduate schools and teachers' perceived efficacy to teach character education (Jones, Ryan, and Bohlin, 1998; Milson, 2003; Milson and Mehlig, 2002).

\section{Expert Correspondence}

The interview questions were submitted to a panel of experts for review. The final interview protocol is listed in Appendix C. A panel of experts was used to make sure the study "provided the necessary methodological rigour and with good knowledge of the social medium in which it is being applied” (Landeta, 2006, para.1). The experts were selected because of expertise in their chosen field. In this case, the field of expertise is character education.

The interview questions were submitted to each expert via email. After all experts reviewed and returned them with any revisions, the process was repeated once more with 
the collective revised draft input. Afterwards the revisions were collected and consolidated. Two or more rounds were recommended (Landeta, 2006). The second revision was the final draft that was implemented in the study. An email correspondence (Wiersma, 2000) was sent to each expert explaining the proposed research with instructions for question critique and revision, as well as timelines for return response.

The panel of experts was comprised of national and state experts. Two national experts, Dr. Thomas Lickona, and Dr. Spencer Kagan were enlisted, as well as state expert Lisa Burton. Dr. Phillip Vincent, another national expert, was designated as a standby, as well as Dr. Michael Corrigan, state expert. Dr. Vincent highly recommended Dr. Michael Corrigan as another expert, reporting that he was the most highly regarded educational researcher of his knowledge (P. Vincent, personal communication, March 28, 2008). Biographies may be found in Appendix D. Three experts from the pool of five responded for both rounds of revision.

An email correspondence (Wiersma, 2000) was sent to each expert explaining the proposed research with instructions for question critique and revision, as well as timelines for response return. A draft of the message can be found in Appendix E. After the two rounds of revision were completed, a table was constructed to show the process. It can be found in Appendix F.

The principal of the middle school study was contacted via letter to introduce the researcher and proposed study, as well as to set up further contact to obtain permission and ascertain the most efficient way to contact teachers and conduct the research. The letter is contained in Appendix G. 
After revisions by the panel of experts were complete, the researcher conducted a pilot test with three schoolteachers. Yin (1984) notes that this interview trial run helps researchers to refine data collection in terms of data content and procedures. It helps the researcher to develop pertinent lines of questioning and probing. The author terms it a “dress rehearsal.” Yin adds the pilot test may be administered to population different from those in the proposed study design.

The researcher made short notes of clarification during the interview. The interview protocol was utilized along with an audiotape of each interview. Immediately after each interview, notes were taken of the interviewer's perceptions and the entire audiotape was transcribed as soon as the interview schedule allowed (Creswell, 1998). It is important that transcription and analysis take place soon after interviews and observations so that “fresh insights” may be preserved (Patton, 1990). Patton (1990) notes, Interviewing and observing can be exhausting, and it is easy to forgo this time of reflection and elaborations, put it off, or neglect it altogether. To do so is to seriously undermine the rigor of qualitative methods. Interviews and observations should be scheduled so that sufficient time is available for data clarification, elaboration and evaluation.... Thus ideas and interpretations that emerge following an interview or observation should be written down and clearly marked as such. (p.353) 


\section{Document Analysis}

Document analysis was employed as teachers invited the researcher. Document analysis involves collecting and examining public documents such as memos, minutes, records, archival material or private documents consisting of journals, diaries, emails, and letters (Creswell, 2003). Patton (1990) asserts that document analysis in qualitative inquiry yields small parts, exact quotes, or entire passages from material.

When considering data collection, the researcher needs to determine what forms should be employed to answer the research questions (Maxwell, 1996). Maxwell stresses that data collection strategies usually goes through a lengthy period of focusing and revision, even in a carefully designed study. Additionally, this must occur so that accurate data is provided to answer the needed questions and to guard against validity concerns to them.

Data collection took the form of items such as school plan developed by the Character Development Team, and individual teacher lesson plans and character education curriculum materials. See Table 3 for questions comprised for document analysis. 
Table 3: Document Analysis Form

Document and description: Date:

1.Does document reflect the teacher's perception of character education?

If so, how?

2. Is there evidence of any of Kagan's five Approaches to character education?

_ Curriculum Approach

- Character education comprises the entire lesson.

- Special material designed specifically to advance character development.

- Lesson occurs within the confines of the classroom.

Extracurricular Approach

- Character education comprises the entire lesson.

- Furthers character through school activities in addition to regular classroom schedule.

- Found in physical setting other than and in addition to regular classroom. (volunteer activities such as community cleanup, soup kitchen service)

_ Spotlight Approach

- Integrated/ infused into curriculum.

- Highlights character aspects that naturally occur and compliment lesson.

- Focuses upon aspects of regular curriculum that fosters character development.

- Other academic disciplines will be taught along with character education.

_ Contextual Approach

- Integrated/infused into curriculum.

- Develops atmosphere for character development by creating conducive physical environment.

- Focuses upon creating school/classroom environments that nourish and encourage character.

- This approach is not directly used as a lesson. 
Table 3 (continued): Document Analysis Form

_Structural Approach

- Integrated/infused into curriculum.

- Strategy-oriented: How we teach forms character more than what we teach.

- Methodology is stressed as opposed to content.

- Embedded curriculum, methodology-focused. Happens with regular academic content.

- Teaches academic offerings through regular use of character structures to promote good character.

3. Does the document reflect any barriers to delivery of character education?

4. Does the document reflect any factors expediting the delivery of character education?

Document Analysis Summary

Nine of the 10 teachers observed submitted lesson plans for analysis. Of these nine, five showed no evidence of Kagan’s (2002) approaches. Two reflected the spotlight approach, one reflected the structural approach, and one reflected both spotlight and curriculum approaches. The four supplemental materials submitted for analysis were good examples of the presence of character education as both Kagan's (2002) curriculum and spotlight approaches. For a summary of the document analysis, see Table 4. 
Table 4: Document Analysis Summary of the Presence of Kagan’s Five Approaches

\begin{tabular}{|c|c|c|c|c|c|}
\hline & Curriculum & Extracurricular & Spotlight & Contextual & Structural \\
\hline \multicolumn{6}{|l|}{$\begin{array}{c}\text { Lesson Plan } \\
\# 1\end{array}$} \\
\hline $\begin{array}{c}\text { Lesson Plan } \\
\# 2\end{array}$ & & & & & $X$ \\
\hline \multicolumn{6}{|l|}{$\begin{array}{c}\text { Lesson Plan } \\
\text { \#3 }\end{array}$} \\
\hline \multicolumn{6}{|l|}{$\begin{array}{l}\text { Lesson Plan } \\
\# 4\end{array}$} \\
\hline $\begin{array}{c}\text { Lesson Plan } \\
\# 5\end{array}$ & & & $X$ & & \\
\hline \multicolumn{6}{|l|}{$\begin{array}{c}\text { Lesson Plan } \\
\text { \#6 } \\
\end{array}$} \\
\hline $\begin{array}{c}\text { Lesson Plan } \\
\text { \#7 }\end{array}$ & $X$ & & $X$ & & \\
\hline \multicolumn{6}{|l|}{$\begin{array}{c}\text { Lesson Plan } \\
\text { \#8 }\end{array}$} \\
\hline $\begin{array}{c}\text { Lesson Plan } \\
\# 9\end{array}$ & & & $X$ & & \\
\hline $\begin{array}{c}\text { Holt Reading } \\
\text { Text }\end{array}$ & $\mathrm{X}$ & & $X$ & & \\
\hline $\begin{array}{c}\text { Social } \\
\text { Studies } \\
\text { Periodical } \\
\end{array}$ & $\mathrm{X}$ & & $\mathrm{X}$ & & \\
\hline $\begin{array}{c}\text { Science } \\
\text { Supplemental } \\
\text { Book } \\
\end{array}$ & $X$ & & $X$ & & \\
\hline $\begin{array}{c}\text { Character } \\
\text { Development } \\
\text { Team Social } \\
\text { Studies } \\
\text { Resource }\end{array}$ & $\mathrm{X}$ & & $X$ & & $\mathrm{X}$ \\
\hline
\end{tabular}

\section{Observation}

Direct Observation is a method for gathering data concerning people and events as they are occurring (Borg, Gall, \& Gall, 1993). The researcher observes at the research site in a capacity that varies from a nonparticipant to a total participant in the event or activity 
(Creswell, 2003). Direct observation was employed as time allowed and as teachers permitted the researcher.

One pitfall of which to be mindful when observing is that because of the researcher's mere presence, people could say or do things differently, and therefore situations may be altered (Borg, Gall \& Gall, 1993; Leedy \& Ormrod, 2001; Lichtman, 2006). Lichtman (2006) explains that people might desire to please the researcher, or may behave according to what they perceive the researcher views as favorable. Leedy and Ormrod (2001) further warn observers to distinguish between actual happenings and personal interpretations. They add that this is important because interpretations of what is witnessed tend to change throughout the study.

As documented by Lichtman (2006), six questions must be answered before observation can begin. First, it must be determined who will be studied. In this case, teachers and their actions will be observed and compared with their perceptions of what they say they are doing in terms of character education in the classroom. Second, it must be determined whether formal, informal or occasional groups will be observed. In this study, formal groups will be observed. Lichtman (2006) denotes formal groups as “one that exists on a regular basis with the same people serving as a nucleus, such as a class, a family, a team, a gang, or a work unit. These same people who meet regularly either for work or play” (p. 140). Third, the researcher must obtain access to the observation site. Teacher permission will be elicited at the time of each teacher interview. Fourth, the observation focus must be decided. The researcher will examine the physical classroom as well as teacher actions and interactions to determine evidence of character education implementation. Fifth, frequency and length of observation must be planned. In this 
situation, observations will last the length of an entire class period as each teacher permits. Sixth, the role of the researcher must be decided. The researcher will take the role of an unobtrusive observer (Lichtman, 2006). This means that the researcher will play no role in what is being observed. Wiersma (2000) notes, "the limited observer role would be used when opportunities for observation are restricted and other data-collection techniques, of necessity, take precedence” (p. 247).

Creswell's (2003) observational protocol was used with some additions. The original design consisted of a form that has a vertical line down the center to separate it into equal halves. The first half contained descriptive notes that include such things as setting, description of those observed, dialogue, and notes about certain activities. The right half of the form included the observer's reflections of personal assessment. Additional notes contained any needed demographic information. Since the researcher looked for indicators of teacher perception and implementation of character education, criteria for each was presented before the actual observation and personal assessment sections (See Table 5). 
Table 5: Creswell’s Observation Protocol Modified

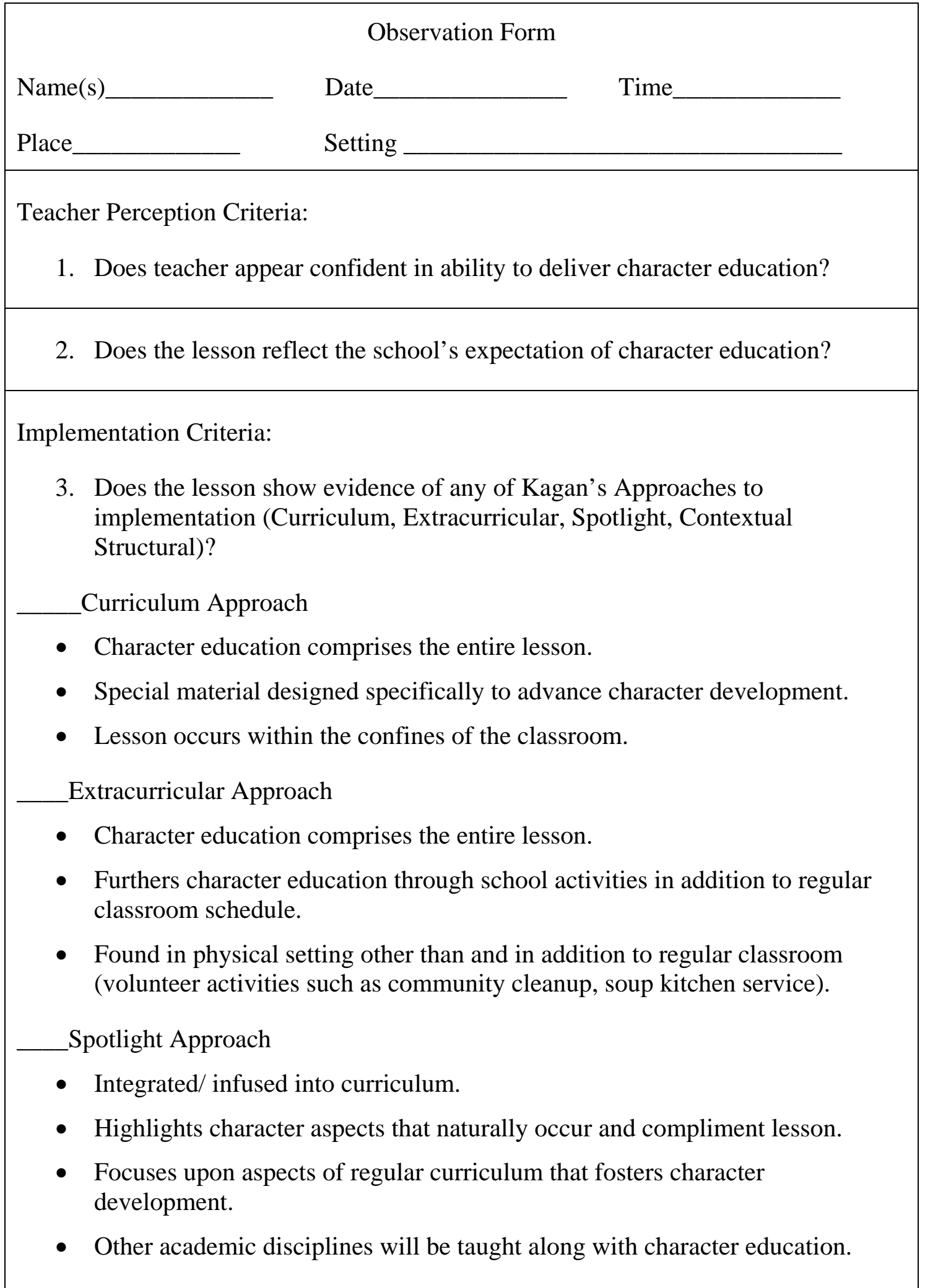


Table 4 (continued): Creswell’s Observation Protocol Modified

Contextual Approach

- Integrated/infused into curriculum.

- Develops atmosphere for character development by creating conducive physical environment.

- Focuses upon creating school/classroom environments that nourish and encourage character.

- This approach is not directly used as a lesson.

Structural Approach

- Integrated/infused into curriculum.

- Strategy-oriented: How we teach forms character more than what we teach.

- Methodology is stressed as opposed to content.

- Embedded curriculum, methodology-focused. Happens with regular academic content.

- Teaches academic offerings through regular use of character structures to promote good character.

4. Are there any apparent obstacles to delivery of character education?

5. Are there any apparent factors expediting delivery of character education?

\begin{tabular}{|l|l|}
\hline Description & Personal Assessment \\
\hline
\end{tabular}

\section{Summary of Observations}

The researcher gained access to 10 classrooms of the 12 interviewed teachers. The school calendar, school wide events, and the facility were examined for any evidence of character education integration in the classroom. All classrooms except one displayed numerous examples of the contextual approach. There were two examples of Kagan's (2002) spotlight approach and one example of the curriculum approach observed as teachers taught. For a summary of observation results, see Table 6 . 
Table 6: Observation Summary of the Presence of Kagan's Five Approaches

\begin{tabular}{|c|l|l|l|c|c|}
\hline & Curriculum & Extracurricular & Spotlight & Contextual & Structural \\
\hline $\begin{array}{c}\text { Observation } \\
\# 1\end{array}$ & & & & $\mathrm{X}$ & \\
\hline $\begin{array}{c}\text { Observation } \\
\# 2\end{array}$ & & & & $\mathrm{X}$ & \\
\hline $\begin{array}{c}\text { Observation } \\
\# 3\end{array}$ & & & $\mathrm{X}$ & \\
\hline $\begin{array}{c}\text { Observation } \\
\# 4\end{array}$ & $\mathrm{X}$ & & $\mathrm{X}$ & \\
\hline $\begin{array}{c}\text { Observation } \\
\# 5\end{array}$ & & & $\mathrm{X}$ & \\
\hline $\begin{array}{c}\text { Observation } \\
\# 6\end{array}$ & & & $\mathrm{X}$ & $\mathrm{X}$ & \\
\hline $\begin{array}{c}\text { Observation } \\
\# 7\end{array}$ & & $\mathrm{X}$ & $\mathrm{X}$ & \\
\hline $\begin{array}{c}\text { Observation } \\
\# 8\end{array}$ & & & $\mathrm{X}$ & \\
\hline $\begin{array}{c}\text { Observation } \\
\# 9\end{array}$ & & & & & \\
\hline $\begin{array}{c}\text { Observation } \\
\# 10\end{array}$ & & & & & \\
\hline
\end{tabular}

\section{Teacher Correspondence}

Letters of participation were sent to each of the twelve selected teachers in hopes of establishing an interview schedule prior to the researcher's arrival at the middle school (see Appendices H and I). A separate letter was sent dependent upon whether the teacher served on the Character Development Team. The researcher made arrangements for communicating consent for participation in interviewing only or participation in observation and document collection at the time of each interview.

\section{Data Analysis}

Wiersma (2000) notes that in qualitative research, data collection and data analysis overlap because analysis naturally begins soon after the onset of data collection. This 
occurs because the researcher is constantly referring to the working hypothesis and unanticipated results. Furthermore, as data collection progresses, less data is collected and more analysis is compiled. The main focus of data analysis in this phenomenological study is to, "search for 'meaning units' that reflect various aspects of the experience" (Leedy \& Ormrod, 2001, p. 157). From this identification then, meaning units are integrated into a "typical experience” (p. 157).

Creswell (1998) notes that data analysis, when graphically depicted, follows a spiral shape that overlaps and repeats over and over. Leedy and Ormrod (2001) endorse this model and agree that it is, "equally applicable to a wide variety of qualitative studies" (p. 161). Creswell explains that the researcher "enters with data of text or images and exits with an account or narrative. In between, the researcher touches on several facets of analysis and circles around and around” (p. 142).

After data collection comes the first loop of the spiral known as "data managing” (Creswell, 1998). Creswell's (1998) data analysis model will be utilized for this study. In this initial stage of data analysis, data is organized into files or any kind of unit. Subsequently, files are translated into "text units" such as words, sentences, or whole narratives that lend themselves to further analysis. It is important at this time to get a sense of the entire scope of data. Agar (as cited in Creswell, 1998) suggests reading all of the documents from start to finish in order to gain a picture of the data as a whole before breaking it into parts. The researcher is further encouraged to record short notes of impressions in the margins of each document. This process constitutes the second “reading and memoing” loop of the upward spiral of analysis (Creswell, 1998). 
The third upward, spiraling loop of this data analysis model is the "describing, classifying, interpreting” stage where the major focus of analysis occurs. Creswell notes of this phase, "here researchers describe in detail, develop themes or dimensions through some classification system, and provide an interpretation in light of their own views or views of perspectives in literature” (1998, p. 144). Description must occur within context of person, place, or event. Description then, according to Creswell (1998), means describing what is seen in detail. Next in this stage is classification, whereby qualitative data is dissected and sorted into categories, themes, or dimensions of information. From this hopefully emerge five or six general "themes." Within each theme will be "sub themes” and even entities within each of these sub themes. The author stresses, in terms of the final narrative, that it is important to narrow down the data to five or six themes so as to manage the large amount of information. Interpretation in this stage consists of the researcher attempting to make coherent sense of the data by forming "larger meanings" of what is occurring with the data.

The fourth and final stage of the data analysis model and last overlapping upward spiraling loop involves representing the results in some sort of understandable way. This may be accomplished by text or graphic form. Metaphors, comparisons, and propositions may be used here. This is the final product of this inductive process that begins with raw data and ends with broad themes (Creswell, 1998). The researcher utilized a reader to examine interview data for themes and compare them to the researcher's identification of themes. The reader was given all transcribed copies of the 12 interviews along with the three research questions and asked to identify what themes she found in them that answer 
the questions. Both the reader and researcher identified the same themes and supporting themes.

\section{Ensuring Rigor}

Rigor is crucial to research. Merriam (1993) emphasizes that rigor is certainly necessary in all research so that results may be trusted. The researcher utilizes complete and comprehensive methods to obtain, record, and examine data all the while consciously striving to stay objective (Leedy \& Ormrod, 2001). Garman (1994) asserts that the study must address a series of questions, such as "Is there sufficient depth of intellect rather than superficial or simplistic reasoning? Are the portrayals sound?” (p. 9).

Merriam (1993) notes that the three major facets constituting rigor are internal validity, reliability, and external validity (generalizability). Internal validity refers to how closely the study findings match reality. Merriam (1993) writes, "Qualitative research assumes that reality is constructed, multidimensional and ever-changing. There is no such thing as a single, immutable reality waiting to be observed and measured “ (para. 8). As a result, there can only exist our interpretations of someone else's interpretation of reality.

Various strategies may be used to strengthen qualitative research. Two were used in this study. They include member checks, and a statement of researcher's experiences, assumptions, biases. These strategies help close the gap between the interpretation of reality and the true reality (Merriam, 1993).

Member checks involved returning to the people from whom data was collected and presenting the interview transcript along with researcher's written initial interpretations to check to ensure impressions were plausible (Merriam, 1993; Plucker, 1990). Teacher interviewees participated in member checking by reviewing a transcript of the interview 
for accuracy and meaning of their responses. Transcribed interviews were given to each teacher for review and then the researcher returned a few days later and conferred with each one to make any needed changes. At that time the interviews were collected and written changes were then incorporated into the transcription of each interview. When changes were suggested the researcher clarified them at that time in the teacher's presence.

A statement of researcher's experiences, assumptions, and biases, presented to the reviewer at the very beginning, is important because it frames the study. By divulging this information, the reviewer is better able to understand how the data was interpreted and results derived (Merriam, 1993). This researcher stated personal experiences and evident assumptions and biases.

Reliability in a qualitative study can be achieved with the addition of an audit trail (Merriam, 1993). An audit trail is a description of how the study was conducted, so that it can be reproduced in a like fashion by other researchers. The strategy was developed by Guba \& Lincoln (as cited in Merriam, 1993). This researcher painstakingly described all means of gathering information to the extent that the study may be replicated from the descriptive narrative.

\section{Possible Results}

Wolcott (2001) cautions the qualitative researcher when forming conclusions to disregard any thoughts that the final chapter has to culminate into a conclusion with some sensational end. Also, the researcher must resist the inclination to write about what “ought to be” instead of reporting, "what is”. Wolcott (2001) notes, "You cannot bridge the chasm between the descriptive and the prescriptive without imposing someone’s 
judgment, whether originating from the people in the setting or from the researcher's own assessment” (p. 121). However, it is certainly acceptable to supply personal viewpoints or professional opinions if they are clearly labeled as such (Wolcott, 2001).

Wolcott states that it is important to concisely document what has been attempted, what new knowledge has been acquired, as well as what new questions have been discovered.

Textual narrative and explanation was the primary means by which this study was reported. According to Patton (1990), typologies are “classification systems that divide some aspect of the world into parts” (p. 393). The indigenous one described by Patton (1990) would seem most pertinent to since it entails analysis of verbal categories used by the participants themselves, and this study heavily relies upon interviews.

In attempting to project possible results of this study, it was hoped that some sort of model or concept map might be formulated. This may emerge from the text as it is arranged and categorized. A concept map, according to Maxwell (1996), is a graphic way to represent a theory. The spider map may lend itself to this material content because it is organized with a central idea or theme around which are situated sub-themes projected outward from each theme (Kinds of Concept Maps, 2007). The researcher envisioned each of the three research questions serving as a theme with supporting data radiating outward as emerging sub-themes.

\section{Summary}

This qualitative phenomenological study entailed data collection primarily consisting of semi-structured interviews, while being supported by direct observation and document analysis when possible and available. Interviews were held according to participant schedules. Each consisted of 19 proposed questions. Patton’s (1990) matrix was utilized 
to construct interview questions. School plans regarding character education, any school plans formulated by the school's Character Development Team, individual teacher lesson plans, as well as curriculum materials were analyzed first with a form developed by the researcher.

Teachers were directly observed teaching in their classrooms as an unobtrusive observer. Creswell's observation form was used. The physical environment of both general school areas and participants’ classroom's were observed for evidence of character- related items.

Data analysis was done through using Creswell’s Data Analysis Spiral. Rigor was insured through internal validity, reliability, and external validity measures. 


\section{CHAPTER 4}

Sow a thought and you reap an action

Sow an action and you reap a habit

Sow a habit and you reap a character

Sow a character and you reap a destiny

Ralph Waldo Emerson (1803-1882)

\section{Introduction}

This chapter begins with school description and profile of the 12 teachers. It reports data from the 12 interviews, 10 observations, and documents consisting of 9 teachers' lesson plans as well as classroom materials that are grouped together and summarized according to each of the three posed research questions. A summary of the results from the three methods of data collection ends the chapter.

\section{School Description}

The following narrative is an accurate depiction from each of the numerous visits to this school. The visitor is greeted with brightly lit gleaming hallways and clean, freshly painted walls and polished floors. The school appears newer than its sixteen years. Six large colorful banners hang in the main and second floor hallways with each enumerating one of the six pillars (traits) from the school's Character Counts! Program. In the corner of the first floor access ramp stands a large decorated evergreen tree. Student artwork lines the hall and parts flutter in the breeze as people walk by. The school appears rich in physical context (Kagan, 2002). Students changing classes walk to their lockers in a surprisingly calm manner with very little horseplay. They appeared happy and made eye contact with this researcher. When in the classroom, almost without exception, they sit 
quietly when the teacher engages in conversation with this researcher or other visitors to the room. The teachers appear relaxed, professional and obviously like their jobs as well as each other. They freely gave of their time, offered information and included this visitor in social and professional conversations, in addition to numerous faculty lunches celebrating seasonal events and activities. Always present throughout the school, the principal warmly welcomed this researcher and gave free access to the school.

Teachers were quoted in the following summary of interview results. The number of times each was directly quoted is presented in Table 7. This represents efforts to equally represent all teachers in the sample. Some teachers, however, expressed themselves more concisely and succinctly than others, so their quote was selected to illustrate each question response even though the others expressed similar ideas in more words.

Table 7: Incidence of Direct Teacher Quotes

\begin{tabular}{|c|c|c|c|c|c|c|c|c|c|c|c|c|}
\hline Teachers & 1 & 2 & 3 & 4 & 5 & 6 & 7 & 8 & 9 & 10 & 11 & 12 \\
\hline $\begin{array}{c}\text { Times } \\
\text { Quoted }\end{array}$ & 4 & 7 & 9 & 4 & 4 & 7 & 3 & 8 & 7 & 5 & 4 & 6 \\
\hline
\end{tabular}

\section{Research Question \#1:}

What are selected middle school teachers' perceptions of character education?

a. How do teachers define character education?

Data that answers this question came from interview questions \#1, \#11, \#12, observation question \#1, and document analysis question \#1. When asked to define character education, 7 of the 12 teachers struggled to articulate their personal definition of character education. Six of them stated their hope or anticipated outcome of the effect 
of character education. One said its goal is to "bring out the self worth in every individual.” Two mentioned trying to make students better people. Another teacher mentioned that tomorrow's generation must have good character to prevent more deterioration of society. Perhaps the most representative definition offered was, "Character education is teaching kids to be well-rounded citizens, law-abiding citizens, to be active citizens, and how to care for others.” When the question was fully probed with each of the 12 teachers, 6 of them mentioned the six pillars of the Character Counts! Program that the school utilizes to define character education. The pillars, as listed on their website, consist of the six character traits of respect, responsibility, trustworthiness, caring, fairness, and citizenship. At this school, one trait was highlighted each grading period. Two of the six teachers who mentioned agreeing to the six pillars said they could not enumerate all of them during the interviews.

Parental influence was included by 3 of the 12 teachers in their definition of character education. One teacher stated in reference to her discussion citing the traits of responsibility, respect, and caring, "But I think as parents, it is something you try to demonstrate every day.” Another teacher said in her reference to the traits of trustworthiness, honesty, and fairness, "They have learned those values from home—not in the school. We just kind of enhance upon that and it is kind of — but a lot of those things they already knew from home.” The last teacher noted, "I think it starts at the foundation of how you are raised, what your morals and values are.”

Teacher modeling was mentioned by 4 of the 12 teachers in defining character education. One said, "We have to be good role models for character education. We have to model what we want them to do.” Another noted, “...it [character education] is 
something you live, show, and try to experience [incorporate] into your teaching everyday.” One teacher noted, “I don’t believe it is something that I can teach. I believe that it is something that I can model.” One teacher said she didn’t subscribe to formal character education, but did convey it by modeling.

The integral nature of character education was noted by 2 of the 12 teachers. One said that its characteristics are overlapping and one could not be presented without having the others. Three teachers distinguished character education as separate from the curriculum: "I think it is probably one of the most important things that we teach.... I think it is more important than our curriculum." Another said, "I don't particularly see the need to have it as a curriculum and I don't really teach it as a curriculum...”

The perspective of all 12 teachers is that the school's emphasis on character education hasn't really changed what teachers do at all since it has been required and incorporated. In summary of their sentiments, one teacher offered, "Again it has really not changed. It is just what we have always done.” One teacher commented that a few teachers then realized the importance of character education and bought into it while there were others who did not. One teacher noted, “I don’t think it is anything that we weren’t doing. We just gave it a name.” Another teacher expressed that the school was a poor place in which to bring character education as it was already being done.

All 12 teachers offered additional comments. Several teachers expressed that the school has good kids and some said their kids have always been good. A teacher commented that in different sports situations, the students have been recognized several years for good sportsmanship and they never have to worry about students destroying property. One teacher said, “... we were in such good shape to start with like when we 
did the initiative, that we didn't see a big jump because from what we hear we were already there. People that come from out of state, we have schools wanting to visit, and I don’t know—I guess it is just what we have always done.” Another commented, “... just because of the environment teachers aren't fighting their little battles.... They may have more time to teach.... but I don't think it [character education] just showed up here, because we were good to start with. So, it is unfortunate for the people who put a lot of money into the funding." One teacher stressed that the money spent for character education would be better spent on helping students with academics. The teacher was referring to money for tutors to boost struggling students. Another teacher questioned whether character education could be taught saying, "I can only show them what I am," and had doubts about her ability to reverse the lack of guidance and nurturing at a young age.

During the observation the of teacher lessons, data reflected that nine of the teachers appeared confident to deliver character education except one teacher who said she deliberately changed her lesson plan so the researcher could "see more." The lesson, however, did not exhibit any of the five approaches advocated by Kagan (2002).

Document analysis showed that eight of the nine teachers' perceptions of character education were supported by their lesson plans. Of these eight, one teacher said she defined character by modeling, so it stands to reason that no instructional strategy related to character education would be documented. The ninth teacher mentioned imparting the six pillars of character to students in her definition of character education, yet did not have characterrelated procedures documented in the lesson plans. All of the classroom books shown to the 
researcher by the teachers supported the teachers' espoused perceptions of character education.

\section{1b. How important is character education?}

Data that answered this question came from interview questions \#2, \#3, \#4, \#5, \#11, \#12, and observation question \#2. The entire sample of twelve teachers evaluated character education as very important. They said things such as, "I think that if you are not somehow addressing it, you are not teaching what you should be.” Another teacher distinguished between formal and informal character education and said, "Formally, I don't put an importance on it.... but as everyday modeling, I think teachers-I put an importance on that."

All twelve of the interviewed teachers expressed personal responsibility for integrating character education in their classroom. Three of them said it was their job. One teacher who made an analogy comparing character education to exposing people to the Bible said,

I feel that I am ultimately responsible, you know, I'm the teacher in the room 40some minutes a day for that group of people I need to embody what this is all about. It's kind of like the Bible, you know, some people never go to church. You better see somebody as a walking Bible; you know, that type of thing.

Another teacher submitted, “I don’t just teach character ed—it is just part of what we do.” One teacher noted, "In the classroom is where it happens.... I'm very aggressive in my teaching and we do a lot of things that are messy and kids have to be very responsible for their supplies and putting them away, and taking care of their own things.... If I ever caught a kid making fun of someone else's work, there would be consequences, you 
know, those kinds of things and they know that.” One said it is especially important for middle school kids to have a place to belong and feel important and she views the school as a "family." Another teacher noted that "salvaging someone’s heart” is most important. “We can always say I'm sorry, but I tell kids sorry doesn’t work forever.” The same teacher, along with two others, noted, “I don’t think the kids are getting a lot of this stuff at home anymore. They are raised in a different time and place. I think it was-we were raised with manners and ‘yes ma’am and no ma’am'. I don’t think kids are getting that today.... it starts at home.” One of these teachers noted the need for character education in dealing with other people and functioning in the world of work. Another said, "Well, unfortunately, I feel we live in a society where parents don't teach their kids how to be good characters, for the most part. So I think it has fallen on the school system to teach character education...”

Three of the 12 teachers commented that they felt the program is important. One mentioned the Golden Rule, while another offered, "We have a lot of power. We mold people’s lives. We ought to be doing it in a positive light.” One teacher liked tying rules to good character, but noted, "I hope everybody gets on board with it because I think in the beginning, people thought it was a lot of fluff.”

The 12 teachers were asked if the 2001 legislation had influenced their teaching character education. Six of the teachers said it had no impact on them. One said, "Again, it is what we have always done.... Basically we have to highlight in our lesson plans if we do something special, but it is something we have always done.” However, one of the 12 teachers responded to the question by noting, “I probably haven’t much.... I may 
make it a little more visible in the classroom. I may have a little more writing of it, but it has always been an important part.”

More emphasis in character education since it became part of the West Virginia State Code in 2001 was noted by 5 of the 12 teachers. Heightened awareness was cited by 3 of the teachers as a result of the school's emphasis on teaching character education. As the first teacher said,

I think it has made some of them that didn’t put emphasis in the classroom put emphasis and take an opportunity for just a teaching moment, which they probably have in the past, but they are like “ooh, this is a teaching moment. Let's take advantage of it—a teachable moment.”

One teacher mentioned the large colorful banners of the six pillars of character that greet people as they walk down the main hall. He said these banners serve as a personal reminder of why the teacher works there. Another teacher noted being more conscious of it in relating to students and said, “...this is how I am going to approach it. He [student] lied to me, so, okay, lying did what? Okay, you have lost my trust. Trust is the one thing that you had and gave it away. I no longer trust you because you lied to me.” One of the 12 teachers said school character education activities have been helpful to raising awareness of character education. The teacher named things such as classroom signs of character quotes, character pep rallies, and student dress-up contests, and highlighting character education plans in teacher plan books. Another teacher disagreed with the "big prizes" given at the student character education pep rallies. The teacher offered, “At the end of the year there were Play Stations, maybe DVD players, I mean big electronic [gifts].” 
One teacher of the 12 teachers conveyed that some have recognized the importance of character education and noted that more of them are doing it because it is a good thing, not just to avoid "the hassle." Two teachers mentioned the importance of character education and expressed that it is simply an extension of them. One teacher added, “These are going to be the leaders of tomorrow that's going to take care of me when I'm old and I just hope that they care about one another and care about the future.”

A teacher offered that character education has been delivered at this school before the legislation by saying,

Just more of an emphasis on it.... Sometimes people do this intuitively. They just know it is the right thing to do, but now that you spend all this money, and you reserve the hotel rooms, and you bring in all these quality speakers and presenters to us, then there is something here. There is something here. The same teacher later noted, I think every teacher would say they are doing it more now. There's more of an emphasis on it and I think that if they ever pull the plug and say, 'well, we are not going to fund this anymore,' I think that I would continue doing it.” Another teacher commented, I do try to relate to the pillars. The kids know, you know, when we do projects, that is being a good citizen. You are going to develop citizenship, you know, and relating to those terms and they see them, and I think they link with—say they link everyday living and everyday action with what those traits are, because that is what they have to do. They [the traits] have to become innate, and until they become innate, then we haven't been very successful.

One teacher said that since they formally have to deliver character education, he uses a specific book that highlights struggling people who rose to greatness in society. Another 
teacher mentioned becoming a better person, teacher, and parent as a result of a placing greater emphasis on character education. The teacher noted, "Sometimes we get kind of cocky with our self and think we are perfect. I always tell my students I have room to improve too. I make mistakes everyday. I think they see that too.”

A teacher commented that the school is special. The teacher pronounced, "There is a spirit in this school unlike most places. The kids respect each other.” The same teacher elaborated on parent involvement by indicating, “Our parents do a very, very nice job of doing character education at home. They do. It shows when they come in here- the level of respect. It gives us a lot to work with.” The teacher also commented on actions of the staff by saying,

We are out there, we are constantly talking to our students, we welcome them when they come into the classroom. They know they are important, not just a warm body for 40 -some minutes only to be herded out and bring in the next group. We try to treat them as unique individuals because that is what they are. Although heightened awareness of character education was noted by several of the teachers since legislation, it is difficult to tell whether this translated into actual instruction because of the low incidence of it found in observations and document analysis.

The school appears to expect teachers to enforce behavioral expectations according to the six enumerated traits of the adopted Character Counts! Program and school discipline policy. In addition, some mentioned posting the weekly character trait quote and the notation of character education in lesson plans for last year, but it was unclear whether they were instructed to do so this current academic year. Other than these 
expectations, apparently teachers can do whatever they choose to address character education.

Research Question \#2:

How do selected middle school teachers implement character education?

Data that answered this research question came from interview questions \#6, \#7, \#8, \#12 observation question \#3, and document analysis question \#2.

Four of the 12 teachers gave examples of how they implement character education in their classrooms. The first one said character education is included into journal writing that utilizes the weekly quote, and has used the six pillars in writing composition assignments as well as poetry lessons. The second teacher mentioned the six pillars could be used as Friday bell ringers (warm up writing topics). The third teacher noted, "We have a lot of areas that fall right into the character education and, you know, the bullying and stuff.... We do a lot of cooperative-type games.... So that they [students] don't have the same partner and they are working with a variety of children and nobody is left out, or feels left out."

Several answers to the question implementation of character education were given by one or two teachers. One teacher of the 12 named journal writing, compositions, and discussions utilizing the posted classroom quote of the week. The Character Counts! Program was noted by two of the 12 teachers as a good program. One teacher mentioned liking the materials and activities of role-playing, skits, as well as hero stories, and also enjoyed the character education conferences offered to the staff each summer. One teacher of the 12 interviewed said that the topic may be obtained from the binder full of character lessons provided by the school's Character Development Team, but the lesson 
itself was not used. The teacher said she utilized the topic as a springboard for class discussion. One teacher noted using a special book that discusses everyday people who prevailed and later became famous. She said she directs a substitute to use it along with accompanying worksheets composed by her when she is out of the classroom. In addition the teacher said she draws from research, travel and classes. The teacher expressed dislike for the required Glencoe text and said it was not used. A few others noted professional content-related organizations, conferences, websites and offices, television programs for parenting classes, personal reading, and song lyrics as sources for character education ideas.

Five of the 12 teachers noted the use of Kagan’s (2002) spotlight approach in their given subject text and materials. Three of these five teachers said they spontaneously highlighted certain character aspects as they arise. As one teacher said, “ I look at the literature. I look at the current events and will do different things, any teacher moment that I can grab onto as long as I can bring out another element, another dimension to it so they can see, you know, the motivation of the character.” Another teacher noted using current events like Hurricane Katrina, outstanding traits of historical figures, and historical events such as the Holocaust and the analysis of Hitler's charismatic traits to incorporate character education.

In addition to the three aforementioned teachers who noted using text and materials to extemporaneously highlight character education, five said they just highlight traits and concepts on an impromptu basis either as part of or separate from the lesson content. One of the teachers commented, “Just any time something like that [student fight] comes up, I use it as an opportunity." Another teacher offered, "You know, a lot of stuff just comes 
out of my head.... I don't consciously say 'this is a lesson about character education.' We just talk about that a lot.”

In short, 5 of the 12 teachers could cite specific ideas tied to concrete sources for character education delivery while 8 of the 12 teachers also said they address it in situations that naturally arise, either in addition to or in place of using specific materials in a deliberate plan.

Character education as it contributes to the learning environment (Kagan’s contextual approach) was suggested by three of the 12 teachers when talking about the importance of character education. Two mentioned the importance of feeling safe from bullying and comfortable in order to learn. Another mentioned student dress as a factor influencing student behavior, learning, and classroom environment. A few other teachers offered positive comments about the large hanging banners in the hallways signifying each of the six character traits.

All of the teachers mentioned teacher modeling throughout the interview as the main avenue to deliver character education. Several valuable comments are noted here. One teacher expressed, “...it [character education] allows us to keep everything in proper context.... we are not delivery systems only for our subject area. We are supposed to model this. We can’t just say 'do this' if we are not willing to do it ourselves.” One teacher noted, "I think the way you act, and talk, and interact reflects on you. So who I am, and who I am around the kids, I hope, influences the way they are. The teacher stressed the importance of keeping one’s word and being a “role model.” The teacher who earlier conveyed that he didn’t teach character education as a curriculum, said, “...I try to model good behavior in front of the students. We talk about the way they should 
act towards each other and the way they should act towards adults, and things such as politeness and respect, and treating others the way you want to be treated.” A teacher averred, “I am a person of character and that’s just my approach to teaching.” This teacher felt insulted by the directive to teach character education noting, "I guess I would have assumed would be coming naturally from a teacher... My delivery in the way that I — is full of character and demonstrating that every day.” Another teacher said, “ "I don’t think we can just teach it [character education], I think we have to model it too.” One teacher said, “This [character education] is throughout my teaching. To actually teach it, you have to do it because children learn by modeling.... That is one of the ways I teach it.” Another teacher noted, "I try to model it [character education], I try to talk about character. We get into many discussions where sometimes the kids think I am off the topic from where we were, but really I'm out there doing exactly what I think I should be doing.” One teacher commented on the importance of the teacher as a role model for character education by modeling a good work ethic.

There was no evidence of any of Kagan’s (2002) approaches to delivering character education in 5 of the 9 lesson plans. The remaining four teachers did show one or more of his five approaches. Two teachers noted the spotlight approach, one showed indicators of the structural approach, while one documented both curriculum and spotlight approaches.

The materials in addition to the nine teacher lesson plans served as good examples of Kagan’s (2002) curriculum, structural and spotlight approach. The Holt reader was the only used on a regular basis and it provided many opportunities to spotlight character education. The science book that highlighted famous scientists who overcame adversity, 
was a compilation of curriculum approach lessons. It was only used by a substitute in the teacher's absence. Both of the socials studies resources were seldom used but had many good curriculum, spotlight, and a few structural examples in them.

The curriculum approach was observed in 1 of the 10 observed lessons. The defining characteristic of this approach is that the entire lesson advances character development. In this case, the lesson entailed the topics of perseverance, positive thinking, and goal setting as part of a life skills curriculum.

The extracurricular approach was not observed in any of the 10 teachers because it involves school activities that occur apart from the regular academic schedule. There were activities such as food drives, a motivational guest speaker (Rachel's Challenge), and a fund raising dance held during school hours for the local humane shelter that have occurred as school-wide projects this academic year.

The spotlight approach was observed in 1 of the 10 observations. This method highlights character aspects that naturally occur within the lesson that are part of the content area, be they planned or unplanned. This teacher sought group consensus about an issue and discussed with the students optimism versus pessimism about life. These aspects lent themselves to the literature story presented. The teacher simply expounded upon them.

The contextual approach was observed in all 10 classrooms. This approach involves creating an atmosphere for character education by creating a nourishing physical environment conducive to developing character education. The weekly-designated character quote of the week was observed in all 10 rooms although it was the only thing observed in one classroom. Behavioral expectations were posted in nine of the 
classrooms in addition to discipline expectations along with various positive, encouraging posters such as ones that read, "Winners make commitments," along with, "Ability can take you to the top, but it takes character to keep you there," and "Think before you act. Patience is the first step toward understanding”.

The structural approach was observed in 1 of the 10 classrooms. This approach is most preferred by Kagan (2002) and it consists primarily of methodology delivery more so than content to further character development. This teacher appeared very deliberate in respect [one trait of six pillars] for students and implemented this trait by taking turns and group decision-making in English class.

In summary, results from the 10 observations showed little evidence of Kagan's (2002) five approaches to delivering character education. One instance each of the curriculum and structural approaches were observed. Although most of the teachers said they utilized the spotlight approach, it was observed once as part of a planned lesson. The extracurricular approach was not observed. Nine of the 10 classrooms observed, as well as the general school areas displayed a rich contextual environment.

\section{Research Question \#3:}

What fosters or inhibits the implementation of character education?

Data that answered this research question came from interview questions \#6, \#7, \#9, \#10, observation questions \#4, \#5, and document analysis questions \#3, \#4. When asked about personal influences from past background and experience that has impacted them, the initial response of from 6 of the 12 teachers was that of "parent" or "parents." All six spoke of the positive influence in their lives. One said he learned the lessons they felt compelled to teach and they exemplified them every day. Another teacher commented, 
“ It was just the way I was raised. ... it was expected. I guess watching my parents-they modeled it.... My parents are very politically involved. We have always had newspapers in the house.... We have always watched the news.” One teacher said, “...they [parents] taught me to be a good parent, and a good person and all that leads to being a good teacher." When asked the definition of a "good person," the same teacher replied,

A good person, I think someone who puts others before themselves. I think someone who thinks of other's feelings before themselves. I think somebody who models is caring, you know, and I think it is just wanting to see good happen and, you know, gets involved to make things better. Not someone who complains or finds what is wrong with something, but looks at it and says 'okay, how can I fix it, or how can I make it better?' If I choose not to do that, then that's it—don't complain. I look at life that way.

Another spoke of her mother’s and family’ strong character influence, “All our siblings are always together, always caring, always loving, always very close. I just pass that on to my kids.... I think it is just having those high expectations, expecting my kids to behave in a certain way. I like them to be respectful.” One teacher noted, "My parents set the best example for us that we could ever have set. They never argued. If they did, we never heard it. They stood firm together.”

Family was cited as the first response by 2 of the 12 teachers as background and experiences that influenced their perspective of character education. One teacher said, "I had a very large family and I was always with cousins and a whole bunch of people. That's the way we were raised. You treat others the way you want to be treated.” The 
second teacher noted traumatic times growing up in school with mean, hateful, girls helped her relate to students. "It is my upbringing, my family, my morals and values. Just those things that was instilled in me from my parents, my grandparents, being brought up in church.... Just being taught the difference from right and wrong from my parents.”

Three teachers also spoke of their family life experiences and backgrounds as contributing to their composition as people who naturally exhibit character education. One teacher expressed, "My background, it is my family. The family and what I expect from my children at home. It is just what is expected.” Another commented, "I think experiencing some things that you went through in your own past that you can relate to some of the kids. You may not get every situation, but you are going to touch home with some of the situations with some of these kids.” One teacher cited the Golden Rule in reference to family,

I just think that things center around the family. You know, I think you learn how to treat people because of the way that you are treated in your family.... That's what you learn before you go to school or before you do anything else. And I think if you are not learning those good behaviors and you don’t have good behaviors at home-you are not going to learn it. You are not going to learn it and we need to be able to teach it to them if they are not going to be taught it at home.

Religion was cited by 4 of the 12 teachers as their first response to the question of background or experiences as influences toward character education. A total of eight teachers included religion in their answers. While two of these eight teachers mentioned 
the influence of 'church,' five specifically identified the Christian faith and one teacher named Catholicism religion. One of the teachers who mentioned the Christian faith noted he was raised in a "very Christian home.” Another teacher noted concern for his own children and that of his students in wanting them to realize God's plan for them. The teacher said, "I want my kids to grow up and be what I believe that they should be and a lot of that is tied to my religion, you know, and what I believe that God has in store for them, and what God wants them to be.” The same teacher later commented, “I say, 'I am teaching you how to be'.... Just how to be, you know, how to be a person, how to be human, how to be compassionate, how to be loving, how to be kind, how to be caring, you know, all those things...” The one teacher who commented on his Catholic faith said, “...I went to Catholic school for a couple of years. You don’t tell those nuns 'no.' I mean you don't.” This teacher later spoke of going to church and mass and enjoying those traditions with large family gatherings.

One teacher of the12 first spoke of a college professor that most impacted their approach to character education. This professor conveyed reservations about the student becoming a teacher. The teacher said this changed her entire perspective and caused her to reevaluate herself and rise to the challenge.

When asked what helps them teach character education, books and classroom materials were mentioned by 1 of the 12 teachers as aiding in its instruction. The teacher noted materials received from character education workshops and conferences, as well as a book by conference speaker Hal Urban as good reference and refresher sources.

Two of the 12 teachers indicated the support of staff working together were found to be helpful. The first teacher spoke of everyone striving to do the same thing in reference 
to discipline, "Like there is no swearing, you know, this is not tolerated then, it is not tolerated building-wide. It is not just one teacher trying to set things up and then they [students] are allowed to do whatever they want in another class.” The second teacher addressed planning in addition to discipline, and said, “... we meet as a staff, and we talk about things that we have done, things that maybe have worked, and we share what worked and what doesn't work.... All of us try to set consequences and run the building, discipline-wise, based on the pillars of character.” Teachable moments or “door openers” were reported by 2 of the 12 teachers as fostering the teaching of character education. One teacher noted, When situations arise within the classroom ... that opens the door.... In middle schools it is there all the time.... You have to be ready for it, and you have to come to expect it.... I don’t look for it. It's just that I think I'm so tuned to it from my years of experience and my life experience. My school experiences and my life experiences, and the fact that I do have my own children, and the fact that I have worked with youth in the past.

Another teacher said, I just look for opportunities to do it. Those teachable moments, you know, when something happens. We had a $\mathrm{BD}$ [behavior disorder] kid the other day in the hall. I was walking down the hall, somebody had broken a pencil and he was picking up the pieces of pencil. He is the one who came to us this year that we have heard just horror stories about, but he saw me doing it and he did it too. And the BD teacher was there and I said, 'did you see what XXX just did?' I mean, to me that was a big thing. 
In relation to the need for character education and barriers to it, five teachers made comments citing the lack of parental guidance as contributing factors. One teacher, in speaking of poor values systems from home, noted one example, “... my mom said, 'if they hit me, hit them back or not to take it."” One teacher commented on the influence of television, radio and computers and said,

They get about everything we try to teach them the opposite. They go home and they can turn the radio on and hear things that we do not allow them to say, they watch TV and the behavior that they see on TV is not a good role model for character ed. It is hard to fight that.... When they turn on their music and every music song has swear words, nudity and sex. Then you come here and say that is not right.

One teacher commented,

Kids need to know how to treat other people and they don’t always learn that. And we don't live in a society really that promotes that anymore.... And we see that on TV. Somewhere in the 70s, I'm going to say, television changed tremendously. The family shows that taught us to be cutting and demeaning, and all of those kinds of negative things developed.... Television has the most power to destroy good human nature and kindness.

Three of the 12 teachers noted no barriers to incorporating character education into the curriculum. Two teachers said time and the push for high standardized test scores and government bureaucracy in education impeded teaching of character education. Another indirectly alluded to lack of time by voicing concern that she couldn't go home with the students because she had so little time with them to counteract bad situations. One felt 
overloaded by professional duties as a special educator. Student anger was named as by 1 of the 12 teachers as an obstacle to character education. One teacher the giving of "big prizes” for displaying good character traits was a barrier to character education and noted, “...many kids present themselves as good people.” Students are given prizes for displaying expected behavior during an award pep rally for character education as recognized by the teaching staff.

In observing the 10 classroom lessons and identifying factors expediting character education, it was noted that teachers speak of a culture of good character at this school. This seems to be perpetuated with teacher modeling of desirable good character traits and enforcement of the school behavior expectations. Although teacher modeling of desirable character aspects is not addressed as one of Kagan’s (2002) character education delivery options, it can be argued that teacher modeling is simply part of classroom management. The document analysis of lesson plans showed few factors expediting it. The additional books voluntarily provided were very good examples of Kagan’s (2002) curriculum, structural and spotlight approaches. Document analysis items may have been offered because they served as good representations of character education.

Two thoughts seem to emerge as obstacles to delivering character education fully at this school. The first is that the kids at this school behave well and the teachers are already doing it "right.” Although it could be argued, and it is readily observed, that this facility is a shining example of good character, which it is, it is obvious that teachers are either unaware of the five approaches to delivering character education, or are deciding not to use them on a widespread basis. 
The second possible hindrance seen to delivering character education at this site is the assumption by the teachers that simple adherence to the school rules constitutes delivering character education. If this were the case, this school could function with just a good discipline policy. There appears to be a very natural overall assumption that if students comply with school rules, then they possess good character.

None of the submitted lesson plans or classroom books reflected barriers to delivery.

\section{Summary}

Overwhelmingly, the participant teachers in this study deem character education as very important. They feel personally responsible for delivering it, yet teachers struggled to define it in words. They feel that they have good students and they have always taught character education in some form. Three crucial elements of character education cited were imparting the six character pillars from the school’s adopted Character Counts! Program, promoting personal student growth, and preparation for adulthood. The teachers feel they have always taught character education. The character education efforts at the school are believed to positively impact students, and teachers feel supported by school and county administrations.

Teachers noted lack of parenting and student home life in the form of television and music influences as problematic in delivering character education. Teachers frequently said parents and then the role of religion positively influenced their views of and ability to teach character education. They mentioned the teachable moment as a tool for imparting character education. One teacher voiced concern for students receiving big prizes for displaying desirable character traits. 
The school is rich in Kagan's (2002) contextual approach that creates an environment conducive to character education, and the extracurricular approach that emphasizes school activities that occur apart from the regular school schedule. Context is important as noted by Burton (2008). However, few formal instances of his spotlight approach were documented in classroom observation, but teachers frequently conveyed they utilize the approach as it naturally occurs and on an unplanned basis. Very few isolated examples of Kagan’s (2002) structure and curriculum approaches were found. Teachers do not appear to be using materials designed by others specifically for character education.

The teacher as a role model emerged as a prevalent finding in this study as the means of delivering character education. Only one teacher mentioned books and classroom materials, character education workshops and conferences as aids to the delivery of character education. The participants mentioned their role as a model to teach character education on a widespread level. The importance of teacher modeling was also widely documented by Brannon, (2008); Vincent (2003); Milson and Mehlig (2002); Jones, Ryan and Bohlin (1998); Titus (1994); and Lickona (1993). 


\section{CHAPTER 5}

The strength of the United States is not the gold at Fort Knox or the weapons of mass destruction that we have, but the sum total of the education and the character of our people

Claiborne Pell (1918-2009)

\section{Introduction}

This final chapter restates the research problem and reviews the major methods used in the study before summarizing the data gathered and discussing their implications.

The purpose of this study was to examine perceptions of selected middle school teachers from one rural county in West Virginia related to their thinking about and implementing character education. Questions included what they consider to be obstacles that interfere with the teaching of character education, as well as factors that may foster the delivery of character education as required by West Virginia State Code in 2001. The three research questions are: 1) What are selected public middle school teachers' perceptions of character education? How do teachers define character education? How important is character education? 2) How do middle school teachers implement character education? 3) What fosters and inhibits the implementation of character education?

The study reported here entailed a purposeful sample of 12 randomly chosen teachers from the 29 full time teachers in one middle school. Six were chosen from the school's established Character Development Team and six were randomly chosen from the 23 remaining members of the teaching staff. This was done to assure an equal representation of both groups. Results were not segregated according to each of these groups as any likes or differences between them were not an object of this study. Data 
collection consisted of 12 teacher interviews that were conducted in each teacher's room during their planning period lasting from 40-50 minutes, 10 classroom observations as an unobtrusive observer, and document analysis of selected teaching resources including lesson plans, a book of plans developed by the school's Character Development Team and other teaching materials.

Probes were used during the interview to obtain more information, clarify, or get more details. phrases such as "please tell me more about," and "help me to understand what is meant by" were used to encourage clarification and elaboration. The researcher said “okay” or pauses were used to encourage further comments. At times, the researcher repeated the teacher's comments back in a paraphrase to insure understanding of meaning.

After each of the 12 teacher interviews, the researcher was granted permission to observe the teacher and a time period was secured. After the observation lasting 50 minutes was completed, the researcher obtained permission to examine lesson plans, and any other materials offered by the teacher. Ten teachers were observed and nine teacher lesson plans were analyzed. Also analyzed were two supplemental materials, each used occasionally by a science and social studies teacher. One reading text utilized by one special education teacher was inspected. A large notebook compiled by the Character Development Team containing lesson plans for social studies was offered for analysis.

All 12-teacher interviews were transcribed and delivered to the teachers to read for accuracy. A few days later, the researcher returned and spoke with each teacher to make any needed changes. When conducting this member checking procedure, teachers were dismayed at their respective word-for-word translations. For clarity and flow of meaning, 
pauses, repetition of phrases and personal speaking habits were omitted in the final citations of the interviewed teachers. A sample page of the transcribed interviews is in Appendix J.

During the teacher interviews, teachers answered the protocol but some tended to revert back to past questions and elaborated on them. For example, themes such as teacher modeling, and positive parental influences were instances in which this was commonly found. Teacher answers of past statements were incorporated with the appropriate question.

\section{Summary of the Results}

The transcribed interviews were read and notes were made in the line margins of reoccurring and meaningful words and phrases. Units in the text were color-coded. For example, all mentions of teacher modeling were highlighted in orange. All 12-teacher responses were grouped and typed according to each interview question. Themes and supporting or sub themes emerged and were summarized with codes. The researcher then compared results with a hired reader. The reader was supplied with copies of all 12 interviews along with the three research questions with directions to identify what in the interviews answered each question. Summaries from each of the interview questions were next analyzed with reference to each of the three research questions guiding this study. For a correlation of how the interview questions were designed to answer each research question, see Appendix K. Presentation of the implications is divided into the three main categories, one for each of the research questions. Subdivisions of the three research-question categories were made using specific interview questions. For each of 
the subdivisions, interview responses, observation data, and document analysis data have been included as appropriate, according to individual themes.

The first research question investigated teacher perceptions regarding the definition and importance of character education. All of the teachers evaluated character education to be extremely important but many had great difficulty articulating a verbal definition for it. Some of the teachers finally defined character education as teaching the six pillars (character traits) from the Character Counts! Program. The teachers also defined it in terms of improvement of the total person such as conformity to rules, treatment of others, feelings of self-worth, and responsibility, as well as preparation for adulthood in the form of being well-rounded, productive citizens. Perhaps the best single definition given by one teacher that emerged is one that reads, "Character education is teaching kids to be well-rounded citizens, law-abiding citizens, to be active citizens, and how to care for others.” Besides stating its crucial importance, the teachers all indicated that they assumed personal responsibility for teaching character education in class and other school activities. Their desire to teach character education appeared to stem from a need to prevent deterioration of society and a positive attitude toward their own families and communities that formed their own characters.

The second research question asked by what means teachers implement character education. Teachers resoundingly averred that they have always taught character education. Teacher modeling emerged as the primary means by which teachers teach character education. They reported it to be used to convey the school's six pillars of character, as well as school behavioral expectations in rule enforcement. When comparing the data to Kagan’s (2002) five approaches to delivering character education, 
the curriculum and structural approaches were almost non-existent. The spotlight approach, while little documented, seemed to be utilized by teachers more on an informal, unplanned basis and combined with "teachable moments."

The school appears rich in the physical contextual approach, which was found to be “essential” by the middle school teachers in Burton’s (2008) study. Also documented to a significant degree was the extracurricular approach. While not found in the generated data and not necessarily revealed in the interviews, there was evidence that this school does many activities apart from the regular curriculum that constitutes Kagan’s (2002) extracurricular approach. Although this staff received as much or more character education training and treatment than any other middle school in West Virginia, along with access to materials, they appeared to utilize almost none of the specific materials or the Kagan (2002) strategies associated with character education.

The third and final research question investigated what fosters or inhibits implementation of character education. The greatest reply for fostering character education was the teachers’ personal value systems. Data indicated personal life experiences, backgrounds, and value systems were contributing to teachers describing themselves as people who naturally exhibit good character. Parental influence, followed by religious upbringing, and then "spotlighting” character events in class or the naturally occurring "teachable moment” in schooling, emerged as factors most contributing to the teacher' ideas of what fosters character education. Conversely, the absence of good parenting and three negative media influences emerged as the prevalent barrier to delivering character education. Lack of parenting and societal influences such as television, music, and electronic games, respectively, appeared as factors that lead to poor 
student value systems. One teacher mentioned, as perhaps not a good practice to follow, the use of large prizes for recognition such as DVD players and Playstations to reward good student character.

\section{Limitations to the Study}

Three limitations emerged from the results of this study. The first entailed the natural investigative limitation inherent to this type of qualitative study. Although data saturation was achieved, the study involved 12 of 29 instructional members of the staff. Results represented a snapshot in time and are used for description and interpretation of the phenomenon labeled “character education.” It then became difficult to make sweeping generalizations concerning huge changes in the field, but it is felt that results may certainly add to the body of research needed to do so.

The second limitation of note to this study was the unknown type and depth of teacher training this staff had received over time. The school was chosen by the West Virginia Department of Education as 1 of 25 schools in the state of West Virginia to be a lighthouse pilot character education site from 2001 to 2005. The school, as part of the million-dollar grant, received training as well as contact and program support by the West Virginia Department of Education, primarily in the form of professional development and program evaluation (L. G. Burton, personal communication, October 29, 2003; Character Education Pilot Grant). The school also received training and funding from its involvement in the study from 2005 to 2009 as a treatment site. (Corrigan, Chapman, Grove, Walls, and Vincent, 2007).

The third limitation to this study entailed the teacher sample composition. No mathematics teachers were represented in the randomly chosen sample. This occurrence 
should be noted, as this content area may be viewed as problematic when integrating character instruction. It is certainly possible, however, to incorporate character education into the curriculum through such strategies as cooperative learning activities or word problems utilizing social scenarios. This experienced faculty is capable of adapting new strategies into their teaching.

\section{Discussion of the Results}

Parental influence emerged as the main influence on teacher value systems contributing to their delivery of character education. This finding is congruent with findings of others who claimed that parents are the first and the biggest impact as teachers of their children (Brannon, 2008; Ponzetti, 2008). Certainly teachers believe and are told to influence youth, but there is no substitute for early and continued parenting. Schools must embark upon a campaign perhaps in concert with local social agencies, to involve parents in academics and extracurricular activities, as well as provide parenting classes aimed at helping the middle school child.

Most of the teachers in this study cited the influence of religion as a major factor in contributing to their teaching of character education. In this study all the teachers claimed a Christian religious preference, it may contribute to some of the teachers' common beliefs and actions. Arthur (2008) agrees that character formation is not independent of religious faith. In fact, Suma-Belanger (2006) noted of her study involving teachers and moral education, found that faith was the core essence of their teaching. The findings of this study may help support these assertions. As Glanzer and Talbert (2005), and Tirri (2003) have stated, it is unreasonable and impossible to expect teachers to separate their personal moral character, which includes religious perspectives, from their professional 
personae. Hunter (2000) argues that attempts to separate teachers and students from their local identities and cultures results in impoverishment and death of character because it robs them of vitality, focus, and motivation in life. Glanzer and Talbert (2005) cited the possibility of teachers integrating personal religious perspectives into the classroom without violating the constraints of law. Clearly, teachers within this study do within the law. They, researchers argue, can quite easily promote character education through indirect means displayed through modeling, teaching or practicing specific character traits such as justice, caring or compassion.

The teachers of this study, while perhaps unaware of the aforementioned research, are simply performing an action that is a natural extension of their own personal value system, which translates into teaching character. They are not espousing or imposing any particular religious view, but are quite innately expressing the major tenets that give meaning and importance to their lives along with guidance and treatment of others.

Results from this study reveal little evidence that teachers are using character education materials or implementing Kagan’s (2002) five approaches (curriculum, extracurricular, contextual, spotlight, and structural) to teaching character education. The teacher may not have received training in the five approaches or they may not choose to use them for some reason. In considering the latter, Leming (2008) agrees that the main reason educational research in character education has not been assimilated into teacher practices is because research strives to produce context-free understandings of effective practice, while teachers work in context-bound environments. No two school environments are alike, nor can they be replicated for research purposes. Additionally, Corrigan, Chapman, Grove, Walls, and Vincent (2007) stated that the market product side 
of character education currently appears one of the most noteworthy "shortcomings and/or challenges" of character education. According to them, some educators perceive marketed programs as fleeting in popularity and merit, and they also view them as separate from the school curriculum Marketed programs may be accepted where the teachers and community see an already prepared source for an important need. This community and the teachers seemingly didn't have such a need. Perhaps more emphasis on instructional strategies with more personal control and flexibility would be preferred over commercially made materials. Berkowitz, Battistich, and Bier (2008) contend that character education consists of a set of implementation strategies among which are interactive teaching methods and direct teaching of character concepts. This entire faculty could be considered to be veteran teachers. They are not only experienced, but selfactualized and have definite opinions and expertise concerning instruction and can adapt strategies to meet their individual teaching styles, strengths, and preferences

This school, despite its considerable training, utilizes teacher modeling to an almost exclusive degree to impart character education. Modeling has always been and always will be a major influence on students. Schwartz agrees that teaching is a moral act (2005, 2007). Current practicing as well as future teachers must embody and exude the characteristics their students are to emulate (Schwartz, 2008). Schwartz lists seven valuable attributes of those who model good character. Teachers must show obvious moral concern and care for others; display actions that indicate a commitment to the intellectual or emotional development of others (students); have congruence between the individual's moral statements, understanding and actions; demonstrate self-reflection and reasoning skill; regulate their own behavior and emotions in accordance with the social 
good of others; and demonstrate empathy and perspective-taking (Schwartz, 2005, p. 64). Hoare (2002) adds grant leeway to self and others. Clearly, the sample teachers have these characteristics. In hiring new teachers such attitudes and dispositions might be good for a teacher to possess. These attributes also serve well as a starting point for screening prospective teachers in teacher education programs.

It must be noted at this point that Burton (2008) in studying character education efforts of elementary, middle, and high school programs, found that teacher modeling was not mentioned by the middle school participants. The elementary and high school participants valued teacher modeling as "an essential factor for effective character education.”

Some educators believe indirect approaches such as teacher modeling may be more effective than direct ones such as Kagan’s curriculum approach. Corrigan, Chapman, Grove, Walls and Vincent (2007) agreed that some prefer the indirect approach to teaching character education. As early as 1986, Ryan noted most moral education that happens in schools is not documented in lesson plans, curriculum guides or behavioral objectives. He noted that students form conceptions of a "good person” by enforcement or lack of rules, rituals and daily classroom life, expectations for and consequences of behavior, and teachers' warnings, advice and manner.

The character education efforts of the school in this study appear to be quite successful. Many agree that character education is linked to student achievement (Berkowitz, Battistich, \& Bier, 2008; Brannon, 2008; Burton, 2008; Davidson, Lickona, and Khmelkov, 2008). This school has consistently earned top standardized test scores. This finding is one indication that what this school is doing works in this school's local 
context. Leming, in support of schools' unique program configurations, notes, “The crafting of character education programs will always be influenced by local characteristics and no two programs will look exactly alike” (2008, p. 152). Certainly this study reveals one effective implementation of character education as he predicts or describes.

The outstanding behavior and compliance of these students as cited by their teachers, does warrant comment. What, exactly, is motivating these students' exceptional behavior? Scales (2003) in documenting characteristics of young adolescents for the National Middle School Association, notes several expected developmental behaviors of middle school students. They experience restlessness and fatigue due to hormonal changes. They need to release energy, often resulting in sudden, apparently meaningless outbursts of activity. They often overreact to situations. They experience mood swings often with peaks of intensity and unpredictability. They may exhibit immature behavior because their social skills and ability to regulate emotions frequently lag behind their cognitive and physical maturity (p. 44, 49, 50). In light of these middle school level traits, the exemplary behavior of students at this school becomes even more noteworthy and of great interest to this researcher. This relationship between the community context or variables comprising the local school environment, and the type of character education need is a subject for future research.

\section{Conclusions}

Results of this study reveal that these teachers deem character education important. This finding is supported by Brannnon (2008) and Burton (2008). Character education was viewed to be important to the development of the entire child, preparation for 
adulthood, and to stem the deterioration of society. These findings are supported by Stoppleworth (2001). They feel personally responsible for delivering character education. They perceive their efforts to be successful and are satisfied with the school's program. The teachers impart character education primarily through modeling their own character, and enforcement of school rules and expectations through the Character Counts! Program. To a lesser degree, they say they employ Kagan’s (2002) spotlight approach by capitalizing on "teachable moments" as they naturally occur. The school is rich in physical support (Kagan's contextual approach) that fosters character education as well as academic learning, an asset that is considered important to the context of instruction (Berkowitz, Battistich, and Bier, 2008; Berkowitz and Bier, 2007; Corrigan, Chapman, Grove, Walls, And Vincent, 2007; Lickona, 2004; Schwartz, Beatty, \& Dachnowicz, 2006). The school also conducts numerous activities, which fulfill Kagan's extracurricular approach; they support altruistic causes such as cancer research, local food pantries and animal shelters. Parental influence, religious background, and the naturally occurring "teachable moments" also were documented as fostering character education. The barriers to teaching character education were viewed primarily as poor student value systems as a result of lack of parenting, poor parenting, and the negative societal influences such as television, music, and electronic games.

Through interviews, classroom observations, walking through the halls, and examining instructional resources, evidence was provided that supports the presence of character education as identified by Kagan's (2002) five categories of evidence. They were present in this school although some appeared with more frequency than others. 
The most noteworthy finding emerging from this study is the teachers' continued adherence to teaching character education almost solely by teacher modeling despite training in additional means. This school is indeed what may be termed a "culture of character.” By all indications, the students exhibit what can be labeled good character. This good character may perpetuate itself over time through the impact of parents, family, along with religious practices and doctrine, with teachers growing up and returning to teach at the same locale. Administrators hold these same values and they, in turn, select teachers with the same traits to work in this school.

\section{General Recommendations}

The teachers in this study understandably struggled to define character education. While character education always will be debated as an elusive and nebulous concept, it is possible for teachers in one setting to have an agreed upon working definition of it. Each school needs to devise its own definition along with a mission statement in order that all may be working toward the same goals. Although teachers in this middle school have a common understanding, it would be helpful, albeit time-consuming, to develop a school wide plan or outline of school efforts toward character education. This may assure the school to have a positive continuation in the long term. If desired and welcomed, this staff also needs to receive training in Kagan’s (2002) five instructional approaches or other specific strategies they might incorporate into their own lessons to fully integrate character education in their academic content.

The unknown effect of material rewards, including "large prizes” to students in recognition for displaying desirable character traits deserves attention. Many of the teachers in the study mentioned the character education "pep rallies” as motivating 
factors although only one teacher expressed concern. Burton's (2008) research revealed that the middle school participants rewarded and valued recognition of good behavior. Although middle school students respond to physical rewards, the concept of rewarding expected behavior and its sustaining effects on character should be further explored. Some developmental educators believe the routine use of rewards negatively affects genuine moral motivation and increase competition (Nucci, 2003; Power, Roney and Power, 2008; Watson, 2008). Perhaps what is needed in one environmental setting to promote recognition of good character is not necessarily appropriate in another environmental setting. Students would need to be involved in the research of this question.

If student character is important in today's educational world, then teacher character must be given importance as students are greatly influenced by them. Recent National Council for Accreditation of Teacher Education (NCATE) standards now require that teachers possess certain "dispositions" which provide a clear connection between teacher education standards and character development. Teacher preparation programs as well as teacher employers must be aware of this study's findings in order to screen prospective teacher candidates as well as groom them. Employers seek to hire the best possible role models for students and the best role models might be related to environmental needs. Recommendations for Further Study

- Since there appears to be a gap between research and practice, more research investigating the implementation of character education is needed. The educational community needs to gather more knowledge concerning any phases 
of implementation, the possible interactions between local context and implementation, along with what does and doesn't work well.

- If future teachers are to be screened for dispositions and identified character traits, then research is needed to explore the relationship between various school/community environments (local contexts) and the success of character education.

- It might be informative for studies such as this that include both Character Development Teams and non Character Development Teams in their sample to separate and analyze the data to determine whether those on the Character Development Team are stronger advocates of the initiative.

- Clearly positive character traits were seen within this school. More observations are needed to identify and elaborate more fully on them.

- This study did not investigate administrators' perceptions of character education. at this school. These assessments impact the teachers, students, and community. The views of all stakeholders including parents and community members could serve as additional topics of study.

- It would be helpful for secondary educators to know if the positive character traits from middle school programs transfer to high school environments.

- Student input into the meaning and definition of character as well as character education would have merit as an additional topic of study.

- Additional research is needed to help teachers change to see themselves as people of character. Case studies could be done seeking to learn how individual teachers 
reflect on their own continuing character development throughout their professional careers.

- This study might be duplicated on a school where emphasis on character education is not believed to be present to reveal how teachers perceive character education. 


\section{REFERENCES}

Amoroso, V.R. (1995). A Comparison of attitudes of academic and technical/ vocational high school teachers towards the teaching of character in the classroom. Dissertation Abstracts International, 56, 4261.

Anderson, J. (2005). The perceptions of students, teachers, and parents regarding the values of the LIFESKILLS and Lifelong Learning Guidelines program. Dissertation Abstracts International, 66, 494.

ARDA, The Association of Religion Archives. (2006). County Membership Report. Retrieved August 26, 2007, from http://wwwthearda.com/mapsReports /reports/counties/54095_2000.asp.

Arthur, J. (2008). Traditional approaches to character education in Britain and America. In L. P. Nucci \& D. Narvaez (Eds.), Handbook of moral and character education (pp. 80-98). New York, NY: Routledge.

Association for Supervision and Curriculum Development. (2004). Moral education. Retrieved July 27, 2004, from http://www.forerunner.com/forerunner/X0108_Moral_education.html

Babbie, E. (1990). Survey research methods ( ${ }^{\text {nd }}$ ed.). Belmont, CA: Wadsworth Publishing Company.

Baker, C. E. (2004). Alabama high school principals and their perceptions of the implementation, importance, and effects of character education. Dissertation Abstracts International, 65, 4052.

Bauer, R. W. (1991). Correlates of student character development in a small high school (Rural schools). Dissertation Abstracts International, 52, 2491. 
Beck, M. J. (2008). Examined lives and examining practice: Fostering teacher learning within the context of a program for ethical and spiritual learning. Dissertation Abstracts International, 69, 2673.

Beets, M. W. (2007). Factors associated with the implementation fidelity of a schoolbased social and character development program: Findings from the Positive Action program, Hawai’i. Dissertation Abstracts International, 68, 3721.

Benson, G.C.S. \& Engeman, T. (1975). Amoral America (Rev. ed.). Durham, N.C.: Carolina Academic Press.

Benninga, J.S., Berkowitz, M.W., Kuehn, P., \& Smith, K. (2006). Character and academics: What good schools do. Retrieved March 19, 2007 from http://www.pdkintl.org/kappan/K_v87/k0602ben.htm.

Berkowitz, M. \& Bier, M. (2004.). What works in character education: A researchdriven guide for teachers. Washington, DC: Character Education Partnership. Berkowitz, M. W. \& M. C. (2007). What works in character education. Journal of Research In Character Education, 5, 29-48.

Berkowitz, M. W., Battistich, V. A., \& Bier, M. C. (2008). What works in character education: What is known and what needs to be known. In L. P. Nucci \& D. Narvaez (Eds.), Handbook of moral and character education (pp. 414-431). New York, NY: Routledge.

Bishop, H.J. (2000). Character education: Do we need it? Retrieved September 20, 2003, from http://www.ci.swt.edu/courses/C15390Peterson/final\%20paper/character \%20edoc. 
Bonner, J. H.(1997). Violence prevention and conflict resolution education in United States public schools: A fifty state survey (Character education, moral development). Dissertation Abstracts International, 59, 1016.

Borg, W.R., Gall, J. P., \& Gall, M.D. (1993). Applying educational research: A practical guide. New York: Longman.

Brannon. D. (2008). Character education—A joint responsibility. [Electronic version]. Kappa Delta Pi Record, 44, 62-65.

Brewer, R. L. (2008). Effect of the Great Expectations character education approach on elementary student achievement. Dissertation Abstracts International, 69, 2008.

Brooks, B. D. \& Goble, F. G. (1997). The case for character education. Northridge CA: Studio 4 Productions.

Burton, L.G. (2008). Character education: Educator perceptions of effective implementation. (Doctoral dissertation, Capella University), 2008. Dissertation Abstracts International, 69, 2138.

Carriveau, P. C. K. (2003). What citizen is of what worth? The role of public education in preparing children for citizenship. Dissertation abstracts International, 64, 4186.

Center for the $4^{\text {th }}$ and $5^{\text {th }}$ Rs. (2004a). Smart and good flyer. Retrieved September 24, 2004, from http://www.cortland.edu/c4n5rs/smart_good_flyer.asp.

Center for the $4^{\text {th }}$ and $5^{\text {th }}$ Rs. (2004b). What is the history of character education? State University of New York at Cortland. Retrieved January 29, 2004, from http://www.cortland.edu/c4n5rs/history.htm. 
Center for the $4^{\text {th }}$ and $5^{\text {th }}$ Rs. (2004c). Educating for character in the high school: Researching promising practices. Cortland, New York: State University of New York at Cortland.

Center for the $4^{\text {th }}$ and $5^{\text {th }}$ Rs.(2007). Staff Biographies. Retrieved August 28, 2007, from http://www.cortland.edu/character/bios.htm.

Chapman, C.E. (2006a, October). “What’s this generation coming to?: Character education in rural West Virginia." Presentation at the First Annual West Virginia University College of Human Resources and Education Alumni Academy, Morgantown, WV.

Chapman, P.E. (2006b, October). The face of character in West Virginia: Linking moral development to academic achievement through reliable and valid research conclusions. Presentation at $13^{\text {th }}$ Annual Character Education Partnership Conference, Washington, DC.

Chapman, P.E., \& Corrigan, M.W. (2007). The face of character in West Virginia: Perceptions about character from the people of the mountain state. Unpublished manuscript, West Virginia University at Morgantown, WV. Marshall University at Huntington, WV.

Character Counts! (1992, July). The aspen declaration. Retrieved October 7, 2004, from http://www.charactercounts.org/aspen.htm.

Character Counts! (2004). Background. Retrieved October 7, 2004, from http://www.charactercounts.org/backgrnd.htm.

Character Development Group. (2007). Profile of a Leader: Dr. Phillip Fitch Vincent. Retrieved August 26, 2007, from http://www.charactereducation. 
Com/AboutUsAboutDrVincent/tabid=160.

Character Education Partnership. (2004a). Eleven principles of effective character

education. Washington, DC. Retrieved April 30, 2004, from

http://www.character.org/principles/.

Character Education Partnership. (2004b). About CEP. Retrieved November 11, 2004, from http://www.characterorg/about/.

Character Education Partnership. (2007). Defining and understanding character education. Retrieved February 26, 2007, from http://www.character.org/site/pp.aspx?c=gwKUJhNYJrF\&b=1049...

Colvin Booher, C. A. (2001). Design standards for elementary, middle/junior high, and high school counseling facilities. Dissertation Abstracts International, 62, 2978.

Costa, A. C. (2004). Meeting the challenge of character education: An analysis of state policies. Dissertation Abstracts International, 65, 1189.

Corrigan, M. \& Chapman, P.E. (2005). West Virginia Department of Education Integrating Effective Character Education Programs in Rural Schools: Measuring a Replicable Model. (grant). Huntington, West Virginia: Marshall University; Morgantown, WV: West Virginia University.

Corrigan, M.W., Chapman, P., Grove, D., Walls, R. T., \& Vincent, P.F. (2007). The importance of multidimensional baseline measurements to assessment of integrated character education models. Journal of Research in Character Education, 5, 103-130.

Crain, W.C. (1985). Kohlberg's stages of moral development. Theories of development. Retrieved November 10, 2004, from 
http://faculty.plts.edu/gpence/html/kohlberg.htm.

Crawford, R. L. (1999). A case study on the perceptions of students in junior high school on the influence of a character education program upon the development of student morality: The missing voice. Dissertation Abstracts International, 60, 2298.

Creswell, J.W. (2003). Research design: Qualitative, quantitative, and mixed method approaches ( $2^{\text {nd }}$ ed.). Thousand Oaks, CA: Sage Publications.

Creswell, J.W. (1998). Qualitative inquiry and research design: Choosing among five traditions. Thousand Oaks, CA: Sage Publications.

Curfman, M. E. (1992). Character education through secondary school literature classes (Moral development). Dissertation Abstracts International, 30, 1051.

Davidson, M., Lickona, T., \& Khmelkov, V. (2008). Smart and good high schools: A new paradigm for high school character education. In L. P. Nucci \& D. Narvaez (Eds.), Handbook of moral and character education (pp. 370-390). New York: NY: Routledge.

Devargas, R. C. (1998). A study of "Lessons of Character": The effect of moral development curriculum upon moral judgment (Character education, fifth-grade). Dissertation Abstracts International, 59, 4042.

Doyle, D. (1997). Education and character: A conservative view. Phi Delta Kappan 78, 440-444. Retrieved September 30, 2003, from http://80web24.epnet.com.www.libproxy.wvu.edu/DeliveryPrintSave. asp $? \mathrm{tb}=0 \& \_u g=1 \mathrm{n}+$. 
Editorial Projects in Education. (2004). On the web. Retrieved January 29, 2004, from http://www.edweek.org/context/topics/issuespage.cfm?id=112.

Engel v.Vitale, 370 U.S. 421 (1962).

Elam, S.M., Lowell, C.R., \& Gallup, A. M. (1994). The $24^{\text {th }}$ annual Gallup Poll of the public’s attitudes toward the public schools. Phi Delta Kappan, 76, 41-56.

Finney, D.L. (2002). Character education through student leadership development, citizenship education, and service learning curricula. Dissertation Abstracts International, 63, 3462.

Flick, U. (1999). An introduction to qualitative research $\left(2^{\text {nd }}\right.$ ed.). Thousand Oaks, CA: Sage Publications.

Forlow, R.L. K. (2002). Teachers’ perceptions of character education: Implications for staff development. Dissertation Abstracts International, 62, 2298.

Friedman, I.A. (1995). Student behavior patterns contributing to teacher burnout. Journal of Educational Research, 88, 281-290.

Garman, N.B. (1994). Qualitative inquiry: Meaning and menace for educational researchers. Paper presented at the Mini-conference on Qualitative Research, Flinders Institute for the Study of Teaching. The Flinders University of South Australia, Adelaide, Australia.

Gaff, J.G., Ratcliff, J.L., \& Associates. (1997). Handbook of the undergraduate curriculum. San Francisco: Josey-Bass Inc.

Gallup Organization (2000). Economy, education, health, crime, and morality most on Americans' minds this election year. Retrieved July 17, 2007, from http://www.gallup.com/search/results.aspx?SearchConType=\&Sear. 
Gallup Organization (2007). Americans remain negative on state of nation's moral values. Retrieved July 17, 2007, from http://www.gallup.com/search/results.aspx?SearchConType=\&Sear.

Gelpi, M. D. (2008). Jesuit high schools as communities of character. Dissertation Abstracts International, 69, 1721.

Gibson, S., \& Dembo, M.H. (1984). Teacher efficacy: A construct validation. Journal of Educational Psychology, 76, 569-582.

Gilbert, S. (2003). Scientists explore the molding of children's morals. New York Times, 5. Retrieved March 19, 2007 from http://www.nytimes.com/2003/03/18/health/children/18MORA.html.

Glanzer, P. L., \& Talbert, T. (2005). The impact and implications of faith or worldview in the classroom: The priority and importance of character. Journal of Research In Character Education, 25-42.

Glassner, B. (1999). The culture of fear: Why Americans are afraid of the wrong things. U.S.A.: Basic Books.

Glesne, C. (2006). Becoming qualitative researchers: An introduction ( $2^{\text {nd }}$ ed.). Boston: Pearson.

Gooding, T. F. (2004). Character education: Perceptions of social skills acquisition in two elementary schools. Dissertation Abstracts International, 65, 364.

Goodlad, J. I. (1984). A place called school. New York: McGraw-Hill.

Green, T.F. (1971). The activities of teaching. New York: McGraw-Hill. 
Guidry, A. O. (2006). Reflective moral inquiry: A process approach for teaching character education in the secondary social studies. Dissertation Abstracts International, 67, 1206.

Halverson, S. (2004). Teaching ethics: The role of the classroom teacher. Childhood Education International. Retrieved July 24, 2004 from http://www.highbeam.com/library/doc3.asp?DOCID=1G1:114008371\&num=78ct r1Info $=$.

Halstead, M.J. (2000). Learning and teaching about values: A review of recent research. Retrieved February 14, 2003, from http://80-web3.epnet.com www.libproxy.wvu...46+sm+KS+so+b+ss+SO+EC99\&cf=1\&fn=21\&rm=25.

Hauer, J. (2003). Educating for character and teachers' moral vitality. Journal of Research in Character Education, 1, 33-44.

H.B. 2073. (1995). Retrieved August 25, 2007 from http://www.legis.state. wv.us/Bill_Text_HTML/1995_SESSIONS?RS.

Headen, O. M. (2006). A description and critical examination of the character education program offerings with an urban elementary school. Dissertation Abstracts International, 67, 1221.

Hoare, C. H. (2002). Erikson on development in adulthood: New insights from unpublished papers. Oxford: Oxford University Press.

Hunter, J. D. (2000). The death of character: Moral education in an age without good and bad. New York: Basic Books.

Huseman, A. S. (2006). A study of academic dishonesty of secondary school students. Dissertation Abstracts International, 67, 3765. 
Jackson, R. W. (1993). An analytical approach to values in our educational system for the student-at-risk population for the young maturing adult students at the high school level (At risk). Dissertation Abstracts International, 54, 4333.

Jones, E.N., Ryan, K., \& Bohlin, K. (1998). Character education and teacher education: How are prospective teachers being prepared to foster good character in students? Action in Teacher Education, 20, 11-28.

Jones, L. A. (2006). Passionate teacher, virtuous teaching: Exploring the relationship between teaching calling, teacher passion and character education. Dissertation Abstracts International, 67, 1208.

Josephson Institute of Ethics. (1992). The Aspen Declaration. Marina del Ray, CA. Josephson Institute of Ethics.

Josephson Institute of Ethics. (2004). Fact sheet. Retrieved October 7, 2004, from, http://www.charactercounts.org/pdf/about/factsheet-JI-0903.pdf.

Kagan, S. (2002, Spring). The structural approach to character education. The $4^{\text {th }}$ and $5^{\text {th }}$ Rs Respect and Responsibility, 8, 1-3.

Kagan Publishing and Professional Development. (2004). Retrieved November 6, 2004 from http:www.kaganonline.com/ContactKaganFrame.html.

Kagan Cooperative Learning. (2006). Vita. Retrieved December 16, 2006, from http://www.Kaganonline.com/Training/SK_Vita_2006.pdf.

Kao, T.C. (2005). High school principals’ values and their symbolic and cultural leadership approaches to character education in China. Dissertation Abstracts International, 66, 845. 
Kaufman, J. A. (2004). A methodologic evaluation study of "Caring Habit of the Month Program”: Cognitive, affective and behavioral effects of an anti-violence program in middle school children. Dissertation Abstracts International, 65, 5107.

Kilpatrick, W.K. (1992). Why Johnny can’t tell right from wrong. New York: Simon \& Schuster.

Kinds of Concept Maps (2007). Retrieved August 26, 2007, from http://

Classes.aces.uiuc.edu/ACES100/MIND/cm2.html.

Kirschenbaum, H. (1977). In support of values education. Social Education, 41, 398402.

Kirshenbaum, H., Harmin, M., Howe, L., \& Simon, S.B. (1977). In defense of values clarification. Phi Delta Kappan, 58, 743-746.

Kohlberg, L. (1984). The psychology of moral development: The nature and validity of moral stages. New York: Harper \& Row.

Koller, J. (2006). A study of the relationship between pre-service character education training and teacher efficacy. Dissertation Abstracts International, 67, 1228.

Landeta, J. (2006). Current validity of the delphi method in social sciences. Technological forecasting and social change, 73, 467-482. Retrieved July 24, 2007, from http://media-server.amazon.com/exec/drm/ anzproxy.cgi/MzAOIOo.

Laud, L. (1997). Moral education in America: 1600s-1800s. Journal of Education, 179, 1-10. Retrieved February 2, 2004, from http://80-web8.epnet.com www.libproxy.wvu.edu/DeliveryPrintSave.asp? tb=1\&_ug=dbs=a. 
LeBlanc, B. F. (2007). Teachers’ perceptions, training, and implementation of character education: Implications for staff development. Dissertation Abstracts International, 68, 1795.

Leedy, P.D., \& Ormrod, J.E. (2001). Practical research: Planning and design (7 $7^{\text {th }}$ ed.). Upper Saddle River, NJ: Prentice-Hall, Inc.

Leming, J.S. (1993). Synthesis of research: In search of effective character education. Educational Leadership, 51. Retrieved April 6, 2004, from http://80web20.epnet.com.www.libproxy.wvu.edu/citation.asp?tb=1\&_ug=dbs+af h\%2Ceri.

Leming, J.S. (2000). What works in character education: A review of the research in the field. Washington, DC: Character Education Partnership.

Leming, J.S. (2001). Integrating a structured ethical reflection curriculum into high school community service experiences: Impact on students’ sociomoral development. Adolescence, 36, 33-45.

Leming, J.S. (2008). Research and practice in moral and character education: Loosely coupled phenomena. In L. P. Nucci \& D. Narvaez (Eds.), Handbook of moral and character education (pp. 134-157). New York: NY: Routledge.

Leming, J.S. \& Silva, D.Y. (2001). Experiencing character education: Student and teacher voices. Paper presented at the American Educational Research Association. Seattle, WA.

Lewis, J. G. (2007). The impact on teacher practice when character education is integrated into curriculum. Dissertation Abstracts International, 68, 1305. 
Lichtman, M. (2006). Qualitative research in education: A user's guide. Thousand Oaks, CA: Sage Publications.

Lickona, T. (1991). Educating for character: How our schools can teach respect and responsibility. New York: Bantam Books.

Lickona, T. (1993). The return of character education. Educational Leadership, 51, 6-11. Retrieved January 29, 2004, from http://www.hiho.ne.jp/taku77/refer/lickona.htm.

Lickona, T. (1999). Religion and character education. Phi Delta Kappan, 81, 21-27. Retrieved September 20, 2003 from, http://80web24.epnet.com.www.libproxy.wvu.edu/DeliveryPrintSave.asp?tb=1\&_ug=dbs.

Lickona, T. (2004). Character matters: How to help our children develop good judgement, integrity, and other essential virtues. New York: Simon \& Schuster.

Lickona T. \& Davidson, M. (2004). Smart \& good high schools: Integrating excellence and ethics for success in school, work, and beyond. State University of New York: Cortland; Washington, DC: Character Education Partnership.

Lickona, T., Schaps, S., \& Lewis, C. (1995). Eleven principles of effective character education. Washington, DC: Character Education Partnership.

Lincoln Y.S. \& Guba, E.G. (1985). Naturalistic inquiry. Newbury Park, CA: Sage Publications.

Lockaby, J. D. (1997). Teaching values in agricultural education (character education). Dissertation Abstracts International, 58, 3806.

Mathison, C. (1998). How teachers feel about character education: A descriptive study. Action in Teacher Education, 20, 29-38. 
Maxwell, L.A. (2006). School shootings in policy spotlight: Safety experts say best idea is level heads but open eyes. Education Week. Retrieved November 6, 2006, from http://www.edweek.org/ew/articles/2006/10/07shoot.h26.html?qs=School Shootings\&print $=1$.

Maxwell, J.A. (1996). Qualitative research design: An interactive approach. Thousand Oaks, CA: Sage Publications.

McClellan, E. B. (1999). Moral education in America: Schools and the shaping of character from colonial times to the present. New York: Teachers College Press.

McDonnell, S. (1995). Character and knowledge. Character Education Conference. St. Louis, MO.

McKay, L., \& Archibald, G., Carr, N., \& Stirling, D. (1996). The dynamics of character education. Journal of Staff Development, 17. Retrieved September 29, 2003, from http://www.nsdc.org/library/jsd/mckay172.html.

McMillan, J.H., \& Schumacher, S. (2001). Research in education: A conceptual approach. New York: Addison Wesley Longman.

Merriam. S. B. (1988). Case Study research in education: A qualitative Approach. San Francisco, CA: Jossey-Bass.

Merriam, S.B. (1993). What can you tell from an n of 1?: Issues of validity and reliability in qualitative research. Personal narratives. Retrieved August 23, 2007, from http://www.coe.uga.edu/quig.merriam93.html.

Miles, M.B. \& Huberman, A.M. (1994). Qualitative data analysis: A sourcebook of new methods ( $2^{\text {nd }}$ ed.). Newberry Park, CA: Sage Publications. 
Milson, A. J. (2003). Teachers’ sense of efficacy for the formation of students' character. Journal of Research In Character Education, 1, 89-106.

Milson, A. J.\& Mehlig, L. (2002). Elementary school teachers’sense of efficacy for character education. Journal of Educational Research, 96,130-138.

Morrison, A.M. (2001). Teach Me, O’Lord! Touchstone Magazine. Retrieved November 10, 2004, from http://www.touchstonemag.com/docs/issues/14.4docs/14-4pg25.html.

Morrison, R. R. (2006). The impact of character education programs on student discipline referrals in Texas public schools. Dissertation Abstracts International, $68,425$.

Narvaez, D.A. (2002). Does reading moral stories build character? Education Psychology Review, 14, 155-171.

Narvaez, D.A. (2002, June). The expertise of moral character. Paper presented at the White House Conference on Character and Community, Washington, DC.

Narvaez, D., Bentley, J., Gleason, T., \& Samuels, J. (1998). Moral theme comprehension in third grade, fifth grade, and college students. Reading Psychology, 19, 217-241.

Narvaez, D.,Gleason, T., Mitchell, C., \& Bentley, J. (1999). Moral theme comprehension in children. Journal of Education Psychology, 91, 477-487.

Nash, R.J. (1997). Answering the virtuecrats: A moral conversation on character education. New York: Teachers College Press.

Nash, R.J. (1999). Faith, hype and clarity: Teaching about religion in American schools and colleges. New York: Teachers College Press. 
National Council for Accreditation of Teacher Education (NCATE). (2008). Professional standards for the accreditation of schools, colleges, and departments of education. Washington, D. C.: NCATE.

National Education Research Memo. (1963, November). NEA Research Division of the National Education Association. Washington, DC.

National Middle School Association. (2003). This we believe: Successful schools for young adolescents. A position paper of the National Middle School Association, Westerville, Ohio

Neill, M. E. (1998). A model for a magnet school based on the interrelation between leadership skills and character education. Dissertation Abstracts International, 59, 3308.

Nord, W.A. \& Haynes, C.C. (1998). Taking religion seriously across the curriculum. Nashville, TN: Association for Supervision and Curriculum Development.

Northwest Ordinance. (1787). Retrieved October 10, 2004, from http://usinfo. state.gov/usa/infousa/facts/democrac/s.htm.

Nucci, L., \& Junker, L. (1982, March). Can morality be separated from religion in the teaching of values? Paper presented at the Annual Meeting of the American Education Research Association, New York.

Nucci, L. (2003). Classroom management for moral and social development. In C. Evertson \& C. Weinstein (Eds.), Handbook of classroom management (pp. 711731). Mahwah, NJ: Erlbaum. 
Olvera, E. O. (2006). A case study of the role an elementary teacher plays in affecting the character educational development of elementary students. Dissertation Abstracts International, 67, 4439.

Otten, E. H. (2000). Character education. ERIC Clearinghouse for Social Studies/Social Science Education (ERIC Document Reproduction Service No. ED444932). Retrieved September 9, 2003, from http://www.indiana.edu/ ssde/chardig.htm.

Pagano, R.R. (2001). Understanding statistics in the behavioral sciences ( $6^{\text {th }}$ ed.). Belmont, CA: Wadsworth Publications.

Patton, M.Q. (1990). Qualitative evaluation and research methods. Newbury Park,CA: Sage Publications.

Pilcher, C. F. (2003). A study of the implementation of character education, learning environment, and school performance scores in selected parishes in Louisiana. Dissertation Abstracts International, 64, 750.

Plucker, F. (1990). The use and validation of qualitative methods used in program evaluation. Paper presented at the Annual Research Conference of the California Association of Community Colleges, Monteroy, CA. Retrieved July 27, 2007 from http://web.ebscohost.com.www.libproxy.wvu.edu /ehost/detail?vid=.

Ponzetti, J. J. Jr. (2008). The family as moral center: An evolutionary hermeneutic of virtue and family studies. In L. P. Nucci \& D. Narvaez (Eds.), Handbook of moral and character education (pp. 61-70). New York, NY: Routledge.

Power, F.C., Higgins, A., \& Kohlberg, L. (1989). Lawrence Kohlberg’s approach to moral education. New York: Columbia University Press. 
Phares, J. (2006, October 29). School safety must be priority. Times West Virginian, pp. 3B.

Power, A. M. R., Roney, K. \& Power, F. C. (2008). Orienting to the public good: Developing a moral self in the middle grades. RMLE Online Research in middle level education, 31, 1-13. Retrieved March 12, 2009, from http:www.rmsa.org/portals/O/pdf/publications/RMLE/rmle_vol31_no6.pdf.

Pressman, J. (2004). “The fine young ladies and gentlemen they are”: Gender and democratic character education in the Seattle Public Schools, 1929-1960 (Washington). Dissertation Abstracts International, 65, 3727.

Purpel, D.E. (1989).The moral and spiritual crisis in education: A curriculum for justice and compassion in education. New York: Bergin \& Garvey.

Purvis, B. L. (2002). The relationship of formal character education program on the Act 26 reports for public middle schools in Pennsylvania. Dissertation Abstracts International, 63, 2073.

Raths, B., Harmin, M., \& Simon, S.B. (1996). Values and teaching. Columbus, OH: Merrill.

Rest, J. (1986). Moral development: Advances in research and theory. New York: Praeger.

Richert, P. L. (2005). Teacher attitudes regarding the teaching of morals and values in the curriculum. Dissertation Abstracts International, 43, 1891.

Ries, E. (1999). A question of character. Techniques: Making education \& career connections, 74, 26-31.Retrieved September 20, 2003, from http://80web24.epnet.com.www.wvu.edu/DeliveryPrintSave.asp?tb= 
$1 \& \_u g=d b s$.

Robinson-Lee, W. (2008). A framework for understanding character education in middle schools. Dissertation Abstracts International, 69, 839.

Rosebrock, J. D. (1996). An evaluation of student and teacher perceptions of the Teen Leadership program at Somerville High School. Dissertation Abstracts International, 57, 2308.

Roso, C. G. (2004). Character education at a Jewish day school: A case study analysis of a school’s curriculum. Dissertation Abstracts International, 65, 400.

Rutland, M. (2003). Character matters! Nine essential traits you need to succeed. Lake Mary, FL: Charisma House.

Ryan, K. (1986). The new moral education. Phi Delta Kappan, November, 228-233.

Ryan, K. (2003). Character education: Our high school's missing link. Education Week, 22, 48-50. Retrieved February 2, 2004, from http://edweek.org/ew/ew_printstory.cfm?slug=20ryan.h22.

Ryan, K. \& Bohlin, K.E. (1999). Building character in schools: Practical ways to bring moral instruction to life. San Francisco: Jossey-Bass.

S.B. 125. (2001). Retrieved on August 26, 2007, from http://www.legis.state. wv.us/Bill_Text_HTML/2001_SESSION/RS.

Scales, P. C. (2003). Characteristics of young adolescents. In This we believe: Successful schools for young adolescents. Position paper of National Middle School Association. Westerville, Ohio. 
Schwartz, M. J. (2005). The modeling of moral character by high school teachers through transformational leadership and emotional competence (dissertation). Washington, D. C.: ProQuest Information and Learning Company.

Schwartz, M. J. (2007). The modeling of moral character for teachers: Behaviors, characteristics and dispositions that may be taught. Journal of Research In Character Education, 5, 1-28.

Schwartz, M. J. (2008). Teacher education for moral character education. In L. P. Nucci \& D. Narvaez (Eds.), Handbook of moral and character education (pp. 583-600). New York, NY: Routledge.

Schwartz, M. J., Beatty, A., \& Dachnowicz, E. (2006). Character education: Frill or foundation? Principal Leadership, 7, 25-30.

Skinner, R. (2003). Character education. Education week on the web. Retrieved January 29, 2004 from http://www.edweek.org/context/topics/issuespage.cfm?id=112.

Smerdon, R. A., Burkham, D. T., \& Lee, V.E. (1999). Access to constructivist and didactic teaching: Who gets it? Where is it practiced? Teachers College Record, 101, 5-34.

Smith, W. E. (1998). Character education in the public schools: A Christian theological construct and model. Dissertation Abstract International, 59, 4188.

Spawn, G.L. (1995). Values and attitudes in the public schools: A historical Perspective. Dissertation Abstracts International, 56, 2143.

Sprinthall, N.A., Hall, J.S., \& Gerler, E.R. (1992). Peer counseling for middle school students experiencing family divorce: A deliberate psychological education model. Elementary School Guidance \& Counseling, 26, 279-294. 
Starr, L. (2005). Is character education the answer? Retrieved March 19, 2007 from http://www.educationworld.com/a_admin/admin/admin097.shtml.

STATS Indiana-USA Counties in Profile (2009). Retrieved January 5, 2009, from the Indiana Economic Development Corporation Web site: http:www.stats.indiana.edu/uspr/a/usprofiles/54/us_over_sub_ pr54.

Stoppleworth, L.O.H. (2001). An ethnographic study of participants’ perceptions of character education including students, parents, teachers, club sponsors, administrators, and community support people (Doctoral dissertation, Louisiana Tech University, 2001). Dissertation Abstracts International, 62, 3009.

Stuen, C. J. (1996). Elementary teachers' perceptions of the characteristics and development of good citizenship in Washington State (Character education). Dissertation Abstracts International, 58, 3840.

Suma-Belanger, B. (2006). The moral educator and the transcendental awe of everyday teaching: A heuristic case study. Dissertation Abstracts International, 67, 4105.

Tabacoff, D. (Executive Producer). (2008a, April 10). The O'Reilly Factor [Television broadcast]. New York: Fox News Network.

Tabacoff, D. (Executive Producer). (2008b, June 12). The O’Reilly Factor [Television broadcast]. New York: Fox News Network.

Tapper, P. A. (2007). Character education programs in Texas Character Plus middle schools and the role of the principal. Dissertation Abstracts International, 68, 2833. 
Tirri, K. (2003). The teacher's integrity. In W. Veugelers \& F. K. Oser (Eds.), Teaching in moral and democratic education. (pp. 65-81). Bern, Switzerland: Peter Lang.

Titus, D. N. (1994, September). Values education in American secondary schools. Paper presented at the Kutztown University Education Conference, Kutztown, PA. Retrieved September 20, 2003, from http://www.hi-o.ne.jp/taku77/refer/titus.htm.

Udayar, S. D. (2008). The influence of character education on student behavior and student academic achievement in Texas Character Plus middle schools. Dissertation Abstracts International, 69, 842.

United States Department of Education (2002, June 5). Education department and secret service release threat assessment guide for schools [press release]. Message posted to web site http://www.ed.gov/print/news/pressreleases/2002/06/06052002.html.

United States Department of Education. (2005, May 31). Character education: Our shared responsibility. Retrieved February 26, 2007, from http://www.ed.gov/print/admins/lead/character/brochure.html.

United States Department of Education. (2006, April 27-28). Proceedings of the Center Resource Group, a joint meeting between Office of Safe and Drug-Free Schools and Character Education and Civic Engagement Technical Assistance Center. Washington Marriott, Washington, DC.

United States Department of Education Institute for Educational Sciences (2002). The what works clearinghouse: Character education. Retrieved March 3, 2009, from http://www.whatworks.ed.gov 
United States Secret Service and United States Department of Education. (2002, May).

The final report and findings of the safe school initiative: Implications for the prevention of school attacks in the United States. Retrieved November 14, 2006, from http://www.secretservice.gov/ntac/ssi_final_report.pdf.

Vincent, P. F. (2003). Roles and procedures for character education: The first step toward school civility ( $2^{\text {nd }}$ ed.). Chapel Hill, NC: Character Development Publishing.

Vincent, P.F. (2003, November). Suggestions for character implementation and development in high schools. Presented at Safe Schools and Character Education Conference, Charleston, WV.

Watson, M. (2008). Developmental Discipline and moral education. In L. P. Nucci \& D. Narvaez (Eds.), Handbook of moral and character education (pp. 175-203). New York, NY: Routledge.

West Virginia Department of Education. (2003, December). State Board Hears Character Education Evaluation Report. [press release]. Message posted to http://wvde.state.wv.us/news/704. Retrieved December 5, 2006.

West Virginia Department of Education. (2005, June). News Alerts. [press release]. Message posted to ttp://wvde.state.wv.us/osshp/section1/NEWSALERTS.htm. Retrieved August 22, 2005.

West Virginia Department of Education. (2006-2007). West Virginia Report Cards. Retrieved January 5, 2009, from http://wvde.state.wv.us/data/report _cards/2006/West\%20/Virginia\%20Report\%20Cards\%202006-2007. West Virginia Department of Education Office of Healthy Schools. (2006). 
Lisa Burton, Coordinator. Retrieved on December 16, 2006 from http://wvde.state.wv.us/osshp/section1/.

West Virginia Department of Education (2007, August). Study shows Character

Education Aids Student Achievement. [press release]. Message posted to http://wvde.state.wv.us/news/1498/. Retrieved February 28, 2008.

West Virginia State Code 18-2-13.(2001).Character Education Integration.

Retrieved on August 26, 2007, from

http://www.legis.state.wv.us/WVCODE/18/WVC\%2018\%20\%20.

Wiersma, W. (2000). Research methods in education: An introduction ( $7^{\text {th }}$ ed.). Boston: Allyn and Bacon.

Wolcott, H.F. (2001). Writing up qualitative research ( $2^{\text {nd }}$ ed.). Thousand Oaks, CA: Sage Publications.

Works of Plato: Apology. (1/1/63). Monarch Notes. Retrieved November 10, 2004, from http://www.highbeam.com/library/doc3asp?DOCID=1P1:28047855\& num=10\&ctr1Info=.

Wynne, E.A. (1989). Transmitting traditional values in contemporary schools. Moral development and character education. Berkley, CA: McCutchan.

Wynne, E.A. \& Ryan, K. (1997). Reclaiming our schools: Teaching character, academics, and discipline (2nd ed.). Upper Saddle River, NJ: Merrill.

Yin, R.K. (1984). Case study research design and methods. Beverly Hills, CA: Sage Publications. 
APPENDICES 
Appendix A: Interview Questions and Relevant Literature of Character Education

\begin{tabular}{|c|c|c|c|}
\hline Questions & $\begin{array}{l}\text { Research } \\
\text { Question }\end{array}$ & Concept(s) & Citation(s) \\
\hline Demographic & $\begin{array}{l}\text { Number of } \\
\text { years teaching } \\
\text { experience. } \\
\end{array}$ & $\begin{array}{l}\text { Experience affects } \\
\text { perception. }\end{array}$ & $\begin{array}{l}\text { Milson, 2003; } \\
\text { Milson \& Mehlig, } \\
2002 \\
\end{array}$ \\
\hline Demographic & $\begin{array}{l}\text { Number of } \\
\text { years on the } \\
\text { middle school } \\
\text { level. }\end{array}$ & $\begin{array}{l}\text { Unique challenges } \\
\text { of curriculum } \\
\text { delivery. }\end{array}$ & 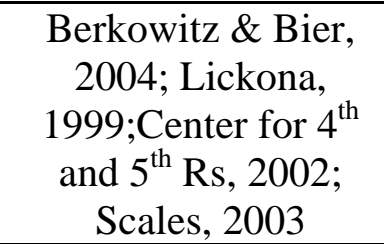 \\
\hline Demographic & $\begin{array}{l}\text { Number of } \\
\text { years at this } \\
\text { school. }\end{array}$ & $\begin{array}{l}\text { Mind set of } \\
\text { institution. }\end{array}$ & $\begin{array}{c}\text { Center for } 4^{\text {th }} \text { and } 5^{\text {th }} \\
\text { Rs, } 2002\end{array}$ \\
\hline Demographic & $\begin{array}{l}\text { Religious } \\
\text { preference. }\end{array}$ & $\begin{array}{l}\text { Preference impacts } \\
\text { curriculum } \\
\text { delivery, } \\
\text { perception. }\end{array}$ & $\begin{array}{c}\text { Halstead, 2000; } \\
\text { Lickona, 1991, 1999; } \\
\text { Nord \& Haynes,1998; } \\
\text { Nucci \& Junker, } \\
\text { 1982; Wynne \& } \\
\text { Ryan, } 1997 \\
\end{array}$ \\
\hline Demographic & $\begin{array}{l}\text { Record } \\
\text { gender. }\end{array}$ & $\begin{array}{c}\text { Gender affects } \\
\text { curriculum } \\
\text { delivery. } \\
\end{array}$ & Freidman, 1995 \\
\hline Demographic & $\begin{array}{l}\text { Subject(s) } \\
\text { Taught }\end{array}$ & $\begin{array}{c}\text { Teacher attitudes of } \\
\text { and perceptions } \\
\text { toward delivery. }\end{array}$ & $\begin{array}{l}\text { Amoroso, } 1995 \\
\text { Burton, } 2008\end{array}$ \\
\hline Demographic & $\begin{array}{l}\text { Current } \\
\text { Position }\end{array}$ & $\begin{array}{c}\text { Perceptions } \\
\text { concerning } \\
\text { delivery. } \\
\end{array}$ & $\begin{array}{l}\text { Amoroso, } 1995 \\
\text { Burton, } 2008\end{array}$ \\
\hline $\begin{array}{l}\text { 1.How would you } \\
\text { define character } \\
\text { education? }\end{array}$ & $\# 1 \mathrm{a}$ & $\begin{array}{c}\text { Definition of } \\
\text { character education }\end{array}$ & $\begin{array}{c}\text { Character Education } \\
\text { Partnership, } 1993 \\
\text { Lickona, } 1991 \\
\text { Otten, } 2000\end{array}$ \\
\hline $\begin{array}{l}\text { 2. What } \\
\text { importance do you } \\
\text { attach to character } \\
\text { education? }\end{array}$ & $\# 1 b$ & $\begin{array}{c}\text { Perception of } \\
\text { character education, } \\
\text { in society, teacher } \\
\text { responsibility, } \\
\text { definition perhaps, } \\
\text { justification for } \\
\text { character education. }\end{array}$ & $\begin{array}{l}\text { Chapman, 2006; } \\
\text { Leming, 1993; } \\
\text { Lickona, 1991, 1992; } \\
\text { Mathison, 1998; } \\
\text { Otten, 2000; } \\
\text { Ryan, 2003; Titus, } \\
\text { 1994; Vincent, 2003 }\end{array}$ \\
\hline $\begin{array}{l}\text { 3. By what actions } \\
\text { does this school/ } \\
\text { county indicate } \\
\text { character education } \\
\text { is important? }\end{array}$ & $\# 1 b$ & $\begin{array}{c}\text { Perceived } \\
\text { importance, local } \\
\text { accountability. }\end{array}$ & $\begin{array}{c}\text { West Virginia State } \\
\text { Code 18-2-13 }\end{array}$ \\
\hline
\end{tabular}


Appendix A (continued): Interview Questions and Relevant Literature of Character Education

\begin{tabular}{|c|c|c|c|}
\hline $\begin{array}{l}\text { 4. How } \\
\text { responsible do you } \\
\text { feel for } \\
\text { implementing } \\
\text { character } \\
\text { education in your } \\
\text { classroom? } \\
\end{array}$ & $\# 1 \mathrm{~b}$ & $\begin{array}{c}\text { Teacher } \\
\text { accountability, at } \\
\text { risk behaviors, safe } \\
\text { schools, perceived } \\
\text { importance. }\end{array}$ & $\begin{array}{l}\text { West Virginia State } \\
\text { Code 18-2-13; } \\
\text { Leming, 1993; } \\
\text { Purpel, } 1989\end{array}$ \\
\hline $\begin{array}{l}\text { 5. How, if at all, } \\
\text { have you changed } \\
\text { the way you deal } \\
\text { with character } \\
\text { education since it } \\
\text { has been required } \\
\text { by WV State Code } \\
18-2-13 \text { ? }\end{array}$ & \#1, \#2 & $\begin{array}{l}\text { Teacher } \\
\text { accountability, } \\
\text { training needed, } \\
\text { teacher perceived } \\
\text { importance. }\end{array}$ & $\begin{array}{l}\text { West Virginia State } \\
\text { Code 18-2-13, } \\
\text { Lickona, 1993 }\end{array}$ \\
\hline $\begin{array}{l}6 \text {. What in your } \\
\text { personal } \\
\text { background or past } \\
\text { experience has } \\
\text { influenced the } \\
\text { teaching of } \\
\text { character } \\
\text { education? } \\
\end{array}$ & \#2, \#3 & $\begin{array}{l}\text { Religion, morality, } \\
\text { character education } \\
\text { connection, } \\
\text { connection between } \\
\text { perceived teacher } \\
\text { preparation and } \\
\text { teacher efficacy, } \\
\text { barriers, aids. } \\
\end{array}$ & $\begin{array}{c}\text { Milson, 2003; } \\
\text { Milson \& Mehlig, } \\
\text { 2002: Berkowitz \& } \\
\text { Bier, } 2004\end{array}$ \\
\hline $\begin{array}{l}\text { 7. How do your } \\
\text { values and beliefs } \\
\text { impact your } \\
\text { approach to } \\
\text { teaching character } \\
\text { education? }\end{array}$ & $\# 2, \# 3$ & $\begin{array}{l}\text { Barriers to character } \\
\text { education delivery, } \\
\text { things that may } \\
\text { expedite character } \\
\text { education delivery. }\end{array}$ & $\begin{array}{c}\text { Berkowitz \& Bier, } \\
2004\end{array}$ \\
\hline $\begin{array}{l}\text { 8. What kinds of } \\
\text { things do you do to } \\
\text { teach character } \\
\text { education? }\end{array}$ & \#2 & $\begin{array}{l}\text { Character education } \\
\text { implementation. }\end{array}$ & Kagan, 2002 \\
\hline $\begin{array}{l}\text { 9. What gets in } \\
\text { the way of } \\
\text { implementing } \\
\text { character } \\
\text { education? }\end{array}$ & \#3 & $\begin{array}{l}\text { Barriers to character } \\
\text { education delivery. }\end{array}$ & $\begin{array}{c}\text { Berkowitz \& Bier, } \\
\text { 2004; Berkowitz, } \\
\text { Batttistich \& Bier, } \\
2008\end{array}$ \\
\hline $\begin{array}{l}\text { 10. What helps } \\
\text { you teach } \\
\text { character } \\
\text { education? }\end{array}$ & \#3 & $\begin{array}{c}\text { Character education } \\
\text { curriculum } \\
\text { integration. }\end{array}$ & $\begin{array}{c}\text { Burton, 2008; Kagan, } \\
2002\end{array}$ \\
\hline
\end{tabular}


Appendix A (continued): Interview Questions and Relevant Literature of Character Education

\begin{tabular}{lcc}
\hline $\begin{array}{l}\text { 11. How do you } \\
\text { think the school's } \\
\text { emphasis on }\end{array}$ & $\begin{array}{c}\text { Character education } \\
\text { barriers, character } \\
\text { teaching Character }\end{array}$ & $\begin{array}{c}\text { Berkowitz \& Bier, } \\
\text { 2004; Kagan, 2002; } \\
\text { has affected what } \\
\text { teachers do? }\end{array}$ \\
$\begin{array}{l}\text { 12. Is there } \\
\text { anything else you } \\
\text { would like to add }\end{array}$ & integration; efficacy \& & $\begin{array}{c}\text { 2002, Milson, 2003 } \\
\text { we haven't } \\
\text { discussed? }\end{array}$ \\
\hline
\end{tabular}


Appendix B: Demographic Data of Interviewed Teachers

\begin{tabular}{|c|c|c|c|c|c|c|}
\hline $\begin{array}{c}\text { Subjects } \\
\text { Taught }\end{array}$ & $\begin{array}{c}\text { Total } \\
\text { Years } \\
\text { Teaching } \\
\text { Experience }\end{array}$ & $\begin{array}{c}\text { Years } \\
\text { at } \\
\text { School }\end{array}$ & $\begin{array}{l}\text { Sex of } \\
\text { Teacher }\end{array}$ & $\begin{array}{l}\text { Identifies } \\
\text { Self as } \\
\text { Christian }\end{array}$ & $\begin{array}{c}\text { Member of } \\
\text { Character } \\
\text { Development } \\
\text { Team }\end{array}$ & $\begin{array}{c}\text { Page } \\
\text { Length } \\
\text { of } \\
\text { Interview }\end{array}$ \\
\hline English & 34 & 16 & $\mathrm{~F}$ & $\mathrm{X}$ & & 6 \\
\hline $\begin{array}{l}\text { Reading, } \\
\text { English }\end{array}$ & 31 & 16 & M & $\mathrm{X}$ & $\mathrm{X}$ & 14 \\
\hline Social Studies & 7 & 6 & $\mathrm{~F}$ & X & X & 10 \\
\hline $\begin{array}{l}\text { Library } \\
\text { Science, } \\
\text { Reading, } \\
\text { Technology }\end{array}$ & 24 & 1 & $\mathrm{~F}$ & $\mathrm{X}$ & $X$ & 7 \\
\hline $\begin{array}{l}\text { Health, } \\
\text { Physical } \\
\text { Education }\end{array}$ & 20 & 12 & $\mathrm{~F}$ & $\mathrm{X}$ & & 9 \\
\hline Art & 31 & 16 & $\mathrm{~F}$ & $\mathrm{X}$ & X & 13 \\
\hline $\begin{array}{l}\text { Life Skills, } \\
\text { Parenting, } \\
\text { Food/Nutrition }\end{array}$ & 19 & 8 & $\mathrm{~F}$ & $\mathrm{X}$ & & 17 \\
\hline $\begin{array}{l}\text { Music, Band, } \\
\text { Photo Editing }\end{array}$ & 30 & 16 & $\mathrm{M}$ & $\mathrm{X}$ & & 17 \\
\hline $\begin{array}{l}\text { Special } \\
\text { Education }\end{array}$ & 7 & 5 & $\mathrm{~F}$ & $\mathrm{X}$ & & 13 \\
\hline Science & 7 & 5 & $\mathrm{~F}$ & $\mathrm{X}$ & & 12 \\
\hline $\begin{array}{c}\text { Special } \\
\text { Education }\end{array}$ & 31 & 16 & $\mathrm{~F}$ & $\mathrm{X}$ & $\mathrm{X}$ & 10 \\
\hline $\begin{array}{l}\text { Music, Band, } \\
\text { Technology }\end{array}$ & 25 & 16 & $\mathrm{~F}$ & $\mathrm{X}$ & X & 20 \\
\hline
\end{tabular}




\section{Appendix C: Interview Protocol}

Interview Protocol

Project: Middle School Teacher Perceptions of Character Education

Time of Interview:

Date:

Place:

Interviewer: Lisa D. Lucas

Interviewee Code:

Gender:

Position of Interviewee:

Number of Years Teaching Experience:

Number of Years Experience on Middle School Level:

Number of Years at This School:

Subject(s) Taught:

Religious Preference:

Opening Statement:

Hello, and thank you for spending this time with me. I am a doctoral student from West Virginia University and a former high school learning disabilities instructor of nearly 20 years. My research, a topic that greatly interests me, is character education.

This interview concerns middle school teachers’ perceptions of the meaning of character education as it relates to teacher responsibility, and implementation as well as obstacles. Please note that your responses will remain anonymous. Also, it is your 
prerogative to decline from answering any or all questions. The transcribed interview results will be shared with you to ensure accuracy.

Because your participation and time sacrifice is so greatly appreciated, your participation in this interview will qualify you for a $\$ 20.00$ gas card which will be awarded at the conclusion of the last interview.

I will be audio taping this interview and making some periodic notes to help my memory. After the data analysis is completed, all tapes will be destroyed by fire. Do you understand and agree with these conditions? Do you want to continue with the interview?

Let's begin...

1. How would you define character education?

2. What importance do you attach to character education?

3. By what actions does this school indicate character education is important? By what actions does this county indicate character education is important?

4. How responsible do you feel for integrating character education in your classroom?

5. How, if at all, have you changed the way you deal with character education since it has been legislated by WV State Code 18-2-13? 
6. What in your personal background or past experience has influenced the way you teach character education?

7. How do your values and beliefs impact your approach to teaching character education?

(The following questions pertain to curriculum delivery.)

8. What kinds of things do you do to teach character education? From where do you get your ideas?

9. What gets in the way of integrating character education?

10. What helps you to teach character education?

11. How do you think the school's emphasis on teaching character education has affected what teachers do?

12. Is there anything else you would like to add we haven't discussed? 
Appendix D: Expert Biographies

Dr. Thomas Lickona is a developmental psychologist and Professor of Education at State University at New York at Cortland. He currently is the director of the Center for the Fourth and fifth Rs (Respect and Responsibility). He has been a visiting professor at Boston and Harvard Universities. He is the past president of the Association for Moral Education and serves on the advisory councils of the Character Education Partnership and the Character Counts Coalition. He serves as a consultant to schools on character education and has traveled extensively to numerous countries teaching on the subject of moral values in school and in the home. Dr. Lickona has authored at least six books pertaining to character education including the 2004 Character Matters: How to help Our Children Develop Good Judgment, Integrity, and Other Essential Virtues (Center for the $4^{\text {th }}$ and $5^{\text {th }}$ Rs, 2007).

Dr. Spencer Kagan is the Director of Kagan Publishing and Professional Development which is based upon a research program he conducted beginning in 1968. Kagan Publishing is the world's largest publisher and distributor of cooperative learning and multiple intelligence and resources. His research has yielded nearly 100 publications with one of his books as he 1994 Cooperative Learning. He is known for his development of over 200 simple teaching techniques or instructional strategies to guide the interaction of children with each other, the curriculum, and the teacher, known at structures. He conducts worldwide training institutes and seminars (Kagan Cooperative Learning, 2006). Kagan's structures have been utilized in the delivery of character education. 
Appendix D (continued): Expert Biographies

Lisa Burton is currently employed by Marshall University. She did serve at the West Virginia Department of Education in the Office of Healthy Schools where she was state coordinator of character education. She has developed state conferences on school safety and character education and is currently working as the director of the five-year study involving four West Virginia Counties, The United States Department of Education, Marshall University, and West Virginia University. She is a former teacher who is working on her doctorate in educational leadership (Corrigan \& Chapman, 2005; West Virginia Department of Education Office of Healthy Schools, 2006).

Dr. Philip Vincent is the chief consultant to the five-year research project involving four-counties in West Virginia. He has been a teacher on all three educational levels, principal and superintendent, and serves as the Director of the Character Development Group. He has spoken at numerous workshops and conferences and has authored over 25 books including his 2003 Rules and Procedures for Character Education: The first Step Toward School Civility. He has aided more than 33 school districts in North Carolina in formulating and implementing character education programs and has served as a consultant in character education in more than 25 states (Character Development Group, 2007; Corrigan \& Chapman, 2005).

Dr. Michael Corrigan currently serves as an Assistant Professor in the Educational Foundations Department of Marshall University in West Virginia as well as the Director of Research for the June Harless Center for Rural Education Research and Development there. He has secured numerous grants, among them a 1.87 million grant by the United States Department of Education in collaboration with the West 
Appendix D (continued): Expert Biographies

Virginia Department of Education to longitudinally study K-12 students’ character development over four years. He has authored many papers and received several awards and appointments (West Virginia Department of Education, 2007; M. Corrigan, personal communication, March 28, 2008). 


\section{Appendix E: Emailed Letter of Correspondence to Experts}

Date

\section{Dear Expert,}

My name is Lisa Lucas and I am a doctoral student in the program of Curriculum \& Instruction at West Virginia University, working with Dr. Helen Hazi, my chair. My dissertation is entitled How Character Education is Perceived and Implemented by Selected Secondary Teachers of One Rural County in West Virginia. The purpose of the study is to examine perceptions of selected secondary school teachers from one rural county in West Virginia according to how they think about and implement character education, what they consider to be obstacles that interfere with the teaching of character education, as well as factors that may foster delivery. I need your help to review my interview questions to make sure they align with my research questions.

You are one of three experts that have been selected because of your considerable expertise in the area of character education. First of all, I ask that you please agree to review these interview questions, revise if needed, and return them to me on the enclosed Expert Response Sheet by date. Please examine the interview questions to ensure that they fully address the research questions. I, in turn, will compile your revisions, and then those from the other two experts, and resubmit them to you. After this second round, I will then formulate the final version of questions that will be employed for the interviews. After this process is complete, I will pilot these questions with secondary level teachers. Hopefully this process can be completed in two weeks.

Attached are my questions sorted according to Patton's analysis matrix (Appendix A), the research questions, purpose, and interview protocol along with interview questions, as well as a response sheet. The Chapter III Methodology is available at your request. I know this will take your time, which is precious to all of us these days.

We greatly appreciate your input. If you decline to participate, please contact me at XXXXXX. This process should not be very time-consuming.

Sincerely,

Helen M. Hazi, Ph.D., Principal

Professor of Educational Leadership

Lisa Lucas. Co-Principal

Doctoral Student in Curriculum \& Instruction

Enclosures: (4) Patton's Literature Analysis, Study Purpose, Questions, and Design, Interview Protocol, and Expert Response Sheet. 
Appendix F: Interview Question Expert Response Sheet

\begin{tabular}{|c|c|c|c|c|}
\hline Question & $\begin{array}{l}\text { OK - } \\
\text { Check }\end{array}$ & $\begin{array}{c}\text { Round 1- } \\
\text { Revision } \\
\text { BLUE- (Check if } \\
\text { okay) } \\
\end{array}$ & $\begin{array}{c}\text { Round } 2- \\
\text { Revision- RED } \\
\text { (check if okay) }\end{array}$ & $\begin{array}{c}\text { Final } \\
\text { Question }\end{array}$ \\
\hline $\begin{array}{l}\text { QUESTION \#1. } \\
\text { How would you } \\
\text { define character } \\
\text { education? }\end{array}$ & $\begin{array}{c}\text { X } \\
\text { (C.C., } \\
\text { A.A., } \\
\text { B.B.) }\end{array}$ & & $\begin{array}{c}X \\
\text { (C.C., A.A., } \\
\text { B.B.) }\end{array}$ & $\begin{array}{l}\text { How would you } \\
\text { define } \\
\text { Character } \\
\text { Education? }\end{array}$ \\
\hline $\begin{array}{l}\text { Question \#2 } \\
\text { How is } \\
\text { character } \\
\text { education } \\
\text { Important in } \\
\text { this school? By } \\
\text { what actions } \\
\text { does this school } \\
\text { indicate CE is } \\
\text { important? }\end{array}$ & $\begin{array}{c}\text { X } \\
\text { (B.B.) }\end{array}$ & $\begin{array}{l}\text { Maybe add } \\
\text { another ? for } \\
\text { district? (C.C.) } \\
\text { Needs to be more } \\
\text { precise. For ex., } \\
\text { "By what actions } \\
\text { does this school } \\
\text { indicate that CE } \\
\text { is important?" } \\
\text { (A.A.) }\end{array}$ & $\begin{array}{l}\text { Add something } \\
\text { concerning the } \\
\text { district's } \\
\text { expectation of } \\
\text { CE-this } \\
\text { control's the } \\
\text { school's efforts a } \\
\text { good deal (C.C., } \\
\text { B.B.) } \\
\text { X (A.A.) }\end{array}$ & $\begin{array}{l}\text { By what actions } \\
\text { does this school } \\
\text { indicate CE is } \\
\text { important? By } \\
\text { what actions } \\
\text { does this county } \\
\text { indicate CE is } \\
\text { important? }\end{array}$ \\
\hline $\begin{array}{l}\text { Question \#3 } \\
\text { How } \\
\text { responsible do } \\
\text { you feel for } \\
\text { implementing } \\
\text { integrating } \\
\text { (C.C.) character } \\
\text { education in } \\
\text { your classroom? }\end{array}$ & $\begin{array}{c}\text { X } \\
\text { (B.B.) }\end{array}$ & $\begin{array}{l}\text { “On a scale of } 1 \\
\text { to } 5 \text {, where } 1 \text { is } \\
\text { 'not very } \\
\text { responsible' and } \\
5 \text { is 'very } \\
\text { responsible,' how } \\
\text { responsible do } \\
\text { you feel...” (etc.) } \\
\text { (A.A.) }\end{array}$ & $\begin{array}{l}\text { CE is integrated } \\
\text { into the whole } \\
\text { school, not just } \\
\text { the classroom } \\
\text { (C.C.). } \\
\quad \text { X } \\
\text { (A.A., B.B.) }\end{array}$ & $\begin{array}{l}\text { How responsible } \\
\text { do you feel for } \\
\text { integrating CE } \\
\text { in your } \\
\text { classroom? }\end{array}$ \\
\hline $\begin{array}{l}\text { Question \#4 } \\
\text { How, if at all, } \\
\text { (A.A.) have you } \\
\text { changed the } \\
\text { way you deat } \\
\text { with implement } \\
\text { (C.C.) character } \\
\text { education since } \\
\text { it has been } \\
\text { required? } \\
\text { emphasized in } \\
\text { the school? }\end{array}$ & $\begin{array}{c}\text { X } \\
\text { (B.B.) }\end{array}$ & $\begin{array}{l}\text { Clarify } \\
\text { “required,” By } \\
\text { law? What law? } \\
\text { By district } \\
\text { mandate? By } \\
\text { what? (A.A., } \\
\text { B.B.) Has the } \\
\text { state mandate of } \\
\text { CE changed your } \\
\text { approach to CE? } \\
\text { (C.C.) Can’t } \\
\text { assume person } \\
\text { has changed. } \\
\text { (A.A.) }\end{array}$ & $\begin{array}{l}\text { "Deal with" is } \\
\text { negative—use } \\
\text { "plan, embrace," } \\
\text { and it is } \\
\text { mandated by the } \\
\text { state, it also falls } \\
\text { under the } 21^{\text {st }} \\
\text { century learning } \\
\text { effort (C.C.). } \\
\text { X (A.A., B.B.) }\end{array}$ & $\begin{array}{l}\text { How, if at all, } \\
\text { have you } \\
\text { changed the way } \\
\text { you deal with } \\
\text { CE since it has } \\
\text { been legislated } \\
\text { by WV State } \\
\text { Code 18-2-13? }\end{array}$ \\
\hline
\end{tabular}


Appendix F (continued): Interview Question Expert Response Sheet

\begin{tabular}{|c|c|c|c|c|}
\hline Question & $\begin{array}{l}\text { OK - } \\
\text { Check }\end{array}$ & $\begin{array}{c}\text { Round 1- } \\
\text { Revision BLUE }\end{array}$ & $\begin{array}{c}\text { Round } 2- \\
\text { Revision RED }\end{array}$ & Final Question \\
\hline $\begin{array}{l}\text { Question \#5 } \\
\text { What in your } \\
\text { personal } \\
\text { (A.A.) } \\
\text { background or } \\
\text { past experience } \\
\text { (A.A.) had has } \\
\text { (C.C., A.A., } \\
\text { B.B.) } \\
\text { influenced the } \\
\text { way you teach } \\
\text { teaching of } \\
\text { (A.A.) } \\
\text { character } \\
\text { education? }\end{array}$ & $\begin{array}{c}\text { X } \\
\text { (B.B.) }\end{array}$ & & $\begin{array}{l}\text { This seems like a } \\
\text { good question } \\
\text { and will need } \\
\text { some additional } \\
\text { follow-up time } \\
\text { and discussions } \\
\text { (B.B.). } \\
\text { X (C.C., A.A.) }\end{array}$ & $\begin{array}{l}\text { What in your } \\
\text { personal } \\
\text { background or } \\
\text { past experience } \\
\text { has influenced } \\
\text { the way you } \\
\text { teach CE? }\end{array}$ \\
\hline $\begin{array}{l}\text { Question \#6 } \\
\text { How do your } \\
\text { views-values } \\
\text { and beliefs (A. } \\
\text { A.) impact your } \\
\text { approach to } \\
\text { teaching } \\
\text { character } \\
\text { education? }\end{array}$ & $\begin{array}{c}\text { X } \\
\text { (C.C., } \\
\text { B.B.) }\end{array}$ & $\begin{array}{l}\text { Ask question \#6 } \\
\text { before \#4. (C.C.) } \\
\text { Not clear, views } \\
\text { of what? (A.A.) } \\
\text { Religious, } \\
\text { community, } \\
\text { other such things. } \\
\text { (B.B.) }\end{array}$ & $\begin{array}{l}\text { It would appear } \\
\text { you ignored all of } \\
\text { our } \\
\text { advice...maybe } \\
\text { views of engage- } \\
\text { ment (C.C.). I do } \\
\text { think you need } \\
\text { some focus to this } \\
\text { question...what } \\
\text { influences the } \\
\text { views of these } \\
\text { participants? I } \\
\text { think it is fine to } \\
\text { add faith, com- } \\
\text { munity, profes- } \\
\text { sional knowledge } \\
\text {...etc as examples } \\
\text {.i.e., faith...(B.B.) }\end{array}$ & $\begin{array}{l}\text { How do your } \\
\text { values and } \\
\text { beliefs impact } \\
\text { your approach } \\
\text { to teaching CE? }\end{array}$ \\
\hline $\begin{array}{l}\text { Question \#7 } \\
\text { What kinds of } \\
\text { things do you } \\
\text { do to teach } \\
\text { character } \\
\text { education? }\end{array}$ & $\begin{array}{c}\text { X } \\
\text { (C.C., } \\
\text { A.A., } \\
\text { B.B.) }\end{array}$ & & $\begin{array}{c}\text { X } \\
\text { (C.C., } \\
\text { A.A., } \\
\text { B.B.) }\end{array}$ & $\begin{array}{l}\text { What kinds of } \\
\text { things do you do } \\
\text { to teach CE? }\end{array}$ \\
\hline
\end{tabular}


Appendix F (continued): Interview Question Expert Response Sheet

\begin{tabular}{|c|c|c|c|c|}
\hline Question & $\begin{array}{l}\text { OK - } \\
\text { Check }\end{array}$ & $\begin{array}{l}\text { Round } 1 \text { - } \\
\text { Revision } \\
\text { BLUE }\end{array}$ & $\begin{array}{c}\text { Round } 2- \\
\text { Revision RED }\end{array}$ & Final Question \\
\hline $\begin{array}{l}\text { Question \#8 } \\
\text { What gets in the } \\
\text { way of } \\
\text { implementing } \\
\text { integrating } \\
\text { (C.C.) character } \\
\text { education? }\end{array}$ & $\begin{array}{c}\text { X } \\
\text { (A.A., } \\
\text { B.B.) }\end{array}$ & & $\begin{array}{c}\text { X } \\
\text { (C.C., A.A., } \\
\text { B.B.) }\end{array}$ & $\begin{array}{l}\text { What gets in the } \\
\text { way of } \\
\text { integrating CE? }\end{array}$ \\
\hline $\begin{array}{l}\text { Question \#9 } \\
\text { What helps you } \\
\text { teach character } \\
\text { education? }\end{array}$ & $\begin{array}{c}\text { X } \\
\text { (C.C., } \\
\text { A.A., } \\
\text { B.B.) }\end{array}$ & & $\begin{array}{c}\text { X } \\
\text { (C.C., A.A., } \\
\text { B.B.) }\end{array}$ & $\begin{array}{l}\text { What helps you } \\
\text { teach CE? }\end{array}$ \\
\hline $\begin{array}{l}\text { Question \#10 } \\
\text { How do you } \\
\text { think teachers } \\
\text { have dealt with } \\
\text { eharacter } \\
\text { education since } \\
\text { it has been } \\
\text { required? How } \\
\text { do you think the } \\
\text { school 's } \\
\text { emphasis to on } \\
\text { teaching (A.A.) } \\
\text { CE has affected } \\
\text { what teachers } \\
\text { do? }\end{array}$ & $\begin{array}{c}\text { X } \\
\text { (B.B.) }\end{array}$ & $\begin{array}{l}\text { Dealt } \\
\text { w...negative. } \\
\text { (C.C.) "How do } \\
\text { you think the } \\
\text { requirement to } \\
\text { teach CE has } \\
\text { affected what } \\
\text { teachers do?” } \\
\text { (A.A.) }\end{array}$ & $\begin{array}{l}\text { This question } \\
\text { gets to the school } \\
\text { effort. I'm not } \\
\text { sure if you want } \\
\text { to get involved in } \\
\text { the area of } \\
\text { district support } \\
\text { or district } \\
\text { expectation } \\
\text { (B.B.) } \\
\text { X (C.C.) }\end{array}$ & $\begin{array}{l}\text { How do you } \\
\text { think the } \\
\text { school's } \\
\text { emphasis on } \\
\text { teaching CE has } \\
\text { affected what } \\
\text { teachers do? }\end{array}$ \\
\hline
\end{tabular}


Appendix G: Principal Letter

\section{West VirginiaUniversily}

College of Human Resources and Education

Date

Dear Principal,

My name is Lisa Lucas and I am a doctoral student in the program of Curriculum \& Instruction at West Virginia University, working with Dr. Helen Hazi, my chairperson. My dissertation is entitled How Character Education is Perceived and Implemented by Selected Middle School Teachers of One Rural County in West Virginia. The purpose of the study is to examine perceptions of selected middle school teachers from one rural county in West Virginia according to how they think about and implement character education, what they consider to be obstacles that interfere with the teaching of character education, as well as factors that may foster delivery. I will do this through interviews of approximately half of the teachers comprising your school Character Development Team and the other randomly selected from the instructional staff for a total of approximately twelve teachers. Classroom observation and document analysis of lesson plans and classroom materials from the interviewees will also be utilized as they consent.

I have chosen your school for my research because you are so actively involved in developing and implementing character education. I would like to meet with you to explain my study and hopefully gain approval to use your school. It is my intention to spend a week maximum at the school for data collection this spring.

The secretary to Superintendent advised me to first contact you for approval for this research prior to contacting him. I know from __ County Policy: LD regarding educational research that certain criteria must be met for approval. Please note the enclosed Study Purpose, Research Questions, and Research Design, which will explain the objectives and study design plan. This study will contribute to the improvement of student education because it will further illuminate the development of effective character education programs by highlighting teacher perceptions of implementation, and factors that may hinder or expedite the process.

As a 20-year veteran high school special educator, I well understand the tight schedule and time constraints as well as the need to be as minimally disruptive to the educational process as possible. My study solely involves instructional personnel, just teachers. No students will be involved in this study.

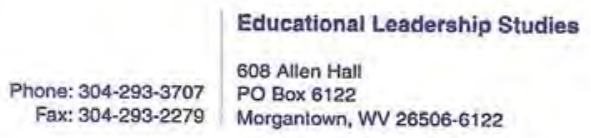

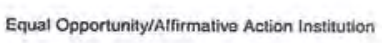


Page 2

Please call (1 XXXX XXX-XXXX) or email me at XXXXXX on when we may meet or talk so I can further explain the study and address any questions you might have. I am anxious to meet and share more of this study proposal. Thank you for your consideration.

Sincerely,

Helen M. Hazi, Ph.D., Principal Investigator

Professor of Educational Leadership

Lisa D. Lucas, Co-Principal Investigator

Doctoral Student in Curriculum \& Instruction

Enclosure: Study Purpose, Research Questions, and Design 
Appendix H: Character Development Team Letter of Participation

\section{West VirginiaUniversity}

College of Human Resources and Education

Department of Curriculum \& Instruction/Literacy Studies

Lisa D. Lucas

RR XX Box XXX

XXXXXX, XX XXXXXX

Date

(Participant's Name)

Middle School

XXXX Drive

XXXX, WV XXXXX-XXXX

Dear (Participant’s Name),

My name is Lisa Lucas and I am a veteran high school teacher of nearly twenty years who is currently completing an Ed. D. in Curriculum \& Instruction at West Virginia University. I will be visiting your school in October and November and would like very much to first interview you concerning your views of Character education and your involvement on the school's Character Development Team. I am investigating middle school teachers' perceptions of character education as well as obstacles to delivery and factors that expedite it. Should you decide to participate in 


\section{Page 2}

this study, I would like to observe your teaching as well as some documents such as character education materials, and lesson plans. West Virginia University’s Institutional Review Board acknowledgment of this study is on file.

Please note that your participation is voluntary. You may participate in all or just the interview portion of my research. You may withdraw from this research at any point or refrain from answering any questions. Your job status or standing will not be affected in any way by refusal to participate or withdraw from this study. All conversations will remain anonymous. The interviews will be audio taped, but these along with written transcripts of each one will be destroyed by fire upon the conclusion of the study analysis.

I realize the time of a middle school teacher is precious-especially planning periods. I would be willing to work with your schedule for interviewing. I can meet for a 30-45 minute interview before or after school or anytime the school is open. I will be visiting the school for 4-5 days, as needed. Those participating will be given a $\$ 20.00$ gift card to a local gas station.

Please indicate your willingness to participate by emailing me at XXXXXXX.com or calling me collect at (XXX) XXX-XXXX and indicating which of the following days and times you can be interviewed. Indicate Monday-Friday during your planning period, before or after school. I will then be in touch with the meeting confirmation.

I am hearing great things about this school and am looking forward to once again be with some of my favorite folks—-schoolteachers. 
Appendix I: Non-Participant Character Development Team Letter of Participation

WestVhrginiaUniversity

College of Human Resources and Education

Department of Curriculum \& Instruction/Literacy Studies

Lisa D. Lucas

RR X Box XXX

XXXX, XX XXXXX

Date

(Participant's Name)

Middle School

XXXX Drive

XXXXX, WV XXXXX-XXXX

Dear (Participant's Name),

My name is Lisa Lucas and I am a veteran high school teacher of nearly twenty years who is currently completing an Ed. D. in Curriculum \& Instruction at West Virginia University. I will be visiting your school in October and November and would like very much to first interview you concerning your views of character education. I am investigating middle school teachers' perceptions of character education as well as obstacles to delivery and factors that expedite it. Should you decide to participate in this study, I would like to observe your teaching as well as view some documents such as

602 Allen Hall PO Box 6122 Morgantown, WV 26506-6122

Phone: 304-293-3441 Fax: 304-293-3802

Equal Opportunity / Affirmative Action Institution 
Page 2

character education materials, and lesson plans.

Please note that your participation is voluntary. You may participate in all or just the interview portion of my research. You may withdraw from this research at any point or refrain from answering any questions. All conversations will remain anonymous. Your job status or standing will not be affected in any way by refusal to participate or withdraw from the study. The interviews will be audio taped, but these along with written transcripts of each one will be destroyed by fire upon the conclusion of the study analysis. West Virginia University’s Institutional Review Board acknowledgment of this study is on file.

I realize the time of a middle school teacher is precious-especially planning periods. I would be willing to work with your schedule for interviewing. I can meet for a 30-45 minute interview before or after school or anytime the school is open. I will be visiting the school for 4-5 days, as needed. Those participating will be given a \$20.00 gift card to a local gas station.

Please indicate your willingness to participate by emailing me at XXXXXX.com or calling me collect at (XXX) XXX-XXXX and indicating which of the following days and times you can be interviewed. Indicate Monday-Friday during your planning period, before or after school. I will then be in touch with the meeting confirmation.

I am hearing great things about this school and am looking forward to once again be with some of my favorite folks—-schoolteachers.

Sincerely, Lisa D. Lucas 
Appendix J: Sample Page of Transcribed Interview

\section{Q. Okay.}

A. And my home background. Being such that I was raised in a very Christian home, a very, a rural farm where responsibility and work was part of our daily life. Where we were involved in a lot of activities, you know, like I was raised in 4-H, Junior Achievements. I was active in school. My parents encouraged me to get involved and develop leadership skills. They supported me in whatever I did, even through college.

If I had art exhibits, I mean my parents came, they taught me to be a good parent, and a good person and all that leads to be a good teacher.

I believe that it was, you know, that.

\section{more about that? \\ Q. Okay. And when you say a good person, can you talk a little}

A. A good person, I think someone who puts others before themselves. I think some one who thinks of other's feelings before theirself. I think somebody who models is caring, you know, and I think it is just wanting to see good happen and you know, gets involved to make things better. Not someone who complains or finds what is wrong with something, but looks at it and say okay how can I fix it, or how can I make it better. If I choose not to do that, then that's it, don't complain. I look at life that way.

\section{Q. Positive?}

A. Um-hum. Being positive.

Q7. How do your values and beliefs impact your approach to teaching character education? We reiterated a little bit there, but - . -

A. I just believe that I treat the kids, and speak to the kids in a manner that I hope that is being able to be modeled. Like I talk to them, if I need them to do something, I try to say can you please throw this away for me? Instead of demanding something from them. I try to be as polite to them as I expect them to be.

Like I said, in my teaching I try to use words so they understand what trustworthy is, and what caring is about and what citizenship is about, and have that make a complete person.

I am the National Honor Society Advisor. A big part of our organization is service. Every month we do a service project and the kids have to learn to do things for other people. 
Appendix K: Correlation of Three Research Questions to Teacher Interview Questions

\begin{tabular}{|c|c|c|c|c|}
\hline Interview Question & $\begin{array}{c}\text { Research } \\
\text { Question } \\
\text { \#1a }\end{array}$ & $\begin{array}{c}\text { Research } \\
\text { Question } \\
\quad \# 1 b \\
\end{array}$ & $\begin{array}{c}\text { Research } \\
\text { Question } \\
\quad \# 2 \\
\end{array}$ & $\begin{array}{c}\text { Research } \\
\text { Question } \\
\text { \#3 }\end{array}$ \\
\hline $\begin{array}{l}\text { 1. How would you define Character } \\
\text { Education? }\end{array}$ & $\mathrm{X}$ & & & \\
\hline $\begin{array}{l}\text { 2. What importance do you attach to } \\
\text { character education? }\end{array}$ & & $\mathrm{X}$ & & \\
\hline $\begin{array}{l}\text { 3.By what actions does this school } \\
\text { indicate Character education is } \\
\text { important? County? }\end{array}$ & & $\mathrm{X}$ & & \\
\hline $\begin{array}{l}\text { 4. How responsible do you feel for } \\
\text { integrating Character education in } \\
\text { your classroom? }\end{array}$ & & $\mathrm{X}$ & & \\
\hline $\begin{array}{l}5 \text {. How, if at all have you changed the } \\
\text { way you deal with Character } \\
\text { education since it has been legislated } \\
\text { by WV State Code } 18-2-13 \text { ? }\end{array}$ & & $X$ & & \\
\hline $\begin{array}{l}\text { 6. What in your personal background } \\
\text { or past experience has influenced the } \\
\text { way you teach character education? }\end{array}$ & & & $\mathrm{X}$ & $\mathrm{X}$ \\
\hline $\begin{array}{l}\text { 7. How do your values and beliefs } \\
\text { impact you approach to teaching } \\
\text { character education? }\end{array}$ & & & $\mathrm{X}$ & $\mathrm{X}$ \\
\hline $\begin{array}{l}\text { 8. What kinds of things do you do to } \\
\text { teach character education? From } \\
\text { where do you get your ideas? }\end{array}$ & & & $\mathrm{X}$ & \\
\hline $\begin{array}{l}\text { 9. What gets in the way of integrating } \\
\text { character education? }\end{array}$ & & & & $\mathrm{X}$ \\
\hline $\begin{array}{l}\text { 10. What helps you teach character } \\
\text { education? }\end{array}$ & & & & $X$ \\
\hline $\begin{array}{l}\text { 11. How do you think the school's } \\
\text { emphasis on teaching character } \\
\text { education has affected what teachers } \\
\text { do? }\end{array}$ & & $\mathrm{X}$ & & \\
\hline $\begin{array}{l}\text { 12. Is there anything else you would } \\
\text { like to add we haven't discussed? }\end{array}$ & $\mathrm{X}$ & $\mathrm{X}$ & $\mathrm{X}$ & $\mathrm{X}$ \\
\hline
\end{tabular}

